\title{
Extended bodies
}

Citation for published version (APA):

de Boer, M. L. (2016). Extended bodies: an empirical-philosophical study to women's bodily experiences in breast cancer. [Doctoral Thesis, Maastricht University]. Datawyse / Universitaire Pers Maastricht. https://doi.org/10.26481/dis.20161214mb

Document status and date:

Published: 01/01/2016

DOI:

10.26481/dis.20161214mb

Document Version:

Publisher's PDF, also known as Version of record

\section{Please check the document version of this publication:}

- A submitted manuscript is the version of the article upon submission and before peer-review. There can be important differences between the submitted version and the official published version of record.

People interested in the research are advised to contact the author for the final version of the publication, or visit the DOI to the publisher's website.

- The final author version and the galley proof are versions of the publication after peer review.

- The final published version features the final layout of the paper including the volume, issue and page numbers.

Link to publication

\footnotetext{
General rights rights.

- You may freely distribute the URL identifying the publication in the public portal. please follow below link for the End User Agreement:

www.umlib.nl/taverne-license

Take down policy

If you believe that this document breaches copyright please contact us at:

repository@maastrichtuniversity.nl

providing details and we will investigate your claim.
}

Copyright and moral rights for the publications made accessible in the public portal are retained by the authors and/or other copyright owners and it is a condition of accessing publications that users recognise and abide by the legal requirements associated with these

- Users may download and print one copy of any publication from the public portal for the purpose of private study or research.

- You may not further distribute the material or use it for any profit-making activity or commercial gain

If the publication is distributed under the terms of Article 25fa of the Dutch Copyright Act, indicated by the "Taverne" license above, 


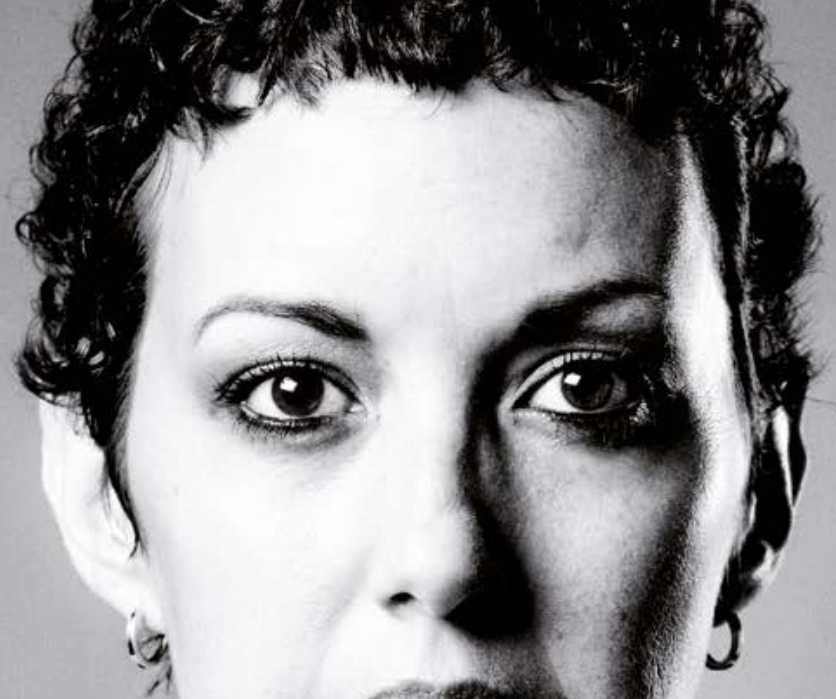

\section{EXTENDED BODIES} An empirical-philosophical study

to women's bodily experiences in breast cancer

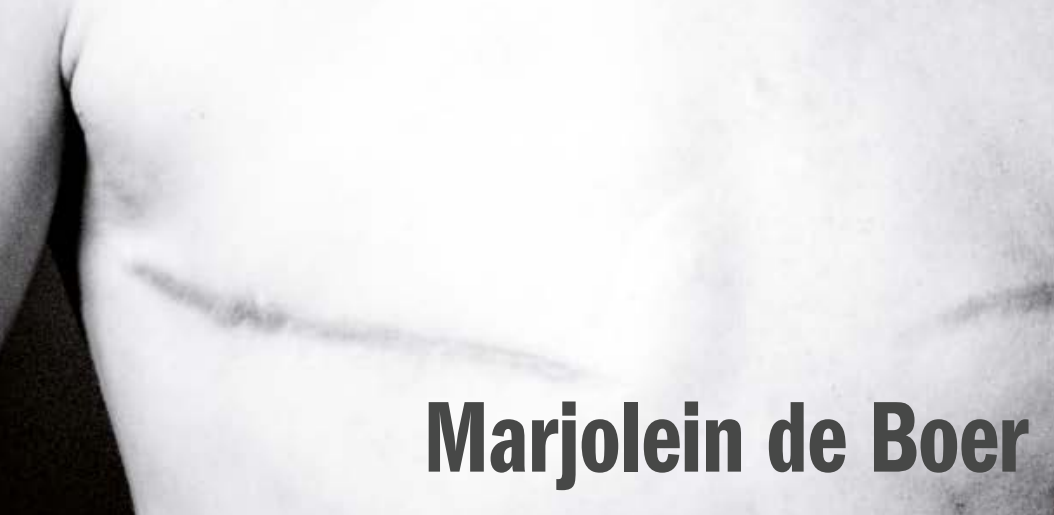


The research presented in this thesis was conducted at the School for Public Health and Primary Care: CAPHRI, Department of Health, Ethics, and Society, Maastricht University, the Netherlands. CAPHRI participates in the Netherlands School of Primary Care Research CaRe.

The research described in this thesis was funded by the Netherlands Organization for Scientific Research (NWO), Vidi grant 276-20-016. Parts of this research was also funded by the Jo Kolk Study Association and by the Association for Scientific Research Limburg (SWOL).

Printing of this thesis was financially supported by the School for Public Health and Primary Care: CAPHRI, and by the Netherlands Graduate Research School of Science, Technology and Modern Culture (WTMC).

(C) Marjolein de Boer, Maastricht 2016

ISBN: 9789461596277

eISBN: 9789461596284

Lay-out, cover design, and printing: Datawyse | Universitaire Pers Maastricht

Cover photo: 'The Scar Project', David Jay Photography, Copyright 2011 (c)

Photo chapter 1: 'Linnie no. 5', Cole Thompson, copyright 2008 (C)

Photo chapter 2 and photo page 25: 'Pictures of Health?', the Estate of Jo Spence, Courtesy Richard Saltoun Gallery, copyright 1982 (c)

Photos page 32: Karin Spaink, copyright 2007 (C)

Photo chapter 3: Laurie Kingston, copyright 2000 (C)

Photo chapter 4: 'I thank whatever gods may be', $4^{\text {th }}$ fullmoon, copyright 2014 C

Photo chapter 5: 'MarziBB22', Bryan Logan, copyright 2013 (C)

Photo chapter 6: Pernille Kjaer, copyright 2013 C

Photo samenvatting: 'The Scar Project', David Jay Photography, Copyright 2011 C

All rights reserved. No part of this thesis may be reproduced or transmitted in any form or by any means, including photocopying, recording, or other electronic or mechanical methods, without prior written permission of the holder of the copyright. 


\title{
EXTENDED BODIES
}

\section{An empirical-philosophical study to women's bodily experiences in breast cancer}

\author{
DISSERTATION \\ to obtain the degree of Doctor at the Maastricht University, \\ on the authority of the Rector Magnificus, Prof. Rianne M. Letschert, \\ in accordance with the decision of the Board of Deans, \\ to be defended in public \\ on Wednesday 14 December 2016 at 14.00 hours
}

by

Marjolein Lotte de Boer 


\section{Promotores}

Prof. dr. K. Horstman

Prof. dr. E.S. Houwaart

\section{Copromotor}

Dr. J. Slatman

\section{Assessment committee}

Prof. dr. G.M.W.R. de Wert (chair)

Prof. dr. I. Devisch (Ghent University, Belgium)

Prof. dr. J.J.D.J.M. Rademakers

Prof. dr. F. Svenaeus (Södertörn University, Sweden)

Dr. A.M.C. Swinnen 
Voor Geertje 



\section{Table of contents}

CHAPTER 1 Introduction

Understanding embodiment in breast cancer

CHAPTER 2 The mediated breast

Shaping women's agencies in their engagements with medical

technologies and prosthetic artifacts in breast cancer

CHAPTER 3 Blogging and breast cancer

Narrating one's life, body and self on the Internet

CHAPTER 4 Sharing lives, sharing bodies

Partners negotiating breast cancer experiences

CHAPTER 5 The surprise of a breast reconstruction

A longitudinal phenomenological study to women's expectations about reconstructive surgery

CHAPTER 6 Discussion

Extending the understanding of embodiment in breast cancer

Appendix

Samenvatting

Valorization

Acknowledgements | Dankwoord

About the author

List of publications (selection) 



\section{Introduction}

\section{Understanding embodiment in breast cancer}


After Pamela's breast cancer diagnosis, both of her breasts and her lymph nodes were surgically removed, and she underwent several cycles of chemo- and radiotherapy, followed by hormone treatment. As soon as her scars healed, Pamela started to wear external breast prostheses. "I always wear them", she tells me in one of the interviews I had with her. Recently, she also began to wear them at night, with a bra on. Three to four times a week, she locks herself in the bathroom, takes them out and cleans them carefully. "And then they go straight back", she says, "even my husband rarely sees me without." For Pamela, wearing her prostheses is, at times, "weird" and "difficult" because it confronts her with the fact that she lost her own, "naturally feeling" breasts. In general, however, she says she would be worse off without them, for that would cause her to feel "a bit naked" and "less feminine".

Breast cancer severely affects and disrupts the lives and bodies of women. ${ }^{1}$ Many women who are diagnosed with breast cancer face not only their own mortality, but also the emotional and physical consequences of undergoing surgical inventions and medical treatments. Depending on the specificities of the diagnosis - the size, location, invasiveness and possible metastases of the cancer tumor(s) - and the required surgeries, such as the removal of lymph nodes or (parts of) one or both breasts, these women are confronted with scarring, breast loss or lymphedema. They may also have to contend with hair loss, nausea, pain, fatigue, stiffness of the joints, increase in body weight, heart problems and loss of bodily functions due to various related treatments, such as radiation therapy, chemotherapy, hormone therapy and immunotherapy. Note that these bodily disfigurements and physical inabilities are not only reserved for women with actual (invasive) cancer tumors. Despite its dominant univocal representation in daily life, breast cancer may also be understood as involving the hereditary breast cancer gene (BRCA1/2). Moreover, in societies in which women (above a certain age) are persistently called upon to attend radiological breast screenings, non-invasive 'stage zero conditions' such as ductal carcinoma in situ (DCIS) or lobular carcinoma in situ (LCIS) are increasingly brought to light. ${ }^{2}$ Löwy (2010) even goes so far as to argue that in such 'prevention societies' we are constantly made aware of the risk of getting breast cancer and that therefore all women are somehow affected by this disease. But in particular women who themselves have to undergo breast cancer treatment are affected, and they need to develop new and altered ways of relating and giving meaning to their life and their body.

\footnotetext{
${ }^{1}$ Breast cancer is not an exclusive female disease. Male breast cancer accounts for around $1 \%$ of all breast cancer cases. This study, however, solely focuses on breast cancer in women.

${ }^{2}$ Breast cancer conditions are typically categorized in stages, ranging from zero to five. In stage zero, there is no evidence of cancer (or non-cancerous abnormal) cells breaking out of the part(s) of the breast in which they started. In stage five, invasive breast cancer cells are detected that have spread beyond the breast and nearby lymph nodes to other organs of the body, such as the lungs, bones, liver or brain.
} 
Pamela is such a woman who had the misfortune of getting breast cancer. When I talk to her, five years have passed since her diagnosis and treatment. Medically speaking, she has recovered from her breast cancer. In her story, however, this disease and its treatment linger as a disruptive life-changing event that still severely affects the ways she experiences and deals with her body. Pamela continues to find new ways of making sense of herself and of relating to her unbreasted body - modes and practices which are often ambiguous. One way of dealing with her mastectomized body is to wear breast prostheses. While it is "difficult" for her to wear these artifacts, it seems harder not to wear them. Without them, she would feel "naked" and "less feminine", even at night and even vis-à-vis her husband. What is significant in Pamela's breast cancer story is that her experiences, dealings and sense-making practices are greatly influenced and co-determined by her prostheses and by how she relates to others (in this case her husband). For Pamela, the experience of breast cancer did not play out in a vacuum, but was directly tied and enacted in relation to her material and social environment. This study is devoted to collecting and investigating breast cancer stories of women such as Pamela. Specifically, I describe and analyze these women's embodied illness experiences and sense-making strategies. How, in other words, do women with the experience of breast cancer deal with and give meaning to themselves and their bodies in relation to the contexts in which they live?

\subsection{EMBODIMENT AND BREAST CANCER IN THE LITERATURE}

There is a vast number of studies in especially onco-psychology and cancer nursing sciences about women's subjective experiences of breast cancer. These empirical studies predominantly discuss indicators of these women's psychosocial and cognitive wellbeing (De Haes and Van Knippenberg 1985; Hutchinson et al. 2012; Mehnert and Koch 2007), such as signs of distress, depression and cognitive impairments, and the ways in which they cope with these psychological challenges (Carver et al. 1993; Sears et al. 2003). Furthermore, a considerable body of research focusses on ways in which breast cancer treatment affects a woman's body and her experience of it, in particular her physical (in)capability (Andrykowski et al. 1998; Gilbert et al. 2010) and her post-surgery appearance (Baxter et al. 2006; Carver et al. 1998; Härtl et al. 2003).

Although many of these studies concentrate on either mental states or bodily experiences, what this literature has in common is that it tends to regard breast cancer experiences as developing along the lines of a more or less fixed and prescribed chronology. Descriptions of the life-changing impact of the breast cancer diagnosis are typically followed by records of emotionally draining and physically demanding treatments. Accounts of such experiences commonly end with the woman's emotional and physical recovery, after which she returns to a (largely) normal everyday reality, to life as it was before the breast cancer (Carver et al. 1993; Sears et al. 2003). In cases of women's 
continued psychosocial burdening or struggles with their marked bodies, scholars and scientists who contribute to this literature often debate how these women can be facilitated by medical and mental health professionals to overcome these difficulties. These kinds of passages with recommendations, Frank (1995) argues, resound with modernist tales about quests of overcoming one's illness and the chaos and deviancy that comes with it - tales that more or less evolved into a standard normative narrative in Western societies.

Moreover, most studies that explicitly attend to women's embodied breast cancer experiences quantitatively measure such experiences. One of the most prominent traditions within this kind of research is the valuation of women's 'body image', that is, of the ways women experience and appreciate their physical appearance, intactness and competence (Baxter et al. 2006; Carver et al. 1998; DeFrank et al. 2007; Gilbert et al. 2010; Härtl et al. 2003). Such studies are valuable in collecting big samples and generalizable outcomes. By way of using questionnaires and self-report scales, however, this kind of assessment leaves researchers with a quite narrow operationalization of the concept of bodily experience and a restrictive evaluation thereof, predominantly through psychological parameters that measure women's perceptions of their physical appearance and their sexual, motor or health-related functionality (Slatman 2011; Leunissen et al. 2015).

The few efforts that combine a broad conceptualization of embodiment - i.e., as not only visual and capable, but also as kinesthetic, tactile, auditory, etc. - with a more indepth exploration of subjective experiences of breast cancer tend to concentrate on the bodily sensations and perceptions of the breast-cancerous person in isolation (Kasper 1994; Landmark and Wahl 2002; Thomas-MacLean 2005). In this kind of research, bodily experiences become the privilege of the physical, singular body: the body that is enclosed by the skin (Shildrick 2015). This kind of exploration of embodiment seems to underscore the positivist "reification of illness as organic disease" (DiGiacomo 1992, 120), in which understandings of subjective illness experiences are reduced to and determined by sensations of the physical, biological body. What is more, such explorations affirm the biomedical belief in the autonomy of the body (Wendell 1996). In doing so, these studies cannot account for the issue that breast cancer experiences are coshaped in relation to the contexts in which this illness occurs, for example, in relation to these women's shared norms and values (De Boer and Slatman 2014; Slatman 2014; Young 2005), their immediate social context (Kayser et al. 2007) and the materials and objects they interact with (Dalibert 2015; Ihde 1990; Verbeek 2010).

By understanding women's breast cancer experiences along the lines of a fixed chronology and by focusing on the breast cancerous body in isolation, onco-psychology and cancer nursing studies are constrained in grasping the complexity and extensiveness of such experiences. In seeking to address this knowledge gap, the aim of this study is to describe and analyze subjective breast cancer experiences in their embodied, detailed and continually evolving terms while exploring the significance of women's 
lived contexts. My analyses are based on empirical fieldwork and are explicitly positioned against the background of a philosophical phenomenological understanding of embodiment as open and extended to the world. Moreover, this thesis takes up phenomenology also as a methodological approach in qualitative research. Such a dual line of enquiry, as we will see, significantly contributes to unraveling the empirical complexities involved in exploring subjective embodied experiences of breast cancer in relation to the contexts in which these experiences occur. Before turning to the empirical investigations (chapters 2, 3, 4, and 5), however, I provide a description of the philosophical theoretical framework (section 1.2) and methodological approach (sections 1.3, 1.4 and 1.5) used in this study.

\subsection{A PHENOMENOLOGICAL PERSPECTIVE ON EXTENDED EMBODIMENT}

The body has been a rather underdeveloped issue in Western philosophy. Prevailing invocations of Cartesian inquiries, for example, regard the body as the static material base of existence, and of no concern to ways in which we experience and make sense of ourselves, others and the world (Shildrick 2015). The philosophical tradition of phenomenology, however, offers a different perspective on what the embodied ' $I$ ' may signify. By suspending the Cartesian concern with what we are, i.e. immaterial minds and material bodies, this tradition enquires into how we are - into how we experience others, the world and ourselves, and thus into the meanings of things in our experience (Husserl 1960; Heidegger 1962). Within this inquiry, phenomenology turns away from the Cartesian sovereign immaterial subject and instead emphasizes the formative role of embodiment and the role of the situatedness of embodied subjectivity in the concrete world we live in. Phenomenologists insist that as embodied beings we live in a state of incessant and constitutive openness to the world. Aho and Aho (2008) explain that "the sense we have of anything, including [of] our own bodies, is made possible only on the basis of a pre-given world in which we are 'always already' involved. It reflects our social class, our race, our gender, our nationality, our historical era, our geographical situation, and countless other factors" (11). Because we are inescapably embodied and we live together with others at a certain time and in a certain place, the experience of who we are is constituted against the background of our particular engagement in the world (De Beauvoir 1949; Merleau-Ponty 1945; Ricoeur 1992; Slatman et al. 2015). Our experiences as embodied beings, in other words, are co-determined by elements outside of our physical body. Being embodied means - paradoxically - to live beyond our skins. We live as extended bodies.

Various traditions within philosophy teach us that there are multiple ways in which we extend ourselves as embodied beings. Existential phenomenologists (Dastur 2000; Heidegger 1962) demonstrate how we are extended in time. As human beings, we live through and within different temporal dimensions. We change over time of course, as is 
true of our body, and our present embodied experiences are never isolated from our past and future. For example, our memories or expectations are always part, be it implicitly or explicitly, of our experiences in the present (De Boer et al. 2015; Steinbock 2006; Zahavi 2005).

In addition to the lived temporal dimensions of who we are, human beings are also extended through their material environment. As the zoologist Dwarkins argues, an argument taken up by the philosopher Dennett (1991), such extendedness is not reserved to human beings, but applies to various animals as well. Under the heading of 'extended phenotype', Dennett describes the way in which living organisms define and defend their 'biological self': a spider constructs a web, and a beaver builds a dam. Both the web and the dam belong to these animals' extended phenotype. Applying this idea to human beings, our extended phenotype can include many things. It may refer to the clothes we wear, the tools we use, a device such as a breast prosthesis and even to the body of others.

Dennett argues, however, that - as human beings - our strongest, most fundamental and possibly unique strategy to define and protect our 'selves' is our ability to construct stories about ourselves. Whereas spiders weave webs to protect and feed themselves, we constantly construct webs of stories. In the stories we create and narrate, we engage in presenting and representing ourselves to others and to ourselves. Within these stories we readily incorporate, ingest and extrude elements of our environment: the objects and artifacts we encounter, but also stories of others and cultural norms and values. We constantly weave these elements like spider webs into strings of narratives about who we are, were and will be, thereby allowing us to trace our experiences in plots about our 'self' over extended time periods (Dennett 1991). The hermeneutical tradition shows us that these stories are not just narratives about the self, that is, they are not only representations of the self. Our narratives also constitute an essential dimension of human existence. Within the stories we tell and re-tell, we interpret and make sense of our continually changing experiences (Ricoeur 1991-b). For this reason, we cannot understand the self independently of our continuous self-interpretation through narratives: we are narrative selves (Zahavi 2005). ${ }^{3}$

While experiences of our embodied selves may indeed be located outside of the present physical body - in the objects we interact with, the memories and expectations we have, the people we hold close, the norms we adhere to, and the narratives we construct - these extensions of the self cannot be boundless. Phenomenologists argue that while our existence is indeed characterized by openness, connectivity or relationality, it is im-

\footnotetext{
${ }^{3}$ Philosophically, there is some question as to whether the narrative self is a sufficient ontological account of the self or whether this narrative self is nothing more than an illusion about the self. In contrast to Ricoeur (1991-b), Dennett (1991), for example, conceives of the narrative self as merely an abstract point at the intersection of various stories, that is, as a persona or fictional character about the self that does not sufficiently capture human existence. The self, Dennett argues, is essentially material and resides in the physical body.
} 
portant to maintain notions of difference, separation and distinctness in understanding subjectivities (Merleau-Ponty 1945; Nancy 2000; Ricoeur 1992). After all, without boundaries to embodied extensions, the self would be omnipresent and, consequently, there would be no distinguishable subject to adhere to anymore. As such, the extended body should be understood not as a merging of the self with the world, with objects and others, or as protracted in time, but as a product of both convergence and divergence from that world, from others and objects, or from former and future selves.

My investigations of how women with breast cancer experience make sense of their breast cancer start from this phenomenological perspective to extended embodiment (Dastur 2000; Ihde 1990; Merleau-Ponty 1945; Nancy 2000; Ricoeur 1992). As such, this thesis pushes beyond conventional meanings of subjective, embodied experiences of breast cancer - as found, for instance, in psychology and nursing sciences - and opens up new positioning marked by both separation and connection, distinctiveness and commonality, that is, by bounded extensions as the very conditions of embodied, breast cancerous life. Of course, extended embodiment is a feature of life in general, namely part of the embodied experience of us all (Shildrick 2015). When it comes to the degree and qualification of embodied extensions in breast cancer, however, there is a good reason for seeing women who live with this illness and its embodied, material, temporal, cultural and social aspects as a specific exemplar of extended embodiment. During and after their treatment, they may, for instance, interact with and even incorporate unfamiliar technologies, objects and artifacts; they may run up against dominant norms about illness and marked femininity; they may become more dependent on others during and after their treatment; or they may feel that their healthy past is not theirs anymore and that their prospects for the future have to be adjusted. These various aspects may be reflected in the ways in which they rework their stories about themselves and their bodies. It should be added that although this study considers categories like illness and gender in understanding the particularity of extended bodily experiences in breast cancer (Svenaeus 2014; Young 2005), it also takes into account a larger array of significant intersectional differences, such as women's ethnicity (Ahmed 2006; Fanon 1967) and age (Zeiler and Guntram 2014), their physical state and ability (Shildrick 2012; Young 2005), as well as the larger socio-cultural environment involved (De Beauvoir 1949; Sontag 1990; Zeiler 2014).

\subsection{A PHENOMENOLOGICAL-NARRATIVE APPROACH TO EMBODIMENT}

While phenomenology is originally a theoretical, philosophical tradition, it may also be used as a research approach in qualitative empirical studies (Smith et al. 2009). Empirical phenomenology aims at disclosing the singularity of the subjective perspective while analyzing how this perspective resides in and intersects with the subject's lived context (Murray and Holmes 2014; Smith et al. 2009). As such, this approach is able to combine 
two foci toward illness that are often discussed separately in the literature: an analysis of discourses and constructions of illness and illness experiences, and of personal renditions of such experiences (Charmaz and McMullen 2011). This double view on illness experiences is especially suitable for my objective in this study: that is, for describing and interpreting women's subjective embodied breast cancer experiences and sensemaking processes within the contexts in which these experiences arise and take shape.

In taking up the task to explore, grasp and understand the constitutive conditions of women's embodied experiences in breast cancer, this study requires a particular strategy, namely to investigate the characteristics of these women's illness stories. As said, the hermeneutical tradition has taught us two important things: narratives enable individuals to describe, recount and represent their experiences, and, secondly, people experience, reinterpret and make sense of themselves, their bodies and their relationship to the world within and through the telling and re-telling of stories (Ricoeur 1991b). Significantly, to the extent that illness is characterized as a severe life interruption or as a "biographical disruption" (Bury 1982, 167) - comprising the body, illness narratives are not only seen as expressing situations of illness, but also as helping to make sense of the unsettling experience, to reorder one's affected bodily existence, and to reconstruct one's sense of self. Moreover, in addition to giving insight into how individuals (re)interpret themselves, the telling of stories also teaches us something about the material, societal, cultural and temporal context in which such narrative meaningmaking takes place. In fabricating their personal stories, people refer to their material and social environment, recollect and reflect on their memories and expectations, and incorporate and appropriate larger cultural, normative discourses and the stories of concrete others (Ricoeur 1981). For this reason, phenomenological explorations of how women experience and make sense of their bodily illness experiences in relation to their lived environment necessarily involve explorations of stories, that is, of women's firstperson narratives that are intrinsically linked to larger constitutive contexts (Slatman and Widdershoven 2010).

\subsection{MULTIPLE BODILY EXTENSIONS}

While investigating the meaning of extended embodiment in breast cancer and analyzing the collected empirical materials, I identified four ways in which such extendedness manifests itself. In this study, I will describe and investigate women's breast cancer stories and how they experience and make sense of their lives and bodies (1) in relation to employed material medical technologies and prosthetic artifacts, (2) within and through the specific media technology of online, personal weblogs, (3) in relation to their intimate partners, and (4), within and through the temporal horizon of their past, present and future expectations of having a breast reconstruction. 
These four manifestations of extended embodiment hardly exhaust the wideranging scope of this phenomenon. The decision to discuss these particular extensions was motivated by their prevalence in the empirical materials I gathered, and by the fact that each of them covers a larger thematic bodily extension, namely a technologicalmaterial, a narrative, a social and a temporal extension. Moreover, the bodily extensions I address are also increasingly debated within scholarly traditions such as health and nursing sciences, psychology, social sciences, Science and Technology Studies (STS), feminist studies, and disability studies. By offering critical reflections from a philosophical phenomenological perspective, this study contributes to these existing discussions about extended embodiment.

It is relevant to note that although I distinguish four embodied extensions in this study, these manifestations are in many ways interdependent and intertwined. For instance, women may write about their experiences with prostheses on their weblog which in a figurative sense may be viewed as a prosthetic artifact as well - or the ways in which these women formulate expectations may be co-dependent on their intimate partners. Moreover, all of these cases involve and cut across further bodily extensions, such as cultural-normative structures about femininity and marked embodiment, and the ways in which these women narrate themselves and their bodies.

\subsection{MULTIPLE NARRATIVE SITES}

Each kind of manifestation of extended embodiment requires an exploration of a particular - what I call - 'narrative site', that is, a particular setting and/or timeframe within and through which these women create and narrate their breast cancer stories. First of all, I explore stories of how women's breast cancer experiences are co-shaped in relation to medical technologies and prosthetic artifacts through individual interviews with women in different stages of having breast cancer (i.e. diagnosis, treatment and its aftermath). These interviews include a wide variety of experiences with such materials and objects. Second, through an analysis of the development of online personal stories of breast cancer bloggers, I discuss how women experience and make sense of their illness on this specific medium. Third, I develop an argument about the intersubjective formation of breast cancer experiences on the basis of duo-interviews with diagnosed women and their partners. Finally, I describe and analyze how women configure and reconfigure their reconstructive expectations over time. To this end, I conducted multiple individual interviews with the same group of women in the process of having breast reconstruction, and I conducted interviews with a couple of women five years after having their reconstruction.

From February 2012 to February 2014, I collected many breast cancer stories within various narrative sites. In total, I interviewed 12 women up to four times in the process of breast cancer diagnosis, at different stages of having (had) breast cancer, and while 
having a breast reconstruction. In addition, I interviewed 8 couples who deal with breast cancer and 2 partners of women with breast cancer. Finally, I read and re-read 13 personal weblogs of women who have (had) breast cancer, of which I followed 5 for over a year. Next to conducting interviews and collecting weblogs, I also did observations during breast cancer consultations in a plastic surgery clinic and at a radiological breast screening center in order to contextualize the experiences as narrated in the interviews and on the weblogs. The resulting pages of transcribed empirical materials were interpreted and analyzed in order to describe and explore the abovementioned four cases of extended embodiment in breast cancer.

The next four chapters of this study each cover one of the abovementioned manifestations of extended embodiment and the corresponding narrative sites. They were written as journal articles, and therefore each one of them has a separate section on methodology. As such, these sections provide an account of the research method employed in each individual empirical study. Because they may obscure the design of this study as a whole, the sections below describe the overall methodological structure of this study.

\section{Interview studies}

This thesis project started out with a study of a specific and optional aspect of breast cancer treatment, namely breast reconstruction and how its interrelated experiences change over time. The request to conduct this qualitative study came from the head of a plastic surgery facility in the Southern part of the Netherlands. The results of this study were reported in an article about how women shape and reshape their expectations about their breast reconstruction (see chapter 5).

In the course of this study, I was invited to observe consultations with women who were in the process of (possibly) having a breast reconstruction at the abovementioned plastic surgery facility. For a period of four months, I attended these consultations one morning each week, and took notes of what went on. Before or after such observation moments, I recruited seven women for an interview upon their first visit to the facility. These interviews took place just before their planned breast surgery. During the first interview, I invited these women for three more interviews in the year after their breast reconstruction. Conducting more than one interview with these women allowed me to follow new developments and adjustments in their breast cancer stories, while it also created opportunities for establishing a relationship of trust with the respondents, a context in which they would feel comfortable to share intimate information. In some cases I did not conduct all of the three additional interviews planned either because my interviewees had personal reasons not to participate anymore or because they did not further pursue breast reconstruction. Moreover, in order to investigate how in the years after the surgery bodily experiences may change, I also recruited three women who had reconstruction surgery five years earlier. For their contact information, I relied on the 
hospital's archive. For this study, I conducted 26 interviews with 10 women at different stages of their reconstructive process between October 2012 and February 2014.

In considering that phenomenology as an empirical approach strives for openness in teasing out stories, from the start I encouraged the participants to talk freely about their breast cancer experiences during the interviews. Although I zoomed in on issues related to reconstruction, substantial parts of the interviews dealt with other aspects of these women's breast cancer experiences. Prevalent themes addressed include women's dealing with technologies and artifacts during their breast cancer diagnosis, treatment and its aftermath, and the nature of their relationships with family, friends and in particular their intimate partners during and after breast cancer. These themes served as basis for two interrelated studies: one about women's experience of and dealings with breast cancer as being co-shaped in relation to medical technologies and prosthetic artifacts (see chapter 2), and the other about how these women's breast cancer experiences were shaped intersubjectively with their intimate partner (see chapter 4).

In order to describe and explore an even wider range of women's experiences with technologies and artifacts in breast cancer - and thus to move beyond the experience of women who, at the least, considered having breast reconstruction after having had breast cancer - I recruited two more interviewees. In acknowledging that interacting with breast cancer technologies is not only a 'privilege' of women diagnosed with this illness, I interviewed a woman in the process of diagnosis. I accompanied her, moreover, to the radiological center where I observed her breast screening. After this screening, it turned out that she did not have any malignancies. In addition, I interviewed another woman diagnosed with and treated for breast cancer but who decided not to have breast reconstruction, nor to wear a breast prosthesis. I included these two interviews, together with two exemplary interviews from my study on breast reconstruction, in an article about how women's agency is co-shaped in their encounters with breast cancer technologies and artifacts (see chapter 2).

For the study about how women's breast cancer experiences are shaped in relation to their partners, I conducted and analyzed, together with a research assistant, eight indepth duo-interviews with diagnosed women and their (male) partners and two indepth interviews with only the (male) partner. ${ }^{4}$ This study was developed into an article about how partners co-shape and negotiate their breast cancer experiences (see chapter 4). Interviews with only the male partner were conducted when the ill partner was not able to attend the interview because of health reasons. The first five couples were, again, recruited upon their visit to the abovementioned plastic surgery facility. In order to obtain a more varied sample - beyond couples of which the women consider recon-

\footnotetext{
${ }^{4}$ Note that this study only includes heterosexual couples. The recruitment of couples, however, was open to same sex couples as well. These couples, however, did not present themselves as participants in this study. As the inclusion of lesbian relationships may offer additional and different kind of empirical materials and interpretations, it is worth exploring in future research how women's breast cancer experiences are shaped in relation to their female partners.
} 
structive surgery - I recruited additional couples through a call on a Dutch breast cancer patients website.

These interview studies thus comprised a total of 12 women-respondents and 10 (female and/or male) couples-respondents. Their stories covered a vast range of breast cancer trajectories: from merely being screened and not diagnosed, to being diagnosed with the hereditary breast cancer gene (BRA1/2), to being diagnosed with breast cancer and possible metastases, to having different invasive medical treatments and surgical interventions, and to wearing breast prostheses, undergoing breast reconstruction, or doing neither. Sadly, not all of the women eventually recovered: some did not get better after being treated, others had relapses, and yet others did not recover emotionally or physically from the invasiveness of having (had) cancer and being treated for this disease. The age of the respondents at the first interview ranged between 29 and 75 . Although characteristics such as sexual orientation, nationality and ethnicity were not explicitly documented during the interviews, most respondents said to identify themselves as heterosexual, while one woman identified herself as lesbian and another woman identified herself as bisexual. Moreover, most of the respondents identified themselves as Dutch, while some also claimed to identify strongly with the Southern province of the Netherlands in which most of the respondents lived. Their selfdesignated ethnicity, finally, varied and could generally be traced back to the respondent's country of birth, which was the Netherlands, with the exception of three women from other countries: Surinam, France and Germany. See tables 1, 2, and 3 in the appendix for further details about the respondents.

All of the interviews had the same general structure. By asking open-ended questions, I initially invited the respondents to tell their breast cancer stories, starting from the diagnosis up until the current state of affairs. Next, I zoomed in on issues related to the thematic (interview) studies, that is, to how their experiences were shaped within and through medical technological and prosthetic artifacts, through their intimate relationships with their partners, and within and through their expectations about their breast reconstructions. The interviews also addressed and elaborated other significant themes, such as the role of dominant normative structures, of friends, family and medical professionals, and of temporal dimensions in these women's experience of breast cancer.

The transcribed interviews were analyzed in relation to the three thematic studies introduced above: breast cancer experiences in relation to medical technologies and prosthetic artifacts, in intimate relationships, and within and through women's expectations of breast reconstruction. In my interpretation of the data from the interviews I relied on phenomenological narrative analysis. The varying details of this kind of analysis in each particular study are described in the separate empirical chapters. In general, however, such a phenomenological approach is geared to analyzing the stories of the respondents around a theme or framework that the researcher brings to them, giving due consideration to the linguistic, embodied, material, temporal, social and cultural contexts that shape these narrative accounts, both in the immediate interview setting 
and in the larger context in which the interviews take place (Charmaz and McMullen 2011). By taking up the idea of the hermeneutical circle (Ricoeur 1981; 1991-a), such an analysis begins with an overall reading of the interview, thereby identifying general themes and storylines and gaining insight into the meaning of the whole story. Subsequently, this kind of analysis attends to understanding the relevant concepts and storylines and examines their meaning in relation to the story as a whole, which may change the understanding of this whole. These iterative readings continue until one arrives at an understanding of the story as a whole that best encompasses the meaning of its parts. Moreover, the analysis of the interviews involves interpretation of the respondent's gestures and movements, incorporates self-reflection as to the role of the interviewer, and engages in a conversation with larger theoretical frameworks related to the relevant storylines within the interviews, all of which help the researcher to remain sensitive to nuances and ambiguities of the expressed meanings and the different contexts in which these meanings take shape (Charmaz and McMullen 2011).

\section{Blog study}

Breast cancer stories do not just feature in verbal contexts; quite a few women have also written about their experience with this cancer. From the 1970s onward, there has been a growing body of autobiographical accounts of breast cancer (Couser 1997). Initially, this kind of literature predominantly consisted of accounts in paper form, which include two well-known classics: The Cancer Journals by Audre Lorde (1980) and Eve Sedgwick's essay White Glasses (1993). With the rise of the Internet, however, women increasingly began to tell their stories online, predominantly on the public medium of personal weblogs. This growing body of written autobiographical accounts should not be understood as a matter of just choosing another kind of medium of storytelling. Many authors argue that writing and publishing stories, both offline and online, coshapes the ways in which stories are told and, consequently, the ways in which meaning is attributed to the narrated experiences (Broom 2001; Couser 1997; De Mul 2010; Poster 1995; Turkle 1995). In particular, the distinct features of weblogging open up new possibilities for women to tell their illness stories and shape their sense making processes in new and altered ways. Being similar to an ongoing diary or commentary, this multi-media genre allows individuals to continuously 'log' and adjust their stories in a reverse chronological order on a self-designed, open access, interactive Web page (Page 2008). Therefore, at the same time that I conducted the interview studies, I also attended to women's textually narrated breast cancer experiences online, namely on their personal weblogs (see chapter 3). In doing so, this study explores the significance of McLuhan's (1964) catchy one-liner: "the medium is the message" (7) from the perspective of a contemporary, highly technological context in which the Internet seems to be omnipresent. 
For this blog study, I collected thirteen weblogs of women who have (had) breast cancer by using Google's search engine and also by clicking on links to other weblogs. As these weblogs contained thousands of pages of empirical material about breast cancer experiences, I decided to select five representative weblogs for in-depth study. Details about the selection of the initial 13 weblogs and the eventual 5 weblogs are described in chapter 3. Further characteristics of the 5 in-depth weblogs I analyzed can be found in table 4 in the appendix.

Between February 2012 and February 2013, I read the weblogs on a monthly basis and documented the updates - additions and adjustments - on these blogs. This allowed me to gain insight into how these bloggers' online breast cancer stories develop over time. Through a phenomenological narrative analysis of the weblogs, I managed to identify emergent themes and storylines. Many bloggers do not only use text but also audio-visual materials. My analyses therefore relies on interpretation of written text as well as of pictures, background colors, and sound- and video files. As such, the method of narrative analysis applied in this thesis should be understood broadly: it comprises semantic interpretation of spoken and written words and sentences, but also of silences and supportive gestures (in the interview studies), as well as of illustrative visual and auditory materials (in the blog study).

\subsection{OUTLINE OF THIS THESIS}

This thesis addresses the broad question of how women who have (had) breast cancer experience, deal with and make sense of themselves and their bodies in relation to the contexts in which they live. By taking up the phenomenological perspective on embodiment as being extended, I discuss how women's embodied breast cancer experiences are shaped, constructed, determined and influenced within and through their technological, material, narrative, socio-cultural, and temporal-existential environment. During my fieldwork, I came to focus on four particular manifestations of such extended embodiment in breast cancer: their medical technological and prosthetic material extendedness, their narrated and blogged extendedness, their extendedness to their intimate partners, and their expectational, temporal extendedness. The following four chapters, describe the meaning of these embodied extensions for these women's breast cancer experiences and sense-making processes.

Prevalent scholarly traditions such as philosophy of technology (Dalibert 2015; Ihde 1990; Verbeek 2010;) and Science and Technology Studies (Akrich 1992; Latour 1994; Oudshoorn 2015), but also philosophical phenomenology (Heidegger 1962; MerleauPonty 1945), typically understand 'extended embodiment' as 'materially and functionally extended'. This literature explores how human beings, in their encounters with their environment and while being engaged in all kinds of projects and actions, extend their bodies through interactions with and incorporation of various tools, instruments and 
devices. The second chapter explicitly relates to this established tradition of extended embodiment. Based on the analysis of four exemplary stories of women who went through the process of breast cancer diagnosis, treatment, and its aftermath, I argue that women's encounters and interactions with, and incorporations of medical breast cancer technologies and prosthetic artifacts influence and co-determine their embodied agency. In this chapter, I understand embodied agency as a subject's embodied capacities to act and perceive in the world, which dates back to the idea of intentionality in terms of 'I can' (Husserl 1960; Merleau-Ponty 1945). How does engaging with medical technologies and prosthetic artifacts in breast cancer co-shape the embodied agency of the women involved?

In the third chapter, I turn to a medium for storytelling that could also be understood as a contemporary and technological, prosthetic artifact: women's personal breast cancer weblogs (De Mul 2010; Turkle 1995). In this chapter, I describe how the specificity of this medium co-shapes the breast cancer stories of five diagnosed bloggers. How are these women's experiences and their sense-making processes represented and constructed within and through their personal weblogs?

Cancer is increasingly considered to be a disease that affects both women-patients and their partners, and that therefore is a shared experience. Such experience, however, is predominantly understood as restricted to the realm of emotional and communicative well-being (or lack thereof) (Ussher et al. 2011; Germino et al. 1995; Zahlis and Shandis 1991). In the fourth chapter, I explore breast cancer as a social, intersubjective experience from a different perspective, namely as a thoroughly embodied experience. By analyzing the stories of couples who deal with breast cancer and by mobilizing Nancy's (2000) concept of sharing, I show how embodied breast cancer experiences and sense-making processes are intimately shared and co-shaped. How is breast cancer intersubjectively experienced with one's intimate partner?

These first few chapters implicitly reveal that women's breast cancer experiences change over time. In the fifth chapter, I explicitly focus on this temporal dimension as experienced by women who suffer from breast cancer. By analyzing developments in the stories of ten women, I discuss how their experiences and sense-making processes in the context of breast cancer are shaped and influenced by their constantly changing future horizon, and specifically, by their expectations about their breast reconstruction. A considerable body of research discusses such expectations, predominantly within the framework of realistic and unrealistic expectations (Denford et al. 2011; Snell et al. 2010). In the last chapter, however, I start from the question of what having expectations actually means beyond this restrictive, dichotomous understanding. How are women's embodied, breast reconstruction experiences and dealings extended through time, and specifically, to their expected, reconstructed future?

In the concluding chapter of this thesis, chapter six, I return to the general question of how women's embodied breast cancer experiences and sense-making processes are shaped, constructed, determined and influenced within and through their different 
lived contexts. Moreover, I reflect on the employed phenomenological-narrative approach and on how the results discussed in this thesis contribute to understanding breast cancer experiences and sense-making structures, and to experiences of deviant bodies and bodily change in general. Finally, I elaborate on how the conclusions of this thesis could be of practical and emancipatory value not only to current, former and future breast cancer patients, but also to a wider group of people with non-normal bodies. 


\section{REFERENCES}

Ahmed, S. (2006). Queer phenomenology: Orientations, objects, others. Durham: Duke University Press.

Aho, J. and Aho, K. (2008). Body Matters: A Phenomenology of Sickness, Disease, and Illness. Lanham, MD: Lexington Books.

Akrich, M. (1992). The de-scription of technological objects. In: Bijker, W.E. and Law. J., Shaping technology/building society. Cambridge: MIT Press, 205-224.

Andrykowski, M. A., Curran, S.L. and Lightner, R. (1998). Off-treatment fatigue in breast cancer survivors: a controlled comparison. Journal of behavioral medicine, 21(1), 1-18.

Baxter, N. N., Goodwin, P. J., Mcleod, R. S., Dion, R., Devins, G., and Bombardier, C. (2006). Reliability and validity of the body image after breast cancer questionnaire. The breast journal, 12(3), 221-232.

Broom, D. (2001). Reading breast cancer: Reflections on a dangerous intersection. Health, 5(2), 249-268.

Bury, M. (1982). Chronic illness as biographical disruption. Sociology of health \& illness, 4(2), 167-182.

Carver, C.S., Pozo-Kaderman, C., Price, A.A., Noriega, V., Harris, S.D., Derhagopian, R.P., Robinson, D.S., Moffatt, F.L. (1998). Concern about aspects of body image and adjustment to early stage breast cancer. Psychosomatic medicine, 60(2), 168-174.

Carver, C.S.; Pozo, C., Harris, S.D., Noriega, V., Scheier, M.F., Robinson, D.S., Ketcham, A.S., Moffat, F.L., Clark, K.C. (1993). How coping mediates the effect of optimism on distress: a study of women with early stage breast cancer. Journal of Personality and social psychology, 65(2), 375-390.

Charmaz, K., and McMullen, L. M. (2011). Five ways of doing qualitative analysis: Phenomenological psychology, grounded theory, discourse analysis, narrative research, and intuitive inquiry. Guilford Press.

Couser, G.T. (1997). Recovering bodies: Illness, disability, and life writing. Madison, Wisconsin: University of Wisconsin Press.

Dalibert, L. (2015). Living with Spinal Cord Stimulation: Doing Embodiment and Incorporation. Science, Technology and Human Values: 10.1177/0162243915617833.

Dastur, F. (2000). Phenomenology of the event: Waiting and surprise. Hypatia, 15(4), 178-189.

De Beauvoir, S. D. (1949). Le deuxième sexe. Paris: Gallimard.

De Boer, M. and Slatman, J. (2014). Blogging and breast cancer: Narrating one's life, body and self on the Internet. Women's Studies International Forum, 44, 17-25.

De Boer, M., van der Hulst, R., and Slatman, J. (2015). The Surprise of a Breast Reconstruction: A Longitudinal Phenomenological Study to Women's Expectations About Reconstructive Surgery. Human Studies, 38(3), 409-430.

DeFrank, J. T., Mehta, C. C. B., Stein, K. D., and Baker, F. (2007). Body image dissatisfaction in cancer survivors. Oncology Nursing Forum, 34(3), 625-631.

Denford, S., Harcourt, D., Rubin, L., and Pusic, A. (2011). Understand normality: A qualitative analysis of breast cancer patients concepts of normality after mastectomy and reconstructive surgery. Psycho-Oncology, 20(5), 553-558.

Dennett, D. (1991). Consciousness Explained. Boston: Little, Brown and Co.

DiGiacomo, S. M. (1992). Metaphor as illness: Postmodern dilemmas in the representation of body, mind and disorder. Medical Anthropology, 14(1), 109-137.

Fanon, F. (1967). Black skin, white masks. New York: Grove Press.

Frank, A. W. (1995). The wounded storyteller, body, illness and ethics. Chicago and London: University of Chicago Press.

Germino, B. B., Fife, B. L., and Funk, S. G. (1995). Cancer and the partner relationship: What is its meaning?. Seminars in Oncology Nursing, 11(1), 43-50.

Gilbert, E., Ussher, J. M., and Perz, J. (2010). Re-negotiating sexuality and intimacy post-cancer: The experiences of carers in a couple relationship with a person with cancer. Archives of Sexual Behavior, 39(4), 998-1009.

de Haes, J. C. J. M. and F. C. E. Van Knippenberg (1985). The quality of life of cancer patients: a review of the literature. Social science \& medicine, 20(8), 809-817. 
Härtl, K., Janni, W., Kästner, R., Sommer, H., Strobl, B., Rack, B., and Stauber, M. (2003). Impact of medical and demographic factors on long-term quality of life and body image of breast cancer patients. Annals of oncology, 14(7), 1064-1071.

Heidegger, M. (1962). Being and time. Oxford: Basil Blackwell.

Husserl, E. (1960). Cartesian meditations: an introduction to phenomenology. The Hague: Martinus Nijhoff.

Hutchinson, A. D., Hosking, J. R., Kichenadasse, G., Mattiske, J. K., and Wilson, C. (2012). Objective and subjective cognitive impairment following chemotherapy for cancer: a systematic review. Cancer treatment reviews, 38(7), 926-934.

Ihde, D. (1990). Technology and the lifeworld: From garden to earth. Bloomington and Indianapolis: Indiana University Press.

Kasper, A. S. (1994). A feminist, qualitative methodology: A study of women with breast cancer. Qualitative sociology, 17(3), 263-281.

Kayser, K., Watson, L. E., and Andrade, J. T. (2007). Cancer as a 'We-Disease': Examining the Process of Coping from a Relational Perspective. Families, Systems \& Health, 25(4), 404-418.

Landmark, B. T., and A. Wahl (2002). Living with newly diagnosed breast cancer: a qualitative study of 10 women with newly diagnosed breast cancer. Journal of advanced nursing, 40(1), 112-121.

Latour, B. (1994). On technical mediation: Philosophy, sociology, genealogy. Common Knowledge, 3, 29-64.

Leunissen, T., de Boer, M., van der Hulst, R., and Slatman, J. (2015). Exploring novel dimensions of body experience after breast reconstruction. JPRAS Open, 7, 32-41.

Lorde, A. (1980). The cancer journals. London: Sheba Feminist Publishers.

Löwy, I. (2010). Preventive strikes: women, precancer, and prophylactic surgery. Baltimore: JHU Press.

McLuhan, M. (1964). Understanding media: The extensions of man. New York: McGraw Hill.

Mehnert, A. and Koch, U. (2007). Prevalence of acute and post-traumatic stress disorder and comorbid mental disorders in breast cancer patients during primary cancer care: a prospective study. Psycho-Oncology, 16(3), 181-188.

Merleau-Ponty, M. (1945) Phénomenologie de la perception. Paris: Gallimard.

de Mul, J. (2010). Cyberspace odyssey. Towards a virtual ontology and anthropology. Castle upon Tyne: Cambridge Scholars Publishing.

Murray, S.J and Holmes, D. (2014). Interpretative Phenomenological Analysis (IPA) and the Ethics of Body and Place: Critical Methodological Reflections. Human Studies, 37(1), 15-30.

Nancy, J.-L. (2000). Being Singular Plural. Stanford: Stanford University Press.

Oudshoorn, N. (2015). Sustaining cyborgs: Sensing and tuning agencies of pacemakers and implantable cardioverter defibrillators. Social studies of science, 45(1), 56-76.

Page, R. (2008). Gender and genre revisited: Narratives of illness on personal blogs. Genre: A quarterly devotes to generic criticism, 41(3-4), 149-175.

Poster, M. (1995). The second media age. Cambridge: Polity.

Ricoeur, P. (1981). Hermeneutics and the Human Sciences: Essays on Language, Action and Interpretation. Trans. John B. Thompson. Cambridge: Cambridge University Press.

Ricoeur, P. (1991-a). From Text to Action: Essays in Hermeneutics II. Trans. Kathleen Blamey and John B. Thompson. Evanston: Northwestern University Press.

Ricoeur, P. (1991-b). Narrative identity. In: D. Wood (ed.), On Paul Ricoeur: Narrative and Interpretation. London and New York: Routledge.

Ricoeur, P. (1992). Oneself as another. Trans. Kathleen Blamey. Chicago: University of Chicago Press.

Sears, S. R., Stanton, A. L., and Danoff-Burg, S. (2003). The yellow brick road and the emerald city: benefit finding, positive reappraisal coping and posttraumatic growth in women with early-stage breast cancer. Health Psychology, 22(5), 487-497.

Sedgwick, E. (1993). White glasses. In: Tendencies. Durham, N.C.: Columbia University Press, 252-266.

Shildrick, M. (2012). Dangerous Discourses: Subjectivity, Sexuality and Disability. London: Palgrave Macmillan.

Shildrick, M. (2015). "Why Should Our Bodies End at the Skin?": Embodiment, Boundaries and Somatechnics. Hypatia, 30(1), 13-29. 
Slatman, J. (2014). Our Strange Body: Philosophical Reflections on Identity and Medical Interventions. Amsterdam: Amsterdam University Press.

Slatman, J. and Widdershoven, G. (2010). Hand Transplants and Bodily Integrity. Body \& Society, 16(3), 69-92.

Slatman, J. (2011). The Meaning of Body Experience Evaluation in Oncology. Health Care Analysis, 19(4), $295-311$.

Slatman, J., Halsema, A. and Meershoek, A. (2015). Responding to Scars After Breast Surgery. Qualitative health research: 1049732315591146.

Smith, J. A., Flowers, P., and Larkin, M. (2009). Interpretative phenomenological analysis. Theory, method and research. London: Sage.

Snell, L., McCarthy, C., Klassen, A., Cano, S., Rubin, L., Hurley, K. and Pusic, A. (2010). Clarifying the expectations of patients undergoing implant breast reconstruction: a qualitative study. Plastic and Reconstructive Surgery, 126(6), 1825-1830.

Sontag, S. (1990). Illness as Metaphor and AIDS and its metaphors. New York: Anchor Books.

Steinbock, A. J. (2006). Time, otherness, and possibility in the experience of hope. In: Vandevelde, P. (ed.) Issues in Interpretation Theory, Milwaukee: Marquette University Press, 271-289.

Svenaeus, F. (2014). The body uncanny: Alienation, illness, and anorexia nervosa. In: Zeiler, K. and Käll, L.F. (eds.) Feminist phenomenology and medicine, New York: SUNY Press, 201-221.

Thomas-MacLean, R. (2005). Beyond dichotomies of health and illness: life after breast cancer. Nursing Inquiry, 12(3), 200-209.

Turkle, S. (1995). Life on the screen, identity in the age of the internet. London: Phoenix.

Ussher, J. M., Wong, W. T., and Perz, J. (2011). A qualitative analysis of changes in relationship dynamics and roles between people with cancer and their primary informal carer. Health, 15(6), 650-667.

Verbeek, P.-P. (2010). What things do: Philosophical reflections on technology, agency, and design. Pennsylvania: Penn State Press.

Wendell, S. (1996). The Rejected Body: Feminist Philosophical Reflections on Disability. London and New York: Routledge.

Young, I. M. (2005). On female body experience: "Throwing like a girl" and other essays. Oxford: Oxford University Press.

Zahavi, D. (2005). Subjectivity and selfhood: investigating the first-person perspective. Cambridge, Massachusetts, and London: The MIT Press.

Zahlis, E.H. and Shandis, M.E. (1991) Breast Cancer: Demands of the Illness of the Patients Partner. Journal of Psychosocial Oncology, 9(1), 75-93.

Zeiler, K. (2014). A philosophical defense of the idea that we can hold each other in personhood: intercorporeal personhood in dementia care. Medicine, Health Care and Philosophy, 17(1), 131-141.

Zeiler, K., and Guntram, L. (2014). Sexed embodiment in atypical pubertal development: Intersubjectivity, excorporation and the importance of making space for difference. In: Zeiler, K. and Käll, L.F. (eds.) Feminist phenomenology and medicine, New York: SUNY Press, 141-160. 


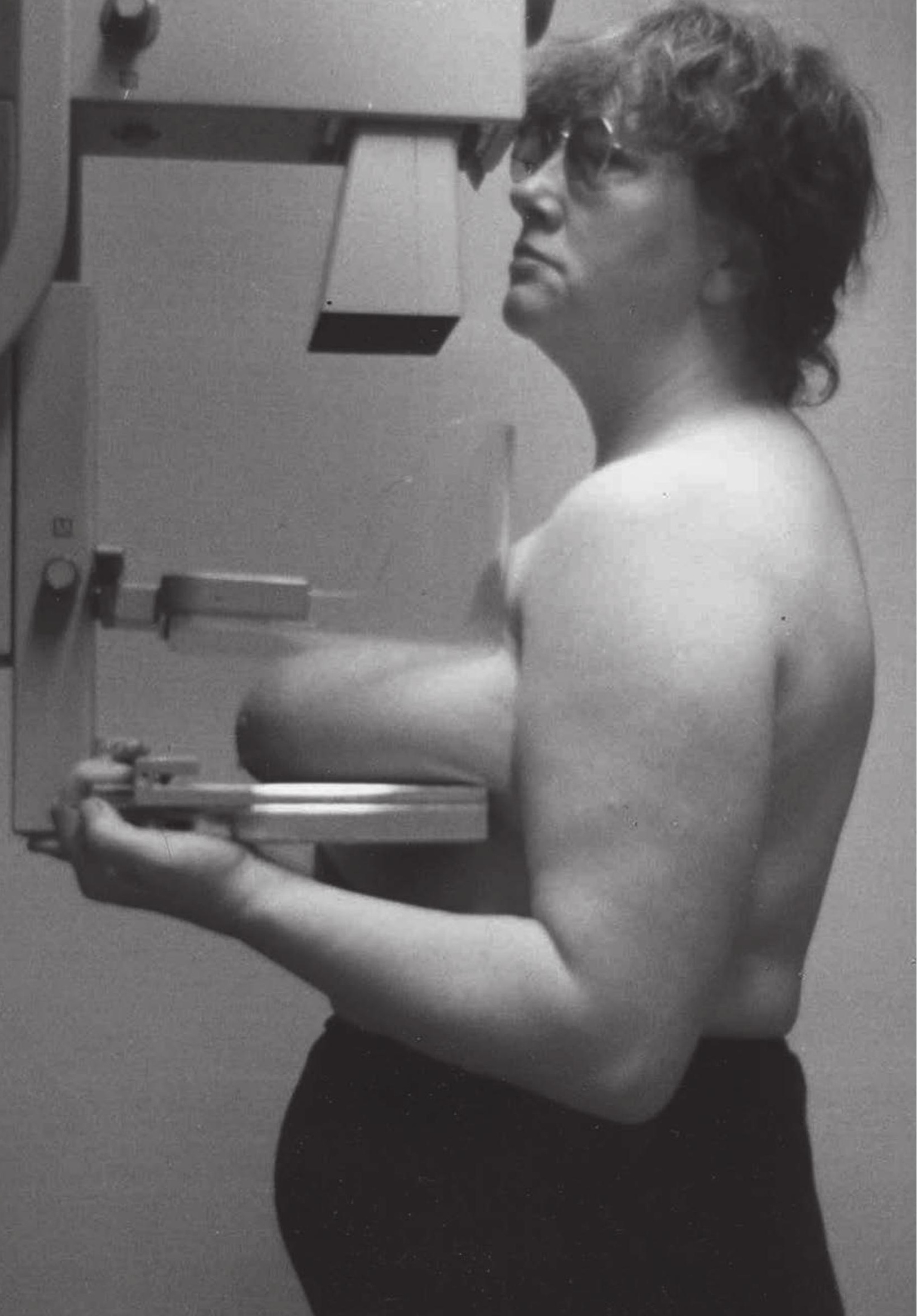




\section{CHAPTER}

\section{The mediated breast}

Shaping women's agencies in their engagements with medical technologies and prosthetic artifacts in breast cancer 



\subsection{INTRODUCTION}

Passing through the hands of the medical orthodoxy can be terrifying when you have breast cancer. I determined to document for myself what was happening to me. Not to be merely the object of their medical discourse but to be the active subject of my own investigation. Here whilst a mammogram is being done I have persuaded the radiographer to take a picture for me. She was rather unhappy about it, but felt it was preferable to my holding the camera out at arm's length and doing a self-portrait. (Caption 'Mammogram', Spence 1988, 153)

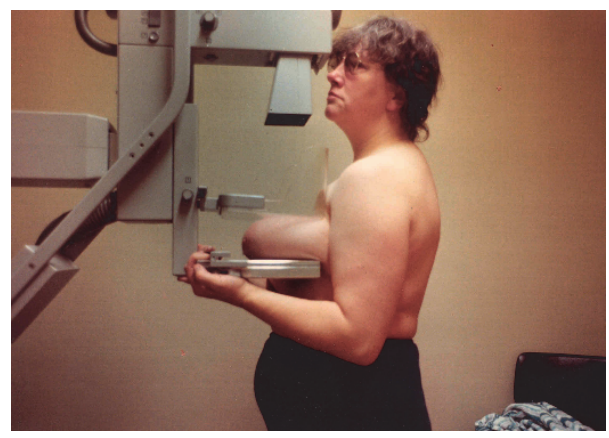

Figure 1 'Mammogram' (Picture of health?, 1982) by Jo Spence, copyright (C) the Estate of Jo Spence. Courtesy Richard Saltoun Gallery

The photo entitled 'Mammogram' by British photographer Jo Spence captures a telling experience of engaging with technology in the context of breast cancer. In the frame, we see Spence standing in profile, naked from the waist up, while her right breast is compressed between the two plastic plates of the mammography ( $x$-ray) machine. At first sight, 'Mammogram' documents the restrictive positioning of a woman-patient invoked by the medical routine of subjecting her body to diagnostic machinery. In correspondence with a long feminist tradition, spence holds that this kind of inquiry is objectifying, suppressive and always in imminent danger of usurping selfhood: in being - quite literally - pinned down by the machine, she feels she hands over the control over her body, leaving her vulnerably exposed and terrified (Poovey 1987; Dykstra 1995; Sharp 2000). The accompanying caption, however, discloses how Spence, by deploying a technology of her own - her photo camera -, adds her own perspective, thereby constituting another kind of experience. The photograph allows her "to go over the experience again [later on] and use [it] as a kind of touchstone" (Spence and Coward 1986, 25). As such, she becomes more than only "the object of [...] medical discourse": she also becomes "the active subject of [her] own investigation" (Spence 1988, 153). For Spence, the act of photography is a way of posing the question of what kind of self is represented and created amidst medical routines and through technology. "The potential of photography," she remarks, lies both in revealing her "lack of agency" with her breast in the machine and in "healing [her] agency" through taking a photograph (Spence 1995, 104-105).

Although Spence's agentic experiences are particular and personal by definition, as well as historically framed within feminist activism of the 1980s, they still raise general questions about the agency of women in the context of breast cancer. For what does agency - or the lack thereof - exactly mean in the face of breast cancer diagnosis, dur- 
ing the disease's treatment, and in its aftermath? And how does engaging with technologies and artifacts in breast cancer co-shape the agency of the women involved? By considering these questions, the argument of this paper focuses on the meaning and construction of women's agency in their various engagements with breast cancer technologies and artifacts.

All women who deal with (the diagnostic possibility of) having breast cancer relate to, interact with, and, to some extent, incorporate a range of medical technologies and prosthetic artifacts. Their breasts are squeezed into a mammography machine, they get tubes inserted for chemotherapy, they are exposed to daunting radiotherapy equipment, and they wear external breast prostheses or incorporate implants in a breast reconstruction. Following recent research in Science and Technology Studies (STS) and philosophy of technology, we argue that such engagements shape the ways these women approach and experience themselves and their lives. Technologies and artifacts mediate people's existence (Ihde 1990; 2002; Verbeek 2006). These fields of study, however, predominantly attend to the agency of technologies: that is, to the ways in which technologies inhibit, invite, or provoke users' routines, intentions, and values (Ihde 1990; Akrich 1992; Latour 1994; Ihde 2002; Verbeek 2006). In response, various scholars argue that in order to understand how technology mediates people's life, the agency of users in human-technology relations must be fully reckoned with as well (van Dijck 2009; Dalibert 2015; Oudshoorn 2015).

In taking up this critique and exploring women's agency, we deliberately focus on the mediation of established technologies and artifacts. In doing so, we run counter to the current trend in STS research, which centers around the mediation of new and emerging technologies (Latour 1994; Swierstra and Waelbers 2012; Dalibert 2015). A focus on already implemented, mundane technologies shifts the attention away from the groundwork involved in creating technologies and (the prediction of) their initial impact on the social and moral order. It will instead enable us to concentrate on the meaning of embodied experiences of users who engage with technologies in the here and now. Only after technologies have been used for a sustained amount of time, after all, it may become clear in what ways and to what extent they impact people's actions and experiences (Oudshoorn 2015). In this sense, 'old' breast cancer technologies and artifacts allow space for thinking through the issue of the technologically mediated agency of women.

In this paper, we describe and investigate the agency of women in their engagements with breast cancer technologies and artifacts by presenting and analyzing four exemplary narrative accounts of women in different stages of breast cancer diagnosis and treatment. We explicitly frame our discussion of these empirical cases within the tradition of philosophy of technological mediation (Ihde 1990; 2002; Verbeek 2006) and within a phenomenology of embodied agency (Merleau-Ponty 1945; Young 2005). As discussed in the next sections, this dual theoretical approach will contribute to unraveling the empirical complexities involved in women's technologically mediated agency 
and, as such, it offers us a deeper understanding of the role of this agency. Before turning to the empirical investigation, however, we first elaborate on the concepts of technological mediation and embodied agency.

\subsection{TECHNOLOGICAL MEDIATION AND EMBODIED AGENCY}

In his well-known work, Ihde (1990; 2002) shows that technologies and artifacts coshape or mediate people's experiences and perceptions. He discerns several fundamental ways in which such technological mediations take place: in embodiment, hermeneutics, alterity, and in background relations between humans and technologies. First of all, technologies may be integrated into the bodily sensorium of their users. In such an embodiment relation, technologies become extensions of the user's body and of how she or he perceives and approaches the world. Here, the artifact typically withdraws from people's attention and, ideally, becomes perceptually 'transparent'. In the second, hermeneutic relation, technologies claim explicit attention for themselves. Such technologies may provide a representation of reality that needs to be interpreted by the user in order to constitute a perception of that reality. Note that this hermeneutic relation still evokes some kind of technological, or as Ihde puts it, "referential" transparency $(1990,82)$. While the technology is being read, it refers beyond itself to what is not immediately seen, to a certain account of the world the user lives in - like a thermometer, which delivers a value that needs to be interpreted in order to tell something about the hotness or coldness of the world. Third, technologies, instead of merely being vehicles through which people experience or perceive the world, may also be the terminus of their experience. In this so-called alterity relation, people explicitly interact with technologies, and in doing so, technologies become the center of their attention. Finally, some technologies may not be either embodied or experienced directly, but rather situate what is explicitly present, like constant traffic noise which creates a context through which we experience city life.

Since Ihde, many scholars within the field of philosophy of technology have expanded the scope of the concept of technological mediation by exploring how artifacts mediate not only experience and perception, but also action and praxis (Akrich 1992; Latour 1994; Fogg 2003; Verbeek 2006; Tromp et al. 2011; Rietveld 2012). By reconciling Ihde's work with that of Akrich (1992) and Latour (1994), Verbeek, in particular, formulates an integrated theory of how technologies mediate people's perceptions and how these approach their world and are present in it. Similar to experiences, he argues, people's actions "are not only the result of individual intentions and the social structures in which human beings find themselves [...], but also of [their] material environment" (Verbeek 2006, 366). In other words, 'how the world appears to humans' and 'how humans act in the world' is always to a smaller or larger degree constituted and transformed by artifacts and technologies. 
As various authors have shown, there is a repertoire of figures of such technological mediations. For instance, artifacts may direct people's actions by harder or softer forms of (physical) coercion (Akrich 1992; Latour 1994; Tromp et al. 2011), and convince or persuade users to adopt certain behaviors (Fogg 2003). Drawing on an alternative vocabulary, such as Gibson's eco-psychological account (1979), artifacts (and the environment) are claimed to entail a certain amount of "affordance", in the sense that they variously "afford" possibilities for use and action (Rietveld 2012).

At this point, it is important to note that artifacts and technologies are not neutral intermediaries, but co-determine people's involvement in the world by way of their normative dimension. Technologies mediate actions by attempting to bring about suitable, acceptable, or desirable practices and experiences (Verbeek 2006). For example, a speedometer on the side of the road tries to convince drivers to comply with the speed limit (Tromp et al. 2011), a speed bump enforces drivers to slow down (Fogg 2003), and door handles in cars, often making use of a recess in the door that fits the hand, suggest and solicit an appropriate grip (Rietveld 2012).

This capacity to mediate (moral) practices and experiences, however, is not an essential or static property of the artifacts themselves, but emerges from the context in which these artifacts are used. By referring to Ihde's concept of 'multistability', Verbeek explains that in each particular socio-cultural context an artifact may be used differently. Expanding on Heidegger's well-known hammer example, this means that a hammer may be used to drive nails into a wall, but in intense fury, this same tool may be used as a murder weapon. As such, an artifact may develop various identities in particular contexts of use, thereby allowing for multiple possible perceptions and practices. In this sense, Verbeek $(2009,253)$ argues that technologies may be seen "as conditioned entities [that] condition human life."

In this paper, we are interested in what technological mediation in the context of breast cancer does to the agency of women who engage with the technologies involved. To actually understand changes in agency, we have to outline how to understand the very concept of agency. It is striking that in many studies on technological mediation and agency, the idea of agency remains rather vague and implicit or is only defined in terms of physical activity (Fogg 2003; Tromp et al. 2011). In following Rietveld's (2012) argument that the co-constitution of technologies and people's actions and perceptions presupposes that people are able to act and perceive, we will draw on a phenomenological concept of agency.

According to phenomenology, the condition of possibility for world-disclosure is given with the embodied subject's situation and her possibilities. People's possibilities to be in the world open up because of the mode and limits of their embodied capacities. Phenomenologists have emphasized that it is this kind of embodied skillfulness that is the locus of agency - or the lack thereof - and this is expressed through the utterance 'I can' (Merleau-Ponty 1945) or 'I cannot' (Young 2005). In this sense, it is not active movement ('I do'), but rather perception of or action toward the world that is the primary example 
of human agency. Fundamentally, the notion of 'I can' is inscribed in the tradition of existentialist philosophy, and as such it refers to the idea that human existence is ambiguous in that it is characterized by having possibilities while 'being thrown' into a particular, given situation. Although the notion of 'I can' is primarily associated with prereflective 'motor-intentionality' in the work of Merleau-Ponty, and it is thus directly related to a person's lived body (corps vécu), it is not possible to reduce the degree of '। can' or 'I cannot' to actual physical strengths or impairments. A person's embodied 'I can' is fundamentally framed within a person's situation - one which is never neutral but always already determined by certain power relations and socio-cultural norms. For this reason, women living in a sexist society may have a strong experience of 'I cannot' when engaging in competitive, typically masculine physical activities (Young 2005). A similar dynamic pertains to colored people living in a 'white' society (Fanon 1967; Ahmed 2006) or women who feel that they cannot live up to expectations of female appearance (De Boer and Slatman 2014). ${ }^{5}$ Based on the notion of agency in terms of 'I can' and the idea of agency and (technological) objects conditioning each other reciprocally, this paper explores how women's bodily capacities to create possibilities in the world are shaped in relation to using breast cancer technologies and artifacts.

\subsection{SHAPING AGENCIES IN ENGAGING WITH BREAST CANCER TECHNOLOGIES}

In our empirical analysis of women's technologically mediated agency in the context of breast cancer, we present and analyze four cases: the experiences of Mary, Karin, Grace, and Barbara. The first author interviewed these women as part of a larger empirical-philosophical study on how women who have (had) breast cancer experience and make sense of themselves and their bodies (See: De Boer and Slatman 2014; De Boer et al. 2015). In addition to these interviews, the first author included Karin's personal weblog about her breast cancer experiences and the observations of Mary at her breast screening in the analysis. We obtained ethical clearance for this study from the ethical review board of the Dutch hospital through which the respondents were recruited (file number 13-4-086). Informed consent was obtained from all individual participants included in the study. Mary, Grace, and Barbara are pseudonyms. Karin, a well-known disability activist in the Netherlands, specifically requested that we use her real name. See table 1 in the appendix for further details about the respondents.

\footnotetext{
${ }^{5}$ We adhere to this phenomenological, existential concept of agency since we believe that agency is directly related to the way people orient themselves in their world. Orientation may take place consciously, but most of the time it takes place pre-reflectively (Ahmed 2006). We do not ascribe agency to unconscious physiological or mechanical processes, and in that sense our concept of agency differs radically from, for instance, Goodwin (2008), who argues that anaesthetized mediated bodies possess agency in the sense that they are able to express the level of their blood pressure and heart beat through monitoring technologies.
} 
While these four women all have had encounters with technologies that may speak to cancer patient experiences in general, this study concentrates on engagements that target their feminine body and are particular for their breast cancer. Various medical technologies and prosthetic artifacts involved in the diagnosis of breast cancer - the mammography machine -, its treatment and aftermath - external breast prostheses, breast implants, wigs, etc. - specifically affect feminine facets of life and body parts. Accordingly, such breast cancer technologies co-constitute these women's actions and experiences, and shape aspects of their agency that relate to their femininity and their being (non-/one-) breasted.

Moreover, this study explicitly focuses on a wide range of different temporal and spatial configurations of using these breast cancer technologies. In existing studies, the concept of technological mediation seems to be bounded by a certain temporality and configuration of use. Here, mediation predominantly takes place between humans and manageable, detachable, and momentarily used technologies (Ihde 1990; Verbeek 2006). In this respect, Dalibert (2015) rightly argues, however, that technological mediation may shape user's agency differently in different durations of use and different positions on/in the body. As such, the cases discussed below highlight exemplary aspects of shaping women's female, breasted agencies within various temporal and spatial configurations of using breast cancer technologies: Mary's brief but invasive close encounter with the mammography machine ('choreographing the mammography'), Karin's and Grace's adjustments to their intensively worn prosthetic artifacts ('personalizing prosthetics'), and Barbara's subcutaneous incorporation of her breast implants ('filling/failing the breast reconstruction').

\section{Mary: choreographing the mammography}

Engaging with technology in the context of breast cancer is not only reserved for women who are actually diagnosed with breast cancer. In many Western countries, most women between ages 50 and 75 regularly participate in a national mammography screening program. At a radiological center, these women get their breasts $x$-rayed in order to detect malignancies. ${ }^{6}$

Upon an invitation by Mary, the first author accompanied her to her breast screening. In the radiology room, Mary undressed her upper body behind a folding screen. The analyst put her breasts on the plastic plates of the mammography machine, during which she instructed Mary to embrace the machine and to stand still during the procedure. By standing right behind her, the analyst adjusted Mary's stance: her arms higher

\footnotetext{
${ }^{6}$ For the women within this study, as for most women, the diagnosis of breast cancer starts with having a breast mammogram, a technology that dates back to 1913. Although other types of (less painful) imaging technologies were developed over the last decade, such as thermography and elastography, mammography is still standard for general breast screening. To this day, it offers the most extensively validated and comprehensive diagnostic information.
} 
up, her chest closer to the machine, and her legs wider. During the $x$-ray, the plates squeezed Mary's breasts and while she held on to the machine forcibly, she grimaced from the pain. With a squeaky voice she said: "stop", and then louder: "OUCH!". "Hold on just a bit", the analyst responded. After a few seconds, the plates opened up and Mary looked visibly relieved.

What is indeed an intimate and painful interaction between the mammography machine, Mary, and the radiological analyst may also be understood as the collaborative enactment of the mammography machine's scripts. Technologies have 'scripts', Akrich (1992) and Latour (1994) argue, inasmuch as they prescribe certain actions while they discourage others, just like a theatre play script does. The radiological analyst explained that the mammography machine indeed requires a specific positioning of the screened woman: the breast has to be flattened and separated from the body as much as possible while the woman has to stand still. Such a scripted 'fit' between the device and Mary depends on - what Garland Thomson (2011) calls - "the relational choreography" that plays out between the material and the social environment: in this case, the choreography of the radiologist who put Mary's breast in the machine, adjusted her stance, and encouraged her to endure the pain, and of Mary who held on to the machine forcibly, thereby preventing herself from retracting while the plates painfully squeezed her breasts.

Even though Mary cooperatively performed scripted behavior, she evaluated this encounter with the mammography machine as "painful", "suppressive", and "stressful". Similar to Spence, Mary was able to actively mold this kind of mediation of her actions and experiences to more acceptable ones. As she commented:

They made a note in my file about this [the painfulness of the screening], but they seem to be doing nothing with it. It [the pain] is just necessary, they say. So I developed my own way of dealing with it: breathing deeply and massaging my armpit and breasts to soften the tissue so that the squeezing will not hurt that much. (Mary)

These kinds of strategies seem to help Mary to make the encounter with the mammography machine as comfortable as possible within the range of what the machine allows in order to produce a successful x-ray. As a kind of prologue to the mammography choreography, such bodily experimentation enabled Mary to cope with and even reduce the painful experience enforced by the mammography machine. Note that in doing so, she was not only cooperative, but she also adjusted and appropriated the mammography's mediation: in her interaction with the diagnostic device, she actively pursued and achieved - a better (i.e. less bothersome) experience.

Moreover, whereas current debates on technological mediation predominantly deal with actual use-contexts (Ihde 1990; Verbeek 2006; Dalibert 2015), Mary shows that her experiences and actions outside of the actual usage of the $x$-ray device were already affected by - in Kiran's (2011) terminology - the "technological presence" of the machine. As Mary explained: 
Merely the thought of having to go in again [to her periodic breast screening] makes me feel a bit shaky. It's scary because by doing it [having the x-ray], you may find out that something is wrong. But [if so] I want to know, [...] because it allows you to do something [about it]. (Mary)

This quote underscores that in a society in which the breast is depicted as 'at risk' and the possible carrier of a lethal disease, the mere potentiality of using the mammography machine functions as a reminder to Mary that her body is vulnerable and may harbor danger. Accordingly, she felt anxious, insecure and "a bit shaky", something which, at times, preoccupied her and prevented her from being fully engaged in her daily activities.

At the same time, the presence of the machine did not only affect Mary's daily doings and sense of control over her life and body negatively. Her words suggest that the availability and dreaded functionality of the machine - offering her the possibility to "find out that something is wrong" - also empowered her. By being able to seek the knowledge the machine offers and with an appeal to the promise of exerting control over the body through biomedicine ("it allows you to do something"), she actively tried to avert imagined disastrous illness scenarios. In line with what Kiran holds about technologies that are not taken up or used directly, then, Mary's mixed experiences show that such technologies, rather than merely functioning in the background and contextualizing experiences, actually "profoundly shape the way we live or perceive our lifeworld. [As such,] technologies [as a receding phenomenon] have a much more active role than Ihde assigns to [them]" (Kiran 2012, 83).

Mary's interaction with the mammography machine seems to affect her agency in ambiguous ways. The machine threatened her 'I can' for it reminds her of the risk of having a lethal, disfiguring disease. In its presence, it appears that the assumption 'I can do X later' can no longer be taken for granted by Mary because her possibilities may diminish. This uncertainty - and the fear that comes with it - can be debilitating in the present. In actually being pinned down by the mammography machine, moreover, her bodily 'I can' was impaired because of the temporary inhibition of actually being able to move around, but also because of the involved decline of comfort and the imposition of pain. This technologically mediated 'I cannot (move around/ be comfortable/ stop the pain)' draws attention to the interdependency of her (lack of) agency and this specific social setting: after all, the analyst positioned her and could have put an end to her pain (Garland-Thomson 2011; De Boer and Slatman 2014).

Nevertheless, her agency was not only affected negatively in the mammography machine's mediation. Counter to Spence's experiences and the idea that the objectifying medical gaze strips off women's agency (Poovey 1987; Sharp 2000), Mary shows that scientific objectification is not antithetical to agency. By resolutely turning herself over to the restrictive clinical protocols, she actively invested in the positivist promise of medical expertise that all can be known and controlled. Her will to consent to such an objectifying positioning refers to her agentic properties, signifying both the affirmation 
and the empowerment of her 'I can': by exerting the possibility to participate in a breast screening program, she assured herself that her impending possibilities were less indeterminate, and in doing so, she seemed to regain her ability to presently act and approach her future with (more) confidence. Furthermore, in complying with the painful mammography routines, she remained self-asserting while experimenting with her body. In doing so, she actively renegotiated and reconstituted her 'I can (be comfortable)', albeit only within the bounds of the protocol.

\section{Grace and Karin: personalizing prosthetics}

While Mary got an assuring letter stating that she does not have any malignancies, Karin, Grace, and Barbara did get diagnosed with breast cancer after their breast screening. During chemotherapy and in the aftermath of their mastectomy or lumpectomy, these women related to technologies and artifacts that adhered to their affected - scarred, one/un-breasted and balding - bodies against the status quo of female symmetrically and double breasted, (long-)haired - bodies. For most women, as for Grace and Barbara, this meant wearing external breast prostheses or incorporating internal ones in a breast reconstruction. Karin, however, decided to go around asymmetrically breasted after her unilateral mastectomy. For her, wearing clothes becomes a significant issue. With one missing breast, bras literally do not fit her anymore. On her weblog, Karin writes:

Although I do not want a prosthesis [...], a bra for the remaining breast might be nice: mainly for support. But regarding that [one-breasted bras], there is simply not much available. That is why I did some home crafting. I made a photo report of [how to] make a 'pirate bra'. (Karin)
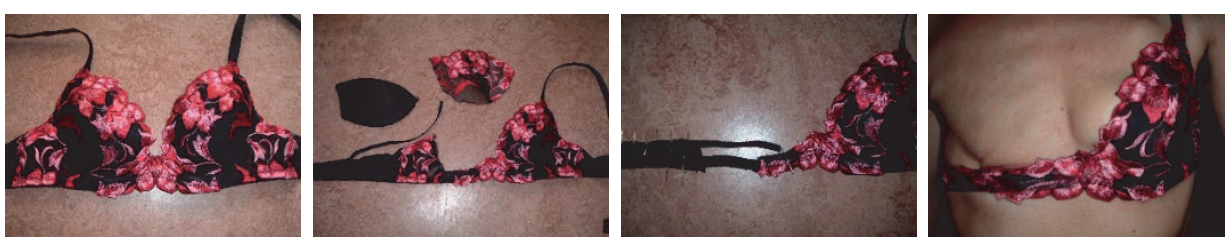

Figure 2 Photo report of making a pirate bra by Karin, copyright (C) Karin Spaink 2007

While a bra may be seen as a way to discipline female bodies into an ideal female form (Yalom 1997), Karin's writings underscore that bras may also provide breast support and comfort. The standard design of a bra, however, assumes a double breasted body and as such, it fails to fulfill its purpose for Karin. Similarly, this bodily norm is also incorporated in the material of shirts: this kind of apparel has the tendency to wrap around Karin's one-breasted body, thereby restricting her movements and requiring her to constantly pull down her shirts. 
In contrast to Ihde's claim that clothes are somewhat embodied - "[it] is part of a fringe awareness [...], without restricting movement" (1990: 110) - Karin shows that with her atypical body clothes may neither be enabling nor transparent in her tactile experience but rather explicitly opaque and uncomfortable. Being ready-to-wear mass produced devices that incorporate presuppositions concerning the female body, bras and shirts do not 'fit' Karin's 'abnormal' body. Consequently, Karin's agency - her possibilities to act in the world - are constrained. In wearing such normative designs, her clothes remain in the foreground of her experiences, thereby restricting her in going around comfortably and hindering her in being engaged in other activities. This 'I cannot' challenges her to tinker with the design of the artifacts themselves. In personalizing her clothes, we argue, she attempts to reconstitute her ability to go around unobstructed and she affirms her agency in the altering activity itself. In fact, Karin's aspired rehabilitation of her 'I can' seems to depend on the ideal of her clothes not being explicitly noticed by her (De Boer and Slatman 2014). Note that this enterprise is paradoxical insofar as it entails Karin's explicit awareness of, and invasive engagement with her clothes: aiming for a transparent clothing experience apparently requires her clothes to become an intensely directive focal point, if not a restrictive one.

As Karin's experience demonstrates, breast surgery greatly affects women's bodies and their agency. While Karin's 'I can' seems to be co-dependent on the tactile comfort of wearing normative clothes on her mastectomized body, for other women who have lost one or both breasts, or parts thereof, their 'I can' seems to be co-determined by their non-normative bodily appearance. Grace is one of them. After her unilateral lumpectomy, which reduced one of her breasts significantly, she feels she appears as an oddity in the eyes of others, thereby attracting other people's stares and glares. In attempting to maintain her 'I can', that is, her ability to go about unobstructed by unwanted gazes, she aims to pass as an anonymous, normally breasted woman by wearing a partial external prosthesis that filled up the removed part of her breast (Goffman 1963; Garland-Thomson 2011). At first sight, the prosthesis effectively masked Grace's marked body: "I do not stand out that much when I walk on the street", she says, "that's nice: I look normal, [...] more feminine". Upon a closer look, however, maintaining her 'I can' is not just a matter of wearing the prosthesis and appearing as breasted. In order for the prosthesis to fulfill its normalizing function in the eyes of by-passers, Grace had to actively engage with it.

During the prosthesis fitting, Grace was offered a pale pink prosthesis. With her dark skin she looked, as she put it, "like a muddy pig with a pink snout". Since there were no dark skin colored prostheses available at the prosthesis shop, she settled for the pink one. She elaborated on wearing such a contrasting prosthesis:

I like to wear deep cleavages: I have nice breasts, you know. But the prosthesis is quite high up my breast, making it [the pink prosthesis] visible. So I did not do that [wear cleavages] anymore. Altogether, it felt just strange to wear it [the 
prosthesis]. [Eventually,] I colored the prosthesis with a brown permanent marker and then it did not stand out that much anymore. [...] It was better. (Grace)

Grace's experiences show that her skin color, which has nothing to do with her biological physical capacities, certainly influenced the way she orientates herself in the world. She inhabits a world in which 'whiteness' is the taken-for-granted background. Her being colored therefore resulted in the fact that often her body, rather than being a zero point for her action and perception, became the object of perception, something which disrupts her full potential of 'I can' (Ahmed 2006). In incorporating the assumption that its user is white by definition, Grace's prosthesis - which, ironically, was designed to allow its wearer to appear as 'normal' and breasted - categorized and segregated her dark skinned body as non-normative and deviant. Consequently, her ways of going about without being bothered by any negative conscious experience of her body was hampered - "it felt just strange" - and actually prevented her from wearing cleavages.

Grace, however, adopted a strategy through which her basic embodied attitude of ' cannot' could be converted into an 'I can'. Concretely, by coloring the prosthesis she allowed herself to go around with a décolleté again. It may be argued that Grace's dark skin color in the dominant white world not only engendered the disabling prosthetic experience but also provoked her ability to change this experience into a more productive one. Having had breast cancer herself, Lorde (2007) suggests that "one of the most basic black survival skills is the ability to change, to metabolize experience, good or ill, into something useful, lasting, and effective. For hundreds of years of survival as an endangered species has taught most of us that if we intend to live, we had better become fast learners" (182). Grace's case may be understood in the same vein: metabolizing her non-normative experience of being a dark skinned breast prosthesis wearer implies that the contrast between her body and the prosthesis is literally wiped out. In doing so, she did not adapt to the normative whiteness of the world, but rather allayed the trigger point that explicitly exposed her as being deviant. As her non-normativity becomes less evident, she relieved - as Ahmed puts it - "[the] pressure upon [her] bodily surface, where the body feels the pressure point as a restriction in what it can do" $(2006,139)$. In this case, Grace reconstituted her 'I can' by passing as less contrasting with the status quo, instead of by conforming to that status quo.

Sometimes, however, wearing a (personalized) prosthetic artifact does not involve a straightforward effort of passing as normal or less deviant in order to move around unhindered by the gazes of others and to maintain one's 'I can'. When Grace lost her hair during chemotherapy, she decided to wear a wig. "People kept staring", she said, "[and] I really wanted to be not only the sick one, I wanted to be normal too". Grace's choice to wear a wig refers to the fact that the loss of hair, especially for women, has powerful significations. It may indicate, as Grace explicitly stated, a state of sickness, but also the resistance of discourses of normative femininity by symbolizing possible disgrace and madness (Freedman 1994). However, in bypassing unfettered gawking that 
accompany such tainting positions, Grace's practice of maintaining her 'I can' through wearing wigs seems to be far from normalizing. She elaborated:

You immediately notice that it [a standard wig] is fake anyway, so you should better have fun with wigs. I did. [...] I had a whole collection of them [party wigs]: in blue, pink, short, long, [...] and one - my favorite - with metallic strings. (Grace)

While a standard wig is designed to resemble real hair, to Grace, this kind of prosthesis appears to be fake immediately. As such, it may covertly reveal her body's nonnormative element. In a surprising response, Grace decided to wear unusual party wigs, which probably attract more, rather than less, staring. Yet attracting such attention may paradoxically be understood as an attempt to normalize the public dimension of having a non-normative body. Crawford (2015) explains that "being unambiguously defined as unlike others, as overtly distinct may function as a way to normalize [her] interactions because [s] he no longer has to contend with those who could not take their eyes of [her]. Just one glance solidifies [her] difference or distinction and allows gazers to 'move on'" (233). Instead of attempting to be normal or less deviant, Grace's wig wearing practice was explicitly geared towards appearing as evidently deviant. In doing so, she encouraged passers-by to qualify her and, subsequently, to move on, thereby maintaining her possibility to go about unhindered by the lingering stares of others.

Note that while Grace may indeed maintain her 'I can' through wearing explicit nonnormative wigs, she did not opt for the other alternative of appearing explicitly different: going around bald. This may indicate that only within the spectrum of the normative (i.e. having hair, whether actually real or really fake), a deviation from the status quo - crazy colored, weird hair - enabled her to pass by with a non-normative appearance and to maintain her possibilities to act in the world (Freedman 1994).

\section{Barbara: filling/failing the breast reconstruction}

Apart from wearing external prostheses, some women opted for a breast reconstruction after their breast surgery. Or rather, as suggested by Barbara, getting a breast reconstruction may itself be an alternative to wearing external prostheses. She recounted her reasons for opting for an artificial implant reconstruction?

Even when I wore a very tight bra [...], even then, the right [breast prosthesis] was always a bit higher than the left [breast prosthesis] and then, when I wore a tight shirt, it looked awful. I always had to pull the right one down, constantly. [...] And the cleaning [of the prosthesis], pff [...]. I felt something like, no, I have to do something about that. (Barbara)

\footnotetext{
${ }^{7}$ Breast reconstructions fall into two general categories. Autologous reconstruction is based upon the usage of own tissue, while alloplastic reconstruction is based upon an artificial implant.
} 
Like in the cases of Karin and Grace, Barbara's words allude to the fact that a certain degree of forgetfulness of one's (practical, sensorial, visual) body widens the scope of possible action. Barbara's external prostheses required cleaning and pulling down, and this could be a source of frustration. The prostheses hindered her in being engaged in other activities by not supporting her embodied capabilities, her 'I can'. For Barbara, getting a reconstruction seemed to be motivated by her aspiration to be less engaged with her body, and maybe even to forget about her prosthetic body altogether. However, it turns out that attaining such a carefree body - which would enable Barbara to be fully engaged with other activities again - not only required a lot of work and awareness, but - in contrast to Karin's and Grace's case - also seemed to be largely beyond her control.

As in most of the implant reconstructions, Barbara's implant was inserted by a balloon expander. This expander was placed beneath her skin by a plastic surgeon and over the course of a couple of months - was periodically injected with a saltwater solution to gradually fill the expander in order to stretch the skin. When the skin was sufficiently stretched, the expander was surgically replaced by the actual implant (Serletti et al. 2011). This process was a time-consuming one, which required periodic and extensive care at the hospital. Moreover, as it was a physically intrusive, uncomfortable, and potentially restricting process, it also demanded Barbara to constantly attend to her own body. As she explained:

Because I have a very thin skin, it [the insertion of the saltwater injection] was [a] very delicate [process]. Often they injected too much and then it was like a hard ball, very painful. [...] On these days, I tried to stay put as much as possible. [...] Well, and yes, you try to avoid those situations so I do not move around a lot anymore since, well, this [she points to her breast]. (Barbara)

Although the reconstruction process was geared towards an extended 'I can', this quote shows that Barbara's possibilities of being involved in the world within the process itself were inhibited. Her 'I can' is not only restricted because of the required periodic maintenance at the hospital or the actual pain in her breast, but also because of her anticipation and attunement to her potentially painful body. That is, her ability to move around and to attend to other activities is to a large extent limited by her avoidance of pain.

After the expander was replaced by the implant, Barbara indeed had a more carefree body in the sense that her prosthetic body did not require constant cleaning and pulling anymore. Unfortunately, the pain from her overstretched skin and especially the fear thereof still occurred from time to time, something which continues to leave her with a limited 'I can'. Moreover, her 'I can' seems to be further restricted in adopting the habit of 'coloring' her overstretched, transparent skin. She elaborated:

So, yes, the skin is so thin now that it all looks a bit bluish. Of course, you see more veins now, and the scars, but also the implant itself is very visible. [...] So I 
put on skin colored concealer [on the breasts] so that the bluishness does not stand out that much. (Barbara)

In contrast to the nature of Barbara's pursuit for a more carefree body, her experiences seem to demonstrate that the actual bodily incorporation of an artifact cannot be equated with an embodiment relation (Ihde 1990). In line with what several authors have argued, the insertion of a prosthesis under the skin may neither amount to its disappearance nor to - quite ironically - its lived transparency (Oudshoorn 2014; Dalibert 2015). In comparison to her external prosthesis, Barbara's implant may even involve more (painful, fearful, color) awareness, which in turn required much care and caution. As such, Barbara failed to obtain a carefree prosthetic body - one that would enable her to forget about it and to extend her agency - through a subcutaneous implant. The strengthening of her agency through such a surgical intervention, however, seems to be largely beyond Barbara's control. We may even argue that, paradoxically, her efforts to control and extend her agency further confine her 'I can'. After all, by adopting the habit of coloring her breasts as a kind of 'damage control strategy', Barbara seems to be more, rather than less, engaged with her body in comparison to the situation prior to her breast reconstruction.

Note that Barbara characterized her reconstructive experience as a "failure of [her] body", especially in relation to the specific social situation in which she finds herself, that is, in relation to her sister who had an implant reconstruction at the same time as Barbara did. "She ended up with real boobies", Barbara said, "so now, when I look at them, [it is as if] they say: na-na boo-boo. [In comparison to her,] I am a helpless loser". Her sister's non-transparent and painless breast seemed to confront Barbara quite dramatically with her 'I cannot': with her limited scope of possibilities to act in the world because of her see-through and (at times) painful reconstruction. It may be argued, moreover, that through Barbara's explicit foregrounding of 'I cannot' in relation to her sister, her scope of possible action may - again - become more limited. Ultimately, she felt not only to be 'losing' from her sister in attaining an extended agency, but also to be "helpless" in doing so.

\subsection{DISCUSSION: MATERIALIZING WOMEN'S AGENCIES IN BREAST CANCER}

By taking the existential, phenomenological concept of embodied agency (MerleauPonty 1945; Young 2005) as a theoretical framework in discussing technological mediation, this article showed that breast cancer technologies shape the agencies of women who engage with them in multiple and sometimes ambiguous ways. We have identified that the embodied possibilities women have in the context of breast cancer - their ' 
can' - may be restricted, reconstituted, maintained, affirmed, and extended in their interactions with and incorporations of various technologies and artifacts.

These mediations of women's agency take place on different bodily levels, within complex temporal structures, and are determined by certain socio-cultural contexts. First of all, various aspects of embodiment are at stake in such mediated agencies: not only these women's bodily capability and sensory experience - 'I can/cannot be comfortable and do stuff' - but also their public appearance and possibility to pass - 'I can/cannot look normal and go around un/obstructed'. Second, whereas these women's 'I can/cannot' may simply refer to the present tense, it may as well denote past and future tenses, or entanglements thereof. As shown, actual mediations may constitute their current 'I can', but the same is true of potential and previous ones that adhere to women's future and past possibilities to act. Finally, this temporal process of mediating embodied agencies in the context of breast cancer does not take place in a vacuum of subject and object, but involves a highly situated matter. The above-described experiences highlight that a technologically mediated agency involves dealing with contemporary, stigmatizing and sometimes harmful norms of sickness, femininity, and ethnicity, some of which are incorporated in the technology or artifact itself. Moreover, the concrete medical and social contexts in which women engage with technological artifacts also play a significant role in how their agency is shaped.

Important to note is that the above-described processes do not imply one-way conditioning relationships between technological artifacts and human agencies, but rather involve reciprocal relationships in which both subject and object are co-constituted. Indeed, technologies shape women's embodied agencies, but women engaged with technologies also massage, shape, and position themselves and their bodies, and even mold and alter the technological artifacts. By playing and negotiating with bodies and artifacts, these women try to appropriate the technological mediation: they actively try to influence the ways in which technologies shape their agency. In doing so, they affirm their agency - that is, their options for action - while attempting to maintain or reconstitute their scope of possible action within the technological mediation.

Based upon the idea that we need a 'material turn', Verbeek argues that it is through the exploration of things, rather than human beings, that we will gain a deeper understanding of how people are present in the world and the world is present for people (Verbeek 2010). In the light of our conclusion, we suggest that this 'material turn' also needs to take into account the dimension of appropriation in the humantechnology relation. It is through acts of appropriation that people (try to) adjust, mold, and alter the technological mediation of their experiences and actions. Within this kind of relationship, both 'objectivities' and 'subjectivities' crystallize around such adjustments. Acknowledging this constitutional double-act turns the attention away from 'technologies' - but also from 'humans' - and toward 'humans with technologies' (or 'technologies with humans'). It reveals the fundamental embeddedness of humans and technologies, of how technologies transform and materialize selves and bodies and, in 
turn, the ways in which humans affect and appropriate these technological mediations. After all, as contended by Latour already, "action and intentionality may not be properties of objects, but they are not properties of humans either" $(1999,192)$. In trying to understand human existence and agency, then, one should neither stop at the technological artifact, nor at the physical borders of the skin. Here, as Latour aptly states, "the name of the game [is] to avoid using the subject-object distinction at all" (1999, 193194). In this sense, we argue that mediation theory, which is guided by the material turn, should not just focus on technologies alone, but needs to move toward an exploration of technologically mediated, material human beings. After all, Jo Spence's 'Mammogram' - the photo with which this article started - is not just a picture of a halfnaked woman whose agency is shaped by various technologies. In demonstrating how her agency both affects and is affected by technological mediations, it appears that the photo is the materialization of a technologically mediated Spence on different levels: the pictured objectification of Spence-in-the-mammography-machine, the implied and assertive Spence-with-her-photo-camera, and the subjectifying photo-of-Spence-in-themachine-with-her-photo-camera. 


\section{REFERENCES}

Ahmed, S. (2006). Queer phenomenology: Orientations, objects, others. Durham: Duke University Press.

Akrich, M. (1992). The de-scription of technological objects. In: Shaping technology/building society, W. E. Bijker and J. Law (eds). Cambridge: MIT Press.

Crawford, C. S. (2015). Body Image, Prostheses, Phantom Limbs. Body \& Society, 21(2), 221-244.

Dalibert, L. (2015). Living with Spinal Cord Stimulation: Doing Embodiment and Incorporation. Science, Technology and Human Values: 10.1177/0162243915617833.

De Boer, M. and Slatman, J. (2014). Blogging and breast cancer: Narrating one's life, body and self on the Internet. Women's Studies International Forum, 44, 17-25.

De Boer, M., van der Hulst, R., and Slatman, J. (2015). The Surprise of a Breast Reconstruction: A Longitudinal Phenomenological Study to Women's Expectations About Reconstructive Surgery. Human Studies, 38(3), 409-430.

Dykstra, J. (1995). Putting herself in the picture: Autobiographical images of illness and the body. Afterimage, 23(2), 16-21.

Fanon, F. (1967). Black skin, white masks. New York: Grove Press.

Fogg, B. J. (2003). Persuasive Technology: Using Computers to Change What We Think and Do. San Francisco: Morgan Kaufmann Publishers.

Freedman, T. G. (1994). Social and cultural dimensions of hair loss in women treated for breast cancer. Cancer Nursing, 17(4), 334-341.

Garland-Thomson, R. (2011). Misfits: A feminist materialist disability concept. Hypatia, 26(3), 591-609.

Gibson, J. J. (1979). The ecological approach to visual perception. Boston: Houghton Lifflin.

Goffman, E. (1963). Stigma. Englewood Cliffs, New Jersey: Spectrum.

Goodwin, D. (2008). Refashioning bodies, reshaping agency. Science, Technology \& Human Values, 33, 345-363.

Inde, D. (1990). Technology and the lifeworld: From garden to earth. Bloomington and Indianapolis: Indiana University Press.

Ihde, D. (2002). Bodies in technology. Vol. 5. Minneapolis and London: University of Minnesota Press.

Kiran, A. H. (2012). Technological presence: actuality and potentiality in subject constitution. Human studies, 35(1), 77-93.

Latour, B. (1994). On technical mediation: Philosophy, sociology, genealogy. Common Knowledge, 3(2), 29-64.

Latour, B. (1999). Pandora's hope: Essays on the reality of science studies. Cambridge, MA: Harvard University Press.

Lorde, A. (2007). Sister outsider: Essays and speeches. Freedom, CA: The Crossing Press.

Merleau-Ponty M. (1945). Phénomenologie de la perception. Paris : Gallimard.

Oudshoorn, N. (2015). Sustaining cyborgs: Sensing and tuning agencies of pacemakers and implantable cardioverter defibrillators. Social studies of science, 45(1), 56-76.

Poovey, M. (1987). Scenes of an indelicate character: the medical "treatment" of Victorian women. In: The Making of the Modern Body: Sexuality and Society in the Nineteenth Century, C. Gallagher, and T. Lacqueur (eds). Berkeley: University of California Press.

Rietveld, E. (2012). Bodily intentionality and social affordances in context. In: Consciousness in interaction. The role of the natural and social context in shaping consciousness, F. Paglieri. (ed). John Benjamins Publishing.

Serletti, J. M., et al (2011). Breast reconstruction after breast cancer. Plastic and reconstructive surgery, $127(6), 124 \mathrm{e}-135 \mathrm{e}$.

Sharp, L. A. (2000). The commodification of the body and its parts. Annual Review of Anthropology: 287-328.

Spence, J. (1988). Putting myself in the picture: A political, personal and photographic autobiography. Seattle, WA: The Real Comet Press.

Spence, J. (1995). Cultural sniping: The art of transgression. New York: Routledge.

Spence, J. and Coward, R. (1986). Body talk? A dialogue between Ros Coward and Jo Spence. In: Photography/politics: Two, P. Holland, J. Spence and S. Watney (eds). London: Comedia Publishing Group.

Swierstra, T. and Waelbers, K. (2012). Designing a good life: A matrix for the technological mediation of morality. Science and engineering ethics, 18(1), 157-172. 


\section{CHAPTER 2}

Tromp, N., Hekkert, P. and Verbeek, P.P. (2011). Design for socially responsible behavior: a classification of influence based on intended user experience. Design Issues, 27(3), 3-19.

Van Dijck, J. (2009). Users like you? Theorizing agency in user-generated content. Media, culture, and society, 31(1), 41-58.

Verbeek, P.-P. (2006). Materializing morality design ethics and technological mediation. Science, Technology \& Human Values, 31(3), 361-380.

Verbeek, P.-P. (2009). Let's make things better: a reply to my readers. Human Studies, 32(2), 251-261.

Verbeek, P.-P. (2010). What things do: Philosophical reflections on technology, agency, and design. Pennsylvania: Pennsylvania State University Press.

Yalom, M. (1997). A History of the Breast. New York: Ballantine Books.

Young, I. M. (2005). On female body experience:" Throwing like a girl" and other essays. New York: Oxford University Press. 


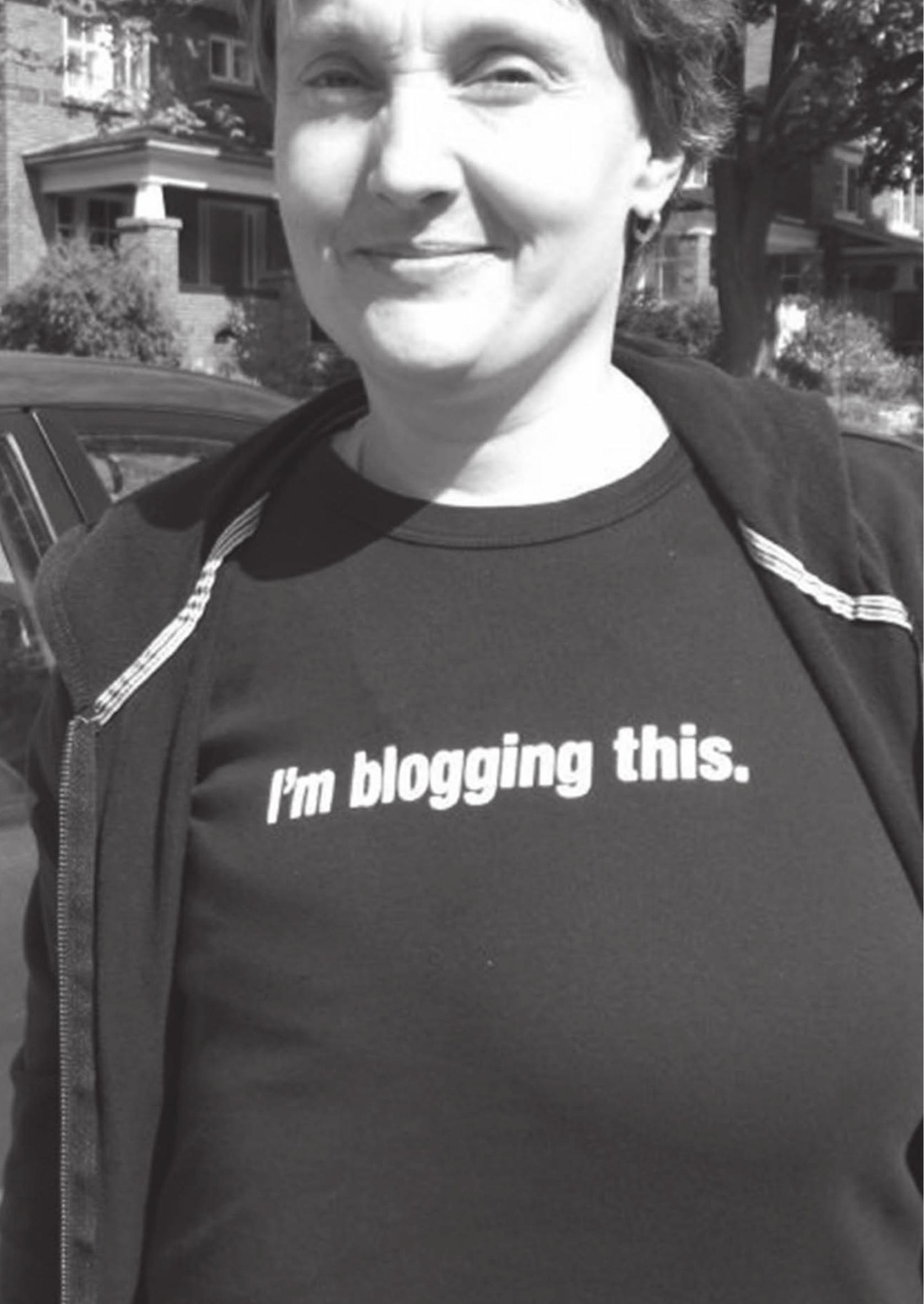




\section{CHAPTER}

\section{Blogging and breast cancer Narrating one's life, body and self on the Internet}

Published as:

De Boer, M.L., and Slatman, J. (2014) Blogging and Breast Cancer, Narrating One's Life, Body and Self on the Internet, Women's Studies International Forum 44, 17-25. 



\subsection{INTRODUCTION}

Breast cancer changes the lives and bodies of women. These women may be confronted with scarring, the loss of one or both breasts, lymphedema due to surgical treatment and their own mortality. They may also have to contend with persistent pain and fatigue, temporary hair loss and nausea, general joint stiffness, increase in body weight, heart problems and loss of bodily functions due to various adjuvant treatments, such as radiation therapy, chemotherapy, hormone therapy, and immunotherapy. Consequent$l y$, the ways these women understand themselves, their lives and their bodies are severely disrupted during and after breast cancer treatment. Living with breast cancer thus requires new ways of relating and giving meaning to a woman's changed self, life and body.

This article describes the ways in which women who have (had) breast cancer endow meaning to themselves, their lives and bodies through the autobiographical stories they tell and re-tell on their personal weblogs. Linking up with the hermeneutical tradition, we start from the general assumption that people make sense of themselves within and through the telling and re-telling of stories (Ricoeur 1991; Widdershoven 1993). People narrate themselves; we constantly make sense of what we experience by fitting these experiences into stories that express how we think of ourselves, of our identity, of who we are. Currently, a growing body of literature recognizes the significance of the Internet as a space where people compose and circulate such narratives (Broom 2001; Orgad 2005; Paasonen 2002; Pitts 2004; Turkle 1995). More and more people have access to the Internet and a high number of users actively share their stories online. Further, as we will outline below, the Internet is a particular and distinct medium; indeed, online autobiographical storytelling differs from offline storytelling (Keim-Malpass and Steeves 2012; Orgad 2005; Pitts 2004). One of the most explicit and typical manifestations of online autobiographical storytelling can be seen on personal weblogs ('blogs'). We will analyze how women with breast cancer make sense of their altered self, life and body while narrating their story on a blog.

This article has a two-fold structure: (1) it provides a theoretical outline of the scholarly debates on the sense making potential of offline and particularly online storytelling about illness experiences in general, and breast cancer experiences in specific, and (2) it provides an in-depth analysis of five personal blogs on breast cancer on the basis of a qualitative empirical study. Subsequently, the results of our empirical study are discussed in light of the debates on storytelling.

\subsection{OFFLINE AND ONLINE STORYTELLING}

The 1970s witnessed an overwhelming emergence of autobiographical accounts of breast cancer (Couser 1997). Over the past three decades, these kinds of autobiog- 
raphies developed into a genre of first-person breast cancer stories (Ehrenreich 2001). The development of this genre coincides with the rise of the post-modern society and its emphasis on individualism and activism. It is therefore claimed that in telling their breast cancer stories, women perform autobiographical writing as an ethical and political act of both reclaiming their own story with a female voice, as well as of empowering other women (Lorde 1980; Morris 2000). In addition to being politically charged, narratives like these also include reflections on one's own self, body and identity. In her breast cancer memoir, 'The Cancer Journals', Audre Lorde (1980), for instance, writes "I did not have to look down at the bandages on my chest to know that I did not feel the same as before the surgery. But I still felt like myself, like Audre." (49). This quote is an explicit example of giving words to the issue of identity, which is an issue that is often meditated upon by breast cancer autobiographers: now that I have (had) breast cancer, who am I? (Herndl 2006).

Breast cancer gives rise to these types of self-reflection since it interrupts the course of one's life and normal experience of one's body. Within the larger context of becoming seriously ill (and subsequently developing a chronic illness), Arthur Frank (1995) calls this jarring experience a temporal and narrative "chaos" (97): the stories once told about people's healthy, unblemished past do not seem to belong to 'them' anymore and the stories about their formerly imagined healthy, even living future lose their meaning. Consequently, their actual presence feels false. The only way out of this chaos is to take stock of what survives the cancerous experience by telling altered or altogether new autobiographical (illness) stories (Frank 1995).

While autobiographies are obviously very personal, they do not emerge in a vacuum. People make sense of what they experience by adhering to shared symbols, norms and metaphors (Berghmans 2012). Accordingly, many theorists argue that breast cancer accounts generally reiterate and affirm mainstream conceptions, stereotypes, norms and ideologies of illness, cancer, beauty and gender. Breast cancer experiences, they argue, are often framed in ways that assume heterosexuality (Lorde, 1980), that emphasize women's positive attitude toward life (Herndl 2006), and that pressure women to look 'normal' (i.e. healthy) and to adopt beautification techniques (Broom 2001; Wilkonson and Kitzinger 1993). Erving Goffman calls this the "management of spoiled identity": the effort of the individual that diverts from the expected norm to present herself as an ordinary person while "not necessarily making a secret of [her] failing" $(1983,31)$. Adhering to such norms and expectations within their own storytelling can be both helpful and harmful for women who have (had) breast cancer. It may be hopeful to see their return to normality being expected (Frank 1995). However, these norms may also give rise to a sense of shame by glossing over and thus discrediting the unpleasant, painful aspects of the breast cancer experience (Broom 2001; Lorde 1980; Sontag 1990).

Even before the Internet became a popular option for telling breast cancer stories, Victoria Broom questioned whether the Internet would be a place where these conven- 
tional norms and ideologies are repeated, or, instead, offer a space for alternative stories about the breast cancer experience (Broom 2001). This question was motivated by the rise of theories on the liberating potential of storytelling online for definitions of selves and bodies in the 1990s. A number of scholars assumed and celebrated the reversibility, interactivity and disembodied nature of the Internet, its dynamic use of hypertext and its lack of socio-cultural context cues. These features, they claimed, stimulate a disruption in the 'offline' ways in which we define ourselves through storytelling. Reversibility may stimulate a constant and highly changing performance of the self (Poster 1995; Waskul, Douglass, and Edgley 2000). The potential of worldwide networking on the Net may facilitate women's formation of online spaces of dialog and resistance (Plant, 2000; Sundén, 2001). Hypertext may enable stories to be told in a nonlinear, a-synchronic way, fostering a fluid, dynamic performance of self (Beetham 2006; De Mul 2010; Gergen 1991). Finally, as physical bodies are absent on the Internet this may leave us with greater freedom to perform our bodies through text (i.e. words and codes) and audio-visual material (i.e. sound, pictures, videos) resulting in multiple online identities (Poster 1995; Turkle 1995), the invention of new genders, or even genderless bodies (Plant 2000; Wilding 1998).

If the proponents of cyber liberation are correct and the Internet is a utopia of endless possibility for storytelling and self-narration, the extensive use of this medium would, compared to offline media, facilitate a broadening of the range of stories about breast cancer experiences (Pitts, 2004). A few studies have evaluated the considerations of these liberation theorists with respect to online stories on breast cancer. Victoria Pitts (2004), in her study on traditional homepages and email lists, claims that women "do make visible [...] the painful and difficult aspects of breast cancer" (39). Yet they do not engage in "gender-play" (55), but rather "circulate conventional messages of [...] femininity" (39). Shani Orgad (2005), in her study on forums and discussion boards, concludes that, indeed, women with breast cancer do not articulate non-normative femininity. In another way, however, they do play with dominant gender roles online, namely through making visible the painful aspects of the illness. Public, online interaction about treatment possibilities and dealing with breast cancer enables women patients "to enter into a dialog where the dominant (doctors, and the medical authorities more generally, which are predominantly male) can no longer systematically silence these [women patient] voices" (Orgad 2005, 159).

Orgad's and Pitts' pertinent studies do not yet address breast cancer writing in blogs. Existing studies on breast cancer experiences in weblogs, by contrast, are predominantly quantitative, not taking into account storytelling as a means of sensemaking (Chung and Kim 2008; Keim-Malpass and Steeves 2012; Meric et al. 2002). Adhering to literature on personal weblogs in general and illness weblogs in particular (Hardey 2002; Heilferty 2009; McCosker 2008; Page 2008), this paper argues that blogs represent a distinct and particular space for online storytelling of breast cancer. Blogs, thus, require their own study. 
What, then, are blogs? Personal blogs are a collection of multi-media entries or small stories ('posts'), similar to an ongoing diary or commentary, written by an individual and published on a self-designed, open access, interactive Web page. On blogs, bloggers 'log' their on-going personal daily experiences online through using both text and audio-visual material. Their multi-media posts are archived in a reverse chronological order (Hardey 2002; Page 2008). Bloggers are able to rewrite their archived stories, often without a record of the changes made (McCosker 2008). Furthermore, while weblogs are very personal, they are also open access and even welcome interaction with their audience through a guestbook or chat room (Heilferty 2009). Given these particular and distinct features of blogging, the analysis of breast cancer blogs opens up new possibilities for gaining insight into how women tell their illness stories online and give meaning to themselves and their bodies.

\subsection{METHOD AND APPROACH}

Since this study aims to understand the ways in which women with breast cancer narrate themselves, their lives and their bodies through blogging we have chosen to conduct a qualitative, narrative approach that focuses on subjective experience. The first author sampled and analyzed thirteen Dutch-language personal weblogs of women with breast cancer. Initially, three weblogs were selected through using the search engine Google (translated Dutch search terms: 'weblog + breast cancer'). The other ten weblogs were found by clicking on links to other weblogs featured on the first three weblogs (virtual snowballing). Weblogs were selected in the sampling process that contained a significant amount of posts (twenty or more).

Almost all the sampled bloggers started blogging at the time of their diagnosis. Some of them were recently diagnosed and just started blogging. Others started blogging a while ago and had left the process of treatment behind them. All the bloggers underwent major invasive and disfiguring treatment, such as radiotherapy, chemotherapy, mastectomy or the removal of the lymph nodes. Most were still regularly updating their weblogs, generally once or twice a week. Some weblogs seem to have stopped. These women's posts vary in length: some are very lengthy (more than 600 words and multiple pictures), others brief (several sentences and few pictures) or even empty (no words at all and no pictures). Consequently, the sample of thirteen weblogs consists out of thousands of pages of visual and textual materials.

The first author read the sampled blogs and broadly analyzed emergent themes and storylines. However, as the preliminary analysis of the thirteen blogs contained too much material for in depth analysis, a representative smaller sample out of the bigger sample was selected. The smaller sample was formed on the basis of six identified features that significantly shaped the blogged stories within the larger sample: (1) stage of the illness experience at the moment of selection, (2) age of the bloggers at the mo- 
ment of selection, (3) level of professionalism, (4) design of the weblog, (5) level of intimacy with readers and (6) scope of the weblogs. Eventually, five weblogs were selected for adequately representing the variety within these features. In this way, a heterogeneous smaller sample was formed. The smaller sample included the following blogs: (1) 'Good tits, Bad tits' by Jeanette, (2) 'Just standing still' by Lucretia, (3) 'Ingeborg here and now' by Ingeborg, (4) 'I write, therefore I am' by Karin, and (5) 'Bosom blues' by Cancer Chick (see table 4 in the appendix for a summary of the five sampled weblogs on the basis of the six central features of the larger sample). ${ }^{8}$

The selected five blogs were followed by the first author on a monthly basis for a year (February 2012-February 2013) in order to capture changes and additions made to the weblogs. Using the encoding software NVivo 9, both the visual and textual contents of this sample were analyzed and interpreted. Emergent themes and storylines of the breast cancer experience were identified in consultation with the other author of the article. This resulted in four different types of self-narration by these women.

\subsection{FOUR DIFFERENT TYPES OF SELF-NARRATION}

Our analysis of the five selected blogs identified four different types of narrating the self. While narrating, webloggers configure themselves in different dramatis personae, namely as Estranged Cancer Patient, as Transient, as Heroic Survivor, and as Disfigured Woman/Girl. ${ }^{9}$ The Estranged Cancer Patient deals with the disruption of these blogging women's normal understanding of themselves and their body as result of the diagnosis and treatment. Women who narrate themselves as Transients get ready to change from stories of disturbance and disruption toward a more coherent and new type of selfnarration. The Heroic Survivor signifies a particular reconfiguring of the self, namely toward an understanding of the self as returning to normalcy or as victorious. Finally, performing the Disfigured Woman/Girl means to act out a certain threat to their feminine, even girlish identity crucial for their breast cancer experience. ${ }^{10}$ Although several of these characteristics can also be found in other media, here we will focus solely on distinguishable and specific aspects of blogged breast cancer self-narrations.

Even if we analytically distinguish different types of self-narration, these should not be considered as separate narrations. In reality, they are interrelated. To some extent,

\footnotetext{
${ }^{8}$ The blog titles and the quoted texts are translated from Dutch by the first author of this article. In the paper, these women's self-chosen blog names are used in order to refer to the different bloggers and blogs.

${ }^{9}$ Drawing upon literature on narrative analysis, these dramatis personae should not be equated with different coping strategies and should not be read as psychological adjustment.

${ }^{10}$ Due to the limited scope of the paper (i.e. online spaces of storytelling and self-definition), this study is not an evaluation of how breast cancer bloggers actually experience and deal with having (had) breast cancer. This analysis only focuses on how they narrate themselves, their lives and bodies online. Further projects should advance the study of the interplay and relation between online self-narration and actual, offline sense making by these women.
} 
they are associated with particular stages of the physical illness experience. For instance, the Estranged Cancer Patient predominantly acts in the stage of treatment, whereas the Disfigured Woman/Girl may enter after treatment when reflecting on mutilating sequelae of it. After scars begin to heal and one gets used to one's altered body, the Transient or Heroic Survivor may make their appearance. It is important to note, however, that the stage of the illness experience does not entirely determine the way these women narrate themselves. In fact, all types of self-narration can be at stake at every stage of the physical illness process: sometimes the chronology is reversed and sometimes (parts of) these self-narrations intermingle and overlap in alternative, paradoxical and surprising ways.

\section{Staging of the Estranged Cancer Patient}

A breast cancer diagnosis is an immense shock in the sense that one is suddenly confronted with an uncertain future: the possibility of severe sickness, hospitalization, a trajectory of invasive treatments with horrible side-effects, and the threat of an untimely death. It is hardly surprising that breast cancer bloggers exhibit shock. Features of the Estranged Cancer Patients include more generally known modes of disturbances that produce a sense of alienation and estrangement from themselves, their lives and bodies, such as a sense of loss of control, feeling betrayed by their bodies, a unrecognizable mirror image and their being reduced to a medical object. In the following, however, we will focus on aspects of these women's storytelling characteristic for blogging: a break with their past and future and their muteness.

Temporal rupture - All women diagnosed with breast cancer refer to a drastic break with both their effectively healthy, unblemished lived past and their imagined and anticipated healthy future. This experience echoes itself in histories, hopes and expectations that some women see as no longer 'theirs' anymore. Ingeborg, for example, writes about herself in the third person when she recounts her life before breast cancer. Other women temper their expectations of their future or even delete all previously made references to their past in their previous blog posts. They literally rewrite their past, something blogging explicitly allows for. As former articulations of past and future lose their meaning and ultimately disappear from their storytelling, all these women seem to be left with is narrating their present life with cancer. In this context, women often use the metaphor of 'being stuck in time'. Lucretia's blog title "Just standing still" speaks volumes.

Muteness - It seems that these women's ultimate estrangement from their past and present lives and bodies is not articulated through (rewritten) words, but through muteness and blankness. Just after diagnoses, Jeanette updates her weblog with empty posts. Later on she recounts: 
I was not able to put my feelings into words; I lost 'my story'. I did not even know what I was feeling let alone that I was able to share it with you. I am literally afraid of dying and this [the empty posts] was the only way to let you know how I was doing... (Jeanette)

Jeanette's words show that the overwhelming experience of one's advanced death as an actual possibility and a threat, results in muteness. Jeanette, rather paradoxically, articulates her 'chaos story' through a wordless story; with empty posts as silent screams of frustration. These kinds of stories are difficult to vocalize because of the inability to narrate. At the same time, they are difficult for others to listen to, which adds to the difficulty of telling them. This becomes apparent in Jeanette's words:

About that [fear of death] you cannot talk in the human world, there you have to adjust to the common denominator. Here on my blog I write what I feel and how it storms in my head. I am literally scared to death! And if you don't want to read about that, then you won't come to my blog anymore?! (Jeanette)

This quote shows that for Jeanette it seems easier - although still very difficult - to recount her story of mortal fear on her blogs, rather than in real life. In a way that is seemingly impossible otherwise, Jeanette claims this public blog-space as distinctively 'hers': an environment in which she plays only by 'her' rules.

These examples of rewriting temporality and the posting of empty posts is interesting in light of Frank's argument that the ultimate cancerous experience can only take on the form of an "anti-narrative" (Frank 1995, 98). Frank understands narratives as meaning-shapers, in that they assemble a coherent sequence of timing, events and experience. In the midst of the overwhelming experience of having (had) cancer, however, these women's formerly ordered temporal narratives no longer suffice and are thus therapeutically rewritten. Time, so it seems, becomes incoherent; it can even disappear in the sense that there is sometimes the experience of having no meaningful time left - no past, no future, and only a false presence. Consequently, there can only be an absence of telling and speaking: an anti-narrative. Our analysis shows that blogs offer the paradoxical possibility to narrate the anti-narrative by telling what cannot be told through the posting of an empty story.

\section{Interlude of the Transient}

At some point while narrating themselves as Estranged Cancer Patients, almost all women carefully present themselves within a discourse of 'getting better'. This anticipation of a passage to survival and of narrating oneself as a Heroic Survivor, however, is still grounded in doubt and often manifests itself through certain (forswearing) rituals in order to deal with that uncertainty. Jeanette, for instance, is afraid of 'jinxing' her hopes for a healthier 
future by writing too much about them. Paradoxically, as hopes and expectations become meaningful again, they still may not be included in these women's stories.

These women's doubts of having a brighter future only seems to diminish when their physical state is improving (i.e. disappearing nausea, hair growing back or scars that heal) or when the end of their treatment or hospital visits is in sight. As Transients, these women disengage from the estranged life of a cancer patient and take on the passage to a more coherent and new type of narrating the self. Old narrations of estrangement and disturbance do not apply anymore, and new ways of understanding oneself have to be developed. This transition is often ritualized: it is marked by a defining symbolic (online or offline) moment - a rite of passage - in which these women consciously adapt and change in order to fit their new ways of understanding themselves. Some women's rite of passage takes shape through a change of design, tone or content of their blog - having more colors or cute pictures of daily life - thus embracing the regained lightness and normality of life.

A transition is not always effortless or comfortable though. A while after finishing treatment, Lucretia changes her blog icon from an angel of death into a butterfly. This change goes hand in hand with extensive meditation whether this is the right symbol for her. After changing it back two times, she finally decides to go for the butterfly, while commenting:

I may all sound too childish, but lately I feel so lost! Hopefully the butterfly [standing for being able to fly away from the cancerous experience] is not too optimistic. (Lucretia)

At this point in her blog, it appears that Lucretia's old blog style, does not fit her altered (and long hoped for) way of understanding herself anymore. This change of heart - and consequently of blog style - surely may result in feelings of desperation and even anxiety.

After these transition rites, women who have (had) breast cancer narrate themselves differently. They give new meaning to themselves and their bodies again. In the form of narrating, this change is marked by a shift from silence or fragmentation to more coherent storytelling. For the narrator - and concurrently the chief character of the story - it mainly means a shift from chaos to control. For example, in the midst of dealing with her diagnosis, mastectomy and adjuvant treatment, Lucretia's writings are marked by unfinished sentences and phrases followed by three or more dots. Sometime after treatment, however, her writing style begins to change: she formulates complete sentences followed by a full stop. Her former fragmented and uncertain story accordingly changes into a more coherent and confident one. Since it needs very little editorial interventions to publish something online, blogging provides an easily accessible space to write and constantly rework stories. It allows these women to articulate their experience in their own, sometimes surprising, unconventional and fragmentized linguistic and visual way. Their (excessive) use of punctuations, their style of formulating (unfinished) sentences and their personalized design is something that might not be possible in more conven- 
tional media. It is within and through these reworked and restyled stories that these women find new ways to understand and give meaning to their 'new' selves.

\section{The appearance of the Heroic Survivor}

The Heroic Survivor, who manifests herself through militaristic and 'happily ever after' discourse, involves a particular reconfiguration of the disruptive cancer experience: a configuration through which women attempt to 're-own' themselves, their bodies their past, present and future. This type of self-narration generally takes on three forms: (1) a return to familiar lived, bodily narratives, (2) a victorious battle story of success, improvement and enhancement and finally (3), a continuation, at least in part, of narrating the self as an Estranged Cancer Patient. The staging of the Heroic Survivor in its various forms is particularly linked to the fact that blogging takes place in the public space, which facilitates sharing stories and connecting with one another.

Return to normality - At a certain point in their storytelling some women succeed in returning to the familiar embodied experience before the breast cancer. They refer to their lives and bodies as looking, feeling and acting as their own again. Cancer Chick, for example, gains weight because of her medication. She feels capable again only after following a strict $1000 \mathrm{kcal}$ diet. Against doctor's advice, she starts with this regime after cheering comments by readers of her blog about the effectiveness of this diet. Interestingly, shortly after stating that she re-gained her slim body Cancer Chick stops updating her weblog. After a few weeks of silence she briefly notes:

You often hear of songwriters that they write their best songs if they are unhappy, well, I finally get what they mean by that. Being happy is great, however, it does not give you a lot of inspiration to write big literary pieces. The muse rather chooses her hosts among the ones that hang somewhere in the emotional gutter. Thus: finally it is a good sign that I write less. (Cancer Chick)

In contrast to the muteness of the Estranged Cancer Patient, the re-gained ability to understand and give meaning to one's life leads Cancer Chick to stop writing. Here, it seems that the therapeutic exercise to write and re-write her story and share it with others in order to give (new) meaning to her life turns out to be successful and thus the need to update her blog diminishes.

Improvement - Other women's cancer experience is transformed into a battle story and, consequently, they seem to perceive their survival as a triumph, telling stories of success, progress and enhancement. They do not feel they are their own again: they narrate themselves as an improved and better 'me'. For example, some women experience their bodies as more capable than ever because their bodies are capable of defeating a lethal disease. Others consider the appearance of their scarred bodies as having surplus value: their scars reflect the battle they have fought and won. Yet others 
emphasize their new-found wisdom by explicitly sharing it with others, in this case, on their blogs. Karin states:

And did you know that more women die from breast cancer than from lung cancer? It is a true battlefield. [Now that I know that], I warn all my friends to check their breasts regularly. And damn, I already saved the life of an acquaintance. [...] So ladies, [referring to the readers of her blogs] let's check those breasts! (Karin)

By taking up the role as a 'guide' and sharing her knowledge as a Survivor, Karin's status as a Hero is affirmed. Not only did she save herself in the "true battlefield", in turn, she also saves others from entering it in the first place.

Continuation of estrangement - While developing and re-developing their happyending stories of returning to normality or improvement, these women nevertheless continue to narrate themselves - at least in part - as Estranged Cancer Patients. Cancer Chick captures this complicated situation by writing:

Most of the time I quite nicely succeed in adjusting my life to all the new small and big discomforts that this disease brings. [...] At least: I would think so. Because this remains the most difficult thing to the treacherous disease that is cancer: you never know for sure whether your body from the inside is as good as it looks from the outside... People ask me: "You are cured now right?", while they draw out the preferred answer by already fiercely nodding their heads. It is always a painful moment when I, against their expectations and sighs, carefully say "no". (Cancer Chick)

Cancer Chick describes the impossibility of definitely closing the breast cancer chapter of her life because of the incessant uncertainty that is part and parcel of the experience of this particular disease. Although she may look healthy, her body may - still or again hide the cancer. Her narration can be read as a refusal to divert one's own and other people's fear that this lethal disease can never be overcome completely.

For other breast cancer bloggers, it is not so much the fear of metastasis and dying that keeps on nagging. Rather, the continued pains and discomforts are still bothering them. Lucretia writes:

All the five of us [fellow sufferers she met on her blog] have learned to live with painful joints, hot flushes with beads of sweat dripping down the spine to the butt crack and sudden windiness. At home this weird body is sometimes unpleasant and shameful, in this company, almost liberating. (Lucretia)

Within the online community of breast cancer patients and survivors, so it seems, everybody is physically deviant. Because of that, these women share their stories without shame or having the feeling that they stir up fear or awkwardness in others.

The Heroic Survivor type discloses yet another codetermining aspect of blogging. Blogs elaborate new social relations and networks of support that offer information 
about breast cancer, much of which is divergent to medical knowledge by addressing (inter)personal issues of the breast cancer experience (see also: Orgad 2005). Women's self-narrations are molded through these relations, networks and information systems. In the midst of online fellow sufferers who have similar stories, women like Lucretia do not feel like strangers anymore. Or by sharing their survival experience and skills online, more experienced women like Karin or the readers of Cancer Chick's blog help less experienced women to picture a bright(er) future - something they often cannot see by themselves - and work toward it. These results are interesting in light of Sherry Turkle's recent book 'Alone Together' (2011), in which she revises her 1990s optimism about the Net. In the end she argues that the Net does not offer us helpful self-constructions but only leaves us with shallow connections and ties that do not bind but only preoccupy. In essence, she claims, we are "alone together" on the Net (Turkle 2011, 1). Our analysis of the Heroic survivor's staging suggests, however, that the Net and blogs in particular can actually connect women. It contradicts Turkle's view that on the Net a real "sense of being connected to [an] other human narrative" cannot exist $(2011,282)$.

\section{Acting out the Disfigured Woman/Girl}

For most women who have (had) breast cancer, it is not only the cancerous illness experience - being diagnosed with a lethal disease and becoming a patient - that is disruptive. Their feminine identity is also at stake. Treatments such as mastectomy, lumpectomy, removal of lymph nodes and loss of hairs and nails, implicitly or explicitly, affect aspect body parts and aspects of their lives invested with their sense of femininity. The Disfigured Woman/Girl, then, crucially involves a disturbed sense of femininity. Seemingly paradoxically, many bloggers narrate themselves as deviating from a stereotypical feminine norm or ideal (Disfigured Woman/Girl) while affirming this very norm (Disfigured Woman/Girl) through using their blog like an embodied avatar. An explicit affirmation of ruling norms of female embodiment, surely, can also function as a strategy to regain one's lost sense of femininity.

Addressing their deviating, masectomized body, the sampled women simultaneously affirm stereotypical femininity. In describing their failure to live up to specific feminine roles and activities (i.e. being caring) or looks (i.e. being breasted), they emphasize their importance and value. Typically, nearly all women visually construct their blogs in a way that strongly adheres to a feminine stereotype. They design their blogs using traditionally feminine colors (i.e. pink or pastel shades), dressing it up with pictures of cuddly toys, hearts, sparkles and angels. Lucretia - who says she has a hard time dealing with her unbreasted appearance, something that makes her feel (in her words) "de-feminized" writes on her blog: 
That blog... oh well... is something like the liberation from the limitations of my actual [masectomized] body. Here, I can be whoever I want to be! [...] It [the design of her blog] fits me. (Lucretia)

Lucretia's use of cute album-like pictures and soft pastel colors on her blog can be interpreted as an act of portraying herself as a feminine woman on her blog, something she cannot do in the real world because of the "limitations" of her 'offline', masectomized body.

From the abundant use of girlish symbolism and the many stereotypical stories in these blogs, these women seem to reassert a sense of conventional femininity or youth, or even a childish innocence that is endangered by the cultural construction of mutilating breast cancer. These women's practice of decorating their blogs with visually striking images may be interpreted as an attempt to appropriate their disfigured, de-feminized bodies. When successful, they seem to virtually compensate for their offline loss of bodily feminine markers. As such, their online spaces can be understood as incorporated: blogs are in themselves a construction of new and complementing or extending, avatar like bodies. Breast cancer bloggers' Internet spaces are thus not disembodied, as Turkle (1995) and other 1990s feminist Internet theorists argue, and do not only echo or exaggerate offline embodiment, like Pitts empirical study shows (Pitts 2004). By using visual material, these women seem to construct new and ideal bodies, an ideal that they can, in fact, no longer epitomize with their offline bodies.

There are, however, exceptions to the dynamic between the experience of being deviant from a stereotypical norm and the quest to reassert this ideal through avatarlike blogs. Within certain contexts this ideal is not that persistent, which enables the emergence of new ways of giving meaning to their changed bodies. Some women use their blogs as a place - a podium even - where they do not feel the need to live up to a dominant norm and actively display their altered, non-normative bodies. Jeanette, for example, repeatedly posts pictures of her bald head and masectomized body, accompanied with texts like:

THIS is my body. Behold it. (Jeanette)

Jeanette's words show that in specific contexts, alternative ways of giving meaning to her deviant body become possible. On her blog, she seems to re-own her body: claiming that "THIS body is my body". By displaying her blemished body on her blogs she, simultaneously, challenges the stigmatization and invisibility of masectomized and bald female bodies.

This display of 'deviant perceptibility' challenges Goffman's claim that we tend to normalize "spoiled [i.e. deviant] identities" by taking up the role of - in this case - an ordinary feminine and healthy woman (Goffman 1963, 31). For indeed, Jeanette and other bloggers in different stages of their breast cancer narratives explicitly claim their de-feminized and sick identity online. They seem to be able to do so because they re- 
gard, as Jeanette does, their blogs as distinctively 'theirs'. The podium of the blog is thus not only ruled by mainstream norms as Goffman might argue, but allows these women a stage in which they can play by their own rules.

\subsection{DISCUSSION AND CONCLUSION}

From our findings we can draw three conclusions: (1) the progression of the four different types of self-narration by women with breast cancer can be understood as a particular process of sense making, namely from feeling alienated to re-owning and re-appropriating themselves while a sense of alienation still lingers. (2) This particular process turns out to be influenced and co-determined by the specificity of blogs as a medium. (3) It still remains to be seen, however, whether this mediation reinforces greater freedom in defining oneself, as the feminist liberation scholars of the 1990s like to believe.

\section{Process of self-narration}

Each type of self-narration we have identified in our analysis illustrates that breast cancer diagnosis calls for new ways of relating and giving meaning to selves, lives and bodies. They involve a particular sense-making process: from alienation to appropriation with lingering alienation. While narrating themselves as Estranged Cancer Patients or Disfigured Women/Girls, women who have (had) breast cancer describe and articulate - often in fragmented ways - the overwhelming and drastically altering events they are confronted with. As a result, they do not experience their lives and bodies as fully owned anymore.

At a certain moment in their storytelling, however, some of these women's selfnarrations begin to change. As Transients, they perform rites of passage within and through which they configure and reconfigure their fragmented stories of alienation into a more coherent story of renewed engagement with their selves, lives and bodies: a story that allows them to re-appropriate and re-inhabit these selves, lives and bodies. Here, these women begin to narrate themselves as Heroic Survivors or Disfigured Women/Girls. Generally they do so by affirming conventional norms and ideologies of femininity (i.e. being breasted and caring) and being sick (i.e. temporally being sick). Yet in certain contexts these women find alternative and surprising norms to adhere to while trying to appropriate themselves. If they succeed in these attempts, they are able to recognize and acknowledge, or even accept and welcome their bodies and lives 'as their own', again or anew.

Fueled by continuous uncertainty, anxiety, discomfort, pain and by feeling mutilated and sometimes 'de-feminized', these women's process of appropriation is still marked by fragmentation in the narrative. Unfolding their stories toward possible Heroic Survivorship and/or Womanhood/Girlishness, they often continue to narrate themselves, at 
least in part, as Estranged Cancer Patients or as Disfigured. Hence, this process of sense making as re-appropriation through different types of self-narration is an ongoing, nonlinear, and never definite one. These women's self-narrations do not constitute a univocal journey toward coherence and appropriation but rather allow fragmentation and multiplicities of illness experiences to hold sway.

\section{The medium is the message}

As already indicated above, these women's process of sense making is influenced and co-determined by several aspects of weblogs. Similar to Sadie Plant's (2000) and Dennis Waskul et al.'s (2000) celebrated aspect of the Internet - its reversibility - blogs offer the possibility of always adding stories and changing existing ones. This facilitates breast cancer bloggers' therapeutic exercise of constantly writing and re-writing old and new stories and self-narrations. Weblogs, thus, allow for active and dynamic, continuous and drastic attunements of understanding one's life, self and body through the shaping and re-shaping of one's (autobiographical) stories.

Another aspect of blogging that influences self-narration is that it allows these women to publish their experience of having (had) breast cancer in a direct, perhaps unthinkingly, un-reflected way, culminating in surprising and unconventional selfnarrations. These women appear to 'blog' with minimal editorial intervention, when and where it suits them. This emphasizes the personalized dimension of blogging ("my blog") and a heightened degree of control these women feel they have over the (unedited) content, (unpolished) linguistic style and visual design of the online representations of their experience (see also: Orgad 2005). We have seen that women sometimes articulate their (continuing) alienating illness experience online in a manner that seems to be impossible, these women argue, in the offline 'real' world. Other women use linguistic and semantic styles (punctuation, unfinished sentences, wordless stories, etc.) that may not be possible in other media. Further, these women use the visual potential of blogs to (co-) shape their stories, and even more, themselves and their (extending) bodies.

Finally, the blogosphere offers these women meaningful new relations with fellow sufferers, and thereby influences their stories in a number of ways. By sharing their stories on their blogs they are able to help each other in decision-making processes, or through the online contact with partners in misfortune they do not feel like strangers anymore.

In sum, the classical statement of Marshall McLuhan is of significance in this study: "the medium is the message" (McLuhan 1964, 7). Indeed, the possibilities of blogging as a medium and breast cancer bloggers' self-narrations are symbiotically related to one another. 


\section{Blogosphere: a disenchanted utopia or a paradise of chaos?}

Our findings lead us to question on which terms these women voice their experience, and thus whether blogging actually achieves its widely professed liberation. Whereas cyberspace and specifically the blogosphere has been welcomed by some as a feminist utopia of free selves and free (of) bodies (Beetham 2006; Plant 2000; Turkle 1995; Wilding 1998), our analysis shows that blogs cannot be understood as a neutral, disembodied territory in which women define themselves absent from dominant and restrictive offline, embodied culture. The blogosphere must be seen as an embodied space where - in characteristic and manifold ways - dominant, stereotypical and normative definitions of situations, bodies and selves are generally affirmed and sometimes contested.

Whereas the jubilance of the cyber liberation movement should be tempered, there are still reasons for celebrating the online genre of breast cancer autobiographies for its emancipatory, liberating potential. In line with studies that explore how women can create and develop emancipatory relations and bonds on the internet (Sundén 2001; Plant 2000), our study reveals that sharing experiences through blogging supports women to acknowledge their non-normative, deviant bodies as their own. They are also encouraged to complement and even challenge medical authority and its dominant (mostly male) doctor - (in this case female) patient relationship through the availability of alternative (non-medical) knowledge systems within these weblogs (see also: Orgad 2005). The abovementioned aspects of blogging that enable and even encourage women to articulate fragmented and unconventional stories of (continued) disturbance and alienation can also be understood as emancipatory and liberating. Since these kinds of chaos stories (Frank 1995) do not resound with the modernist quest to overcome one's illness they signify a process of appropriation that retains continued alienation. This process can be understood as a postmodern act of resistance, or in Goffmanian fashion, as the claiming of "spoiled identities" (Goffman 1963, 31). Although these women thus still tend to generally affirm gender stereotypicality and (modernist) normativity of being sick, by blogging and engaging with other bloggers they also acknowledge and even welcome multiple, fragmented, non-cohesive and non-normative illness experiences and self-narrations.

Through writing and re-writing their stories on the Internet, women with breast cancer narrate themselves as Estranged Cancer Patients, as Transients, as Heroic Survivors or as Disfigured Women/Girls. The progression of these women's self-narrations are read as a process of defining their new and altered selves 'as themselves' - albeit always temporary and never absolute - something they do - however difficult and incompletely - on their own blogged terms. In this sense, these breast cancer blogger's experiences echo Lorde's autobiographical writings as quoted in the introduction of this paper: "I did not feel the same [...] But I still felt like myself" (Lorde 1980, 49). 


\section{REFERENCES}

Beetham, M. (2006). Periodicals and the new media: Women and imagined communities. Women's Studies International Forum, 29(3), 231-240.

Berghmans, R. L. P. (2012). "It's like..." Kankermetaforen en de ervaring van de kankerpatiënt. Tijdschrift voor Gezondheidszorg en Ethiek, 22(4), 106-113.

Broom, D. (2001). Reading breast cancer: Reflections on a dangerous intersection. Health, 5(2), 249-268.

Chung, D. S., and Kim, S. (2008). Blogging activity among cancer patients and their companions: Uses, gratifications, and predictors of outcomes. Journal of the American Society for Science and Information Technology, 59(2), 297-306.

Couser, G. T. (1997). Recovering bodies: Illness, disability, and life writing. Madison, Wisconsin: University of Wisconsin Press.

De Mul, J. (2010). Cyberspace odyssey. Towards a virtual ontology and anthropology. Castle upon Tyne: Cambridge Scholars Publishing.

Ehrenreich, B. (2001). Welcome to cancerland. Harper's Magazine 303(1818), 43-53.

Frank, A. W. (1995). The wounded storyteller, body, illness and ethics. Chicago and London: University of Chicago Press.

Gergen, K. J. (1991). The saturated self. New York: Basic Books.

Goffman, E. (1963). Stigma, notes on the management of spoiled identity. New York: Simon \& Schuster, Inc.

Hardey, M. (2002). Life beyond the screen: Embodiment and identity through the Internet. Sociological Review, 50(4), 570-585.

Heilferty, C. M. (2009). Toward a theory of online communication in illness: Concept analysis of illness blogs. Journal of Advanced Nursing, 65(7), 1539-1547.

Herndl, D. P. (2006). Our breast, our selves: Identity, community, and ethics in cancer autobiographies. Signs: Journal of Women in Culture and Society, 32(1), 221-245.

Keim-Malpass, J. and Steeves, R. H. (2012). Talking with death at a diner: Young women's online narratives of cancer. Oncology Nursing Forum, 39(4), 373-378.

Lorde, A. (1980). The cancer journals. London: Sheba Feminist Publishers.

McCosker, A. (2008). Blogging illness: Recovering in public. M/C Journal: A journal of media and culture, 11(6), Available at: http://journal.media-culture.org.au/index.php/mcjournal/article/view/104. Date accessed: 03 May 2012.

McLuhan, M. (1964). Understanding media: The extensions of man. New York: McGraw Hill.

Meric, F., et al. (2002). Breast cancer on the World Wide Web: Cross sectional survey of quality of information and popularity of websites. BMJ, 324(7337), 577-581.

Morris, D. T. (2000). IIIness and culture in the postmodern age. Berkeley: University of California Press.

Orgad, S. (2005). The transformative potential of online communication, the case of breast cancer patient's Internet spaces. Feminist Media Studies, 5(2), 141-161.

Paasonen, S. (2002). Gender, identity, and (the limits of) play on the Internet. In: Consalvo, M. and Paasonen, S. (eds.) Women \& everyday uses of the internet. New York: Peter Lang Publishing.

Page, R. (2008). Gender and genre revisited: Narratives of illness on personal blogs. Genre: A quarterly devotes to generic criticism, 41(3), 149-175.

Pitts, V. (2004). Illness and Internet empowerment: Writing and reading breast cancer in cyberspace. Health: and Interdisciplinary Journal for the Social Study of Health, IIIness and Medicine, 8(1), 33-59.

Plant, S. (2000). On the matrix: Cyberfeminist simulations. In: Bell, D. and Kennedy, M. (eds.) The cybercultures reader. London: Routledge, 325-436.

Poster, M. (1995). The second media age. Cambridge: Polity.

Ricoeur, P. (1991). Narrative identity. In: Wood, D. (Ed.) On Paul Ricoeur: Narrative and interpretation. London and New York: Routledge.

Sontag, S. (1990). Illness as metaphor and AIDS and its metaphors. New York: Anchor Books. 
Sundén, J. (2001). What happened to difference in cyberspace? The (re)turn of the she-cyborg. Feminist Media Studies, 1(2), 215-232.

Turkle, S. (1995). Life on the screen, identity in the age of the internet. London: Phoenix.

Turkle, S. (2011). Alone together, why we expect more from technology and less from each other. New York: Basic Books.

Waskul, D., Douglass, M., and Edgley, C. (2000). Cybersex: Outercourse and the enselfment of the body. Symbolic Interaction, 23(4), 375-398.

Widdershoven, G. (1993). The story of life: Hermeneutic perspective on the relationship between narrative and life history. In: Josselsson, R. and Lieblich, A. (Eds.) The narrative study of lives. London: Sage.

Wilding, F. (1998). Where is the feminism in cyber feminism? n. paradoxa, 2, 6-13.

Wilkonson, S., and Kitzinger, C. (1993). Whose breast is it anyway? A feminist consideration of advice and 'treatment' for breast cancer. Women's Studies International Forum, 16(3), 229-238. 

Sharing lives, sharing bodies Partners negotiating breast cancer experiences 



\subsection{INTRODUCTION}

You never have cancer alone, always together. Our body, yes; or, well, I do not really mean 'our' body, but she and I ... we have gone through a lot. (Roland)

Roland's partner, Ines, has breast cancer. After having been diagnosed with this potentially lethal disease, she has undergone various invasive medical treatments - mastectomy, lymph node removal, chemo- and radio-therapy. Roland's above-cited words clearly show that he shares in the illness experience: he repeatedly uses the first person plural ('we have gone through a lot', 'our body') and he makes frequent references to a sense of connectedness between him and his partner ('never alone, always together'). By analyzing this and several other couples' illness accounts, we explore in this paper the meaning of breast cancer as an intersubjectively lived experience.

There is a growing recognition that cancer is a shared occurrence perceived to affect both patients and their partners (Ussher et al. 2011). Many studies emphasize the distress of patients and their significant others (Hagedoorn et al. 2008; Germino 1995), reporting that the psychological well-being of the two partners is closely interconnected (Hodges et al. 2005). Other studies focus on couples' changed daily lives after diagnosis, when the patient's partner provides informal care and physical and emotional support (Given et al. 2001; Ben-Zur et al. 2001). Furthermore, relationship dynamics may transform in the context of cancer. As some authors have argued, living with cancer may contribute to couples' communication problems (Zahlis and Shandis 1991), their having more conflicts (Badr and Carmack Taylor 2006) and their decreased sexual wellbeing (Gilbert et al. 2010). Others report that cancer brings partners closer together through the experience of intimacy associated with this particular illness (Manne et al. 2004). This body of literature considers cancer as a thoroughly intersubjective experience and as such, it is quite appropriately described as a 'we-disease' (Kayser et al. 2007).

This article expands on the concept of 'we-disease' by focusing on the preliminary question of what this 'we' actually means for couples who deal with the experience of breast cancer. Indeed, Roland's account suggests a strong connection and identification with Ines, up to a point that it invites us to think of the possibility of a commonly lived, ill body. At the same time, his hesitant and stammering way of talking about 'our' body - saying that it is not really 'our' body and dividing 'our' in 'she' and ' $\mathrm{l}$ ' - reveals that a 'we-experience' is not univocal and involves more than just commonality and connectedness. Talking about a 'we' entails both sameness and difference - identity and dissimilarity, proximity and distance. By drawing on these contrasting aspects related to being a ' $w e^{\prime}$, the issue under scrutiny in this article is the extent and diversity of couples' intersubjectively lived breast cancer experiences. To this purpose, we offer an empirical analysis and discussion of how women diagnosed with breast cancer and their partners shape their 'we-experiences'. Before turning to this empirical investigation, let us first elaborate on the ambiguities in the first-person plural. 


\subsection{WHO ARE 'WE'?}

The perspective that people's lived, embodied experiences are shaped in relation to others has been extensively discussed in academic work (Weiss 1999; Shildrick 2008; Käll 2009; Ribbens McCarthy and Prokhovnik 2014; Zahavi 2014; see also: special issue Body \& Society 16(3) in 2010). Such accounts elaborate on shifting the focus from the still-powerful precept in western thought concerning the individuality of experiences to the realm of intersubjectivity by showing how lived experiences are thoroughly relational and unfold in co-constitutive processes (Blackman 2010; Slatman and Widdershoven 2010; Ribbens McCarthy and Prokhovnik 2014). The increasing attention in cancer research to couples' dyadic coping, communal living arrangements and communication patterns seems to reflect such shifting focus (Hodges et al. 2005; Given et al. 2001; Zahlis and Shandis 1991). Our aim in this paper, however, is not to consider this move away from the paradigm of individuality and neither to merely outline the practical ways in which partners cope, go around and interact. We rather assume relationality as primary and explore the complexities involved in the ways in which couples shape their breast cancer experiences in a shared space.

To understand relationality as something primary, it is informative to look the ideas of the French philosopher Jean-Luc Nancy. By re-interpreting Heidegger's notion of 'Mitsein' as an originary rather than a derived notion of existence, Nancy (2000) claims that our existence essentially involves 'being-with' (être-avec). This notion implies that we are always already in the world with others, and for this reason to be automatically involves to be together and to exist is to co-exist (Nancy 2000). In thinking such togetherness, such 'we-ness', Nancy makes use of many terms, one of which is the French partage. Commonly translated as sharing, this term points to the ambiguity and multiplicity within our co-existence (Devisch 2013). For our analysis, we take Nancy's notion of sharing as a theoretical guideline.

On the one hand, sharing refers to a division, to that which is shared out among a number of different parties. We are able to share our life exactly because self and other are somehow different. Otherwise, we would be the same subjective substance and we would have nothing - no shares - to share. On the other hand, sharing also refers to that which is shared, to what unites us in the sharing. According to Nancy, both connotations are operative in sharing. But if we are different from each other, we may ask: what do we still have in common? What we share, Nancy writes, is not some universal attribute or essence but rather the conditions that allow sharing: our embodied exposure through which we come into contact with each other (Nancy 1990; Devisch 2013). By virtue of our embodied encounters with others - in touching and being touched or seen and being seen - we are affected by each other's touch or gaze without being fully able to know how the other is affected (Zeiler 2014). Sharing a life thus means to be on the limit: through embodied exposure the self is opened up to the other, partakes in the 
other and is marked by the other's alterity without being subsumed into that other (Slatman 2014).

Along the lines of this argument, a 'we' may be thought of as the spacing between bodies, as the lines of separation that allow the self to appear as distinct from the other but that may equally serve as points of their affective connection. Note the plurality in this notion of limit: there are always lines of separation. Indeed, a 'we' consists out of borders between different - not indifferent - bodies. Moreover, every body relates to and divides from another along multiple borders: the self is many things - deadly tumors, healthy appearance, numb breasts and painful arms - and, as such, relates to another individual in many ways. A ' we', then, may be understood as the records of the many fault lines of selves and others, lines that both separate and join them together (Perpich 2005).

These records are constantly subject to change as the fault lines of an embodied 'we' remain porous and malleable (Sorial 2004). The lines of our separation take on different shapes with every specific encounter with another person - with every touch, glance, sound or smell. Rather than mistaking our shared existence for something static or fixed, 'being-with' is always a becoming (Nancy 2000). Sharing a life and being a 'we' is a continuous affective effort of navigating and shaping the spacing between us, of continuously defining and re-defining our sameness and difference through embodied exposure.

Nancy develops his idea of sharing within an ontology which reveals the human condition as inherently social. As such, he does not draw on different ways a 'we' manifests itself. His ontological take nevertheless helps us to understand what is at stake in being a 'we' and, therefore, it challenges us to delve into the ways 'we' are in the world. We will take up this challenge here and employ his theoretical reasoning as a framework for our empirical study, that is, as an instrument to open up a discussion of different ways in which partners share breast cancer experiences. Of course, the dramatic occurrence of having cancer may radically isolate and - sometimes quite literally - separate partners from each other. Our focus, however, is on the ways in which couples constantly navigate and shape their shared existence in the context of such an illness. How do these couples within their affective bodily engagements negotiate and renegotiate, draw and re-draw boundaries of their sameness and difference?

\subsection{COLLECTING WE-EXPERIENCES}

In order to explore and examine 'we-experiences' in breast cancer, we conducted and analyzed eight in-depth duo interviews with diagnosed women and their (male) part- 
ners and two in-depth interviews with only the (male) partner. ${ }^{11}$ During the interviews, the participants were initially encouraged to tell freely about their relationship and their breast cancer experiences. By asking open-ended questions, the interviewer zoomed in on issues related to intersubjective experiences. Taking the hermeneutical idea that stories are not just a representation of experience but rather both express and shape experiences, this narrative approach seems to be especially effective when it comes to uncovering how experiences are intersubjectively shaped. By inviting couples to tell their story simultaneously, we disclose how they intersubjectively shape and negotiate their breast cancer experiences in practice.

The interviews included in this study were carried out independently by the first author of this article and a research assistant. The first five couples were recruited upon their visit to a plastic surgery facility. ${ }^{12}$ In order to obtain a more varied sample (i.e. not only couples of which the women consider opting for reconstructive surgery), additional participants were recruited through a call on a Dutch breast cancer patients website. The age of the respondents ranged between 29 and 72. All interviewees indicated that they were in a stable relationship at the time of the interview. The most recent breast cancer diagnosis was a few weeks before the interview. The other women were diagnosed from a couple of months before the interview up to seven years before it. All women either had a lumpectomy or a mastectomy, and underwent other invasive treatments such as chemotherapy or radiotherapy. While some of these women opted for reconstructive surgery, others chose to wear external prostheses and yet others chose neither one (See table 2 for an overview of data on the respondents).

In the analysis phase, the first author interpreted the collected data by first attributing open, descriptive codes to excerpts of the interviews that are related to sharing and co-shaping of experiences. Examples of these codes are 'partners assisting women: household', 'disagreements/conflict' and 'sexual practices'. Second, on the basis of these codes, more general themes and storylines involving intersubjective breast cancer experiences were identified in consultation with the second and third author of the article.

\subsection{FOUR WAYS OF SHARING}

We identified four different ways of couples' sharing an embodied life in the context of breast cancer. First, while the partners we interviewed may have different kinds of

\footnotetext{
${ }^{11}$ Interviews with only the male partner were conducted when the ill partner was not able to attend the interview because of health reasons.

${ }^{12}$ All interviews were digitally recorded and transcribed verbatim. Upon transcription, all interviews were anonymized. Only the interviewers - one of which is the first author - know the identity of the respondents. Ethical clearance was obtained for this study from the hospital's ethical review board (file number 13-4-086). Informed consent was obtained from all individual participants included in the study.
} 
experiences of breast cancer, it turns out that these differences do not occur in a vacuum: partners are different together. Second, our interviewees testify that sharing a life during and after treatment means that partners have to be there for each other: taking care of each other. Third, given that breast cancer is a life-changing and a body-altering experience, all partners appear to engage at some point in practices of re-connecting with each other, in particular with her new body within and through sexuality and intimacy. Finally, some of the couples in our sample who live through breast cancer together synchronize their embodied daily lives up to a point that these appear to be alike in various and far-reaching ways. Based on these four ways of sharing, we show how the principle of sameness and difference between self and other may take on different ratios (i.e. proportion of sameness to difference) and different modes (i.e. identification/dissimilarity; proximity/distance etc.). In the following sections, we explore how couples shape their shared, affective bodily existence in response to breast cancer; how they continuously define and re-define, negotiate and re-negotiate the many fault lines that both separate and connect them.

Note that although various ways of sharing are theoretically distinguished in the results section, this does not mean that they do not change over time and that they, as we will show, do not intersect and overlap in reality. Furthermore, while the focus is on couples' sharing their lives and experiences of breast cancer, the presented results show that these intimate spacings are embedded within a larger socio-cultural context.

\section{Being different together}

Many of the couples interviewed describe that they have different kinds of the experiences of having breast cancer and getting treatment. These differences may relate not only to the fact that the disease, strictly speaking, physically affects only one of the partners (Zahlis and Shandis 1991), but also to the partners' different emotional and coping responses to diagnosis and treatment (Ben-Zur et al. 2001). In our interview with Luke and Patricia, they tell about their mutual differences. While she speaks about her breast cancer-related concerns with him, he, in turn, says he 'take[s] it [his anxiety] out on nails and bolt'. During her treatment, he build a roofing over their terrace. They elaborate on this as follows:

Luke: For me it was the perfect way to cope, being outdoors, doing stuff. That, maybe, for her was different; she did not know what was going on in my head; [for her] it was not so easy.

Interviewer: Yes, did you feel...

Patricia: Of course, we all have our ways; I was fine with it. And anyway, well, what can you do? [...] But was it easy? No, not really. 
Similarly, Emma and William also have different experiences of and dealings with the cancer, especially when it comes to decision-making. As they explain:

Emma: [I] make my own choices [about treatment options] and you [her partner, William] just hear it afterwards, right?

William: Yes, I trust her. I didn't want to interfere; it's her body after all. You don't have to understand all of it. I was only there to listen and nod.

Both couples seem to have their territories staked out: they have their differences and do not interfere in each other's dealings or perhaps they do not even understand what the experiences of the other entail. Here, the question arises whether these couples' dynamics are stretched beyond the limits of what may properly be understood as sharing. Although they may know of, acknowledge and even accept each other's divergent experiences and dealings, they do not really participate and share each other's differences. Luke and Patricia seem to have a reluctant agreement to not understand each other, and William does not seem to have any voice in Emma's decisions about her body. We may say that these participants - whether voluntarily or not - are yield up in themselves and withdraw from opening up to each other. When these couples speak in the first person plural, then, it seems to signify merely a sum of two unique selves.

For most couples in this study, however, partaking in each other's differences and actually relating to one another proves to be a significant issue. This is the case, for instance, for Kim:

You know, it's my breast and he [Wesley, her partner] doesn't have it. [...] You can never know what it is before you experienced it yourself [having breast cancer]. So I turned to others who have gone through the same. [...] When I meet [other breast cancer survivors], what a feast of recognition it is. But at home it's just different [...]; I would like him to understand, real bad, but well, I guess, no, it's just not possible. (Kim)

For Kim, it seems that in the midst of her and Wesley's (assumed) radical different embodied experiences that relating to each other becomes important. She wants Wesley to understand what she is going through, something that in her view only seems possible if Wesley would have similar embodied experiences, in this case, that of having breasts and breast cancer. For her, understanding each other seems to require a strong sense of identification in which there is a convergent resonation of experiences in each other (Dautenhahn 1997). As such, Kim's story of sharing is a wishful one. Her desire for Wesley to understand her, to identify with her and thus to partake in her experience presumes an interesting, yet unfortunate interplay of sameness and difference between her and her partner: their different embodied experiences instigate Kim's desire for Wesley to understand her, as well as underscore its impossibility.

Being able to relate to each other despite mutual differences, however, does not necessarily involve such a strong demand for identification. Ines, for example, reports 
that Roland fears her dying and him being left behind. She, in turn, is rather preoccupied with 'daily discomforts' and 'getting through the day'. His fears keeps Ines from communicating, at least to some extent, her experiences to him. 'He is so afraid you know', Ines says, 'so this [keeping her experiences to herself] is a way of protecting him'. Despite their different experiences in the face of breast cancer, Ines seems to be capable of understanding Roland's experience and even what he needs: not being confronted with some of her experiences. Her strategy of not disclosing to Roland all her experiences is in fact a sign of (acting on) understanding the other and thus of actively participating in each other's differences.

\section{Being there for you: care-giving and care-taking}

The women who participated in this study are all somehow emotionally burdened by their diagnosis and treatment, and/or they deal with the enduring physical effects of intrusive surgeries and therapies, such as scarring, pain, fatigue and decreased bodily functions. In coping with their fate, they relied to a greater or lesser extent on the support and assistance of their partners (Given et al. 2001; Ben-Zur et al. 2001). Some of the couples' accounts elaborate on him giving her emotional support: showing interest in her well-being or encouraging her to talk with friends. This section, however, focuses on couples' stories of physically assisting each other. These stories detail body care (replacing bandages, assisting in washing or going to the toilet), expatiate on helping her to navigate in public life and expound on ways in which the partner manages to take over her former - often comparably large - roles in the household or as a caregiver of their children.

At first glance, these narrations reveal assisted care routines that are directed to the female caretaker and directed by the male caregiver. 'I stand in front of her in the lines at the supermarket', William tells about his wife Emma, 'to protect her so nobody bumps into her [painful] chest [and arms]. I know how to handle her'. Upon closer inspection, however, such care incidents seem to emerge from a dialectical relationship between the two partners, suggesting an interdependent form of care. While typically the men enact care-giving, the women initiate and co-direct the care arrangement (see also Garland-Thomson 2015). Emma regularly instructs William (how) to help her to reach for certain things because of her painful arms due to lymph node removal. 'In the shower', she says, 'he does the wound on the back. I tell him, no, not that way, and I let him know when it hurts.' While he assists her with particular movements, she assists him in assisting to move (for) her.

Note that the above-described scenes of assistance bring to mind Merleau-Ponty's ' can'. Merleau-Ponty (1945) locates our existential possibilities - the ways we can be 'in the world' - in our motility, and perhaps in the mode and limits of our embodied capabilities. While, as the terminology suggests, Merleau-Ponty focuses on how the embodied self handles her movements and actions, some of this study's couples reveal that 
her bodily possibilities may be managed relationally. For these women, acquiring a comfortable equilibrium of going around easily - of being able to reach for certain things or standing in line - is located in an interdependent intimate relationship of care. This 'we can' may be understood, in the words of Garland-Thomson, as 'a choreography of reciprocal navigation' in which each of the partners contributes to the task of getting her around (Garland-Thomson 2015, 304).

Moreover, while the men take care of the women by contributing to her mobility, this kind of assistance may also involve care for the men themselves. Several of the care-givers report that being there for the other was crucial for being able to live through the illness period. As Chris reports, taking care of his wife was 'not only a distraction from all the rumination; [...] it was essential for me to get through the day!' As such, these couples' care choreographies can be understood as dialectical in the sense that that they are not only directed by both partners but also towards each other. In their caring relationship, these couples' lives and bodies are mutually constitutive as both men and women are assistants in moving the other (to move around), and because both of them take care of the other through (allowing) caregiving.

A dialectical relationship, of course, involves two poles that do not collapse into each other. Likewise, the partners in our study who are involved in a mutually constitutive relationship of care remain to some extent independent and individual. Many of the care-givers comment that assisting and supporting the other can be 'quite heavy at times' (Wesley) or 'a burden [in that] you may have to sacrifice some of your own needs' (Billy). In order to be able to be there for the patient, both physically and emotionally, it is essential, they claim, to have at least some time for themselves. In this context, partners mention activities such as physical exercise, going to work or listening to music. In turn, some of the women also need room for their own activities, something which under the circumstances is hard to find at times. In the same vein, Martha says that she wants to be something other than merely the object of support; in other words, she wants to be acknowledged as having needs of her own, aside from help and support. This becomes clear in the interview with her and her partner Bert:

Bert: Yes yes, at first of course the wound itself needed care, day in day out. [...] I had to do it. Yes, I was really a 'nurse' [...]. [I was] constantly busy with the wound. You wore bandages for over two years, isn't it?

Martha: That is what I find annoying, he does that all the time; I only have to do something like this [puts on a painful face] and then he says "what is it, is there something wrong?!". Once in a while I get pissed at him, I say "stop it". We get into fights because of it all the time. [...] I think he sees me as something he constantly has to nurse. And I want my husband back, right! You know, I am also a sexual creature! [...] Once in a while, as a woman, you just want a man to grab you, you know... 
What these experiences show is that being a self apart from the other - with your own desires, needs and activities - remains significant, that is, a precondition to or part of a mutually constitutive caring relationship. Consequently, as we see played out clearly in Martha and Bert's story, a supportive relationship requires constant negotiation, sometimes even conflict, on where and when to maintain some kind of independence and individuality while being co-constituted by the other.

Despite both partners' best efforts and struggles, however, some caring relationships exceed the limits of what seems possible. This is the case for Wesley:

Well, when you have children that are that young, they need their mom. I cannot give them that special something that mothers have; even if you may want to so badly, you still cannot give them that. (Wesley)

Wesley's quote demonstrates that a supportive relationship does not only relate to couples' negotiation of how, when and where to give and receive assistance, but also relates to the normative structure in which this support may take place. It seems that, in part, Wesley's notion of motherhood and fatherhood prevents him from taking over the caring role of his ill (female) partner. Feminist theorists argue that what we do and in what way is shaped by shared gendered norms and values (Grosz 1994; Weiss 1999). Even more, socialization with and incorporation of certain gender norms may feed into men's and women's perception and experience of what they actually can and cannot do (Young 2005). Wesley's words, then, may be understood as referring to an incorporation of the apparently distinct features of what a mother role and father role should be. This, in turn, inhibits him from offering 'that special something' (whatever that may be) that only mothers supposedly have. Wesley's assumption that he and his partner as care-givers for their children are/should be different prevents him from taking over her care-giving role. Sharing a life by mutually assisting the other, then, does not merely involve the preservation of a certain kind of selfhood - being a self apart from the other with your own activities and needs - but is more about balancing the line of presuming to be - and of acting on being - both different from and similar to the other.

\section{Being reconnected to you: intimacy and sexuality}

The period of diagnosis and treatment is regularly referred to by both partners as a rollercoaster ride in terms of body-altering events. Therefore, after treatment partners attempt to re-connect and familiarize themselves with each other again. The main strategy of re-connecting with her new body our interviewees mention is - quite literally - by exposing oneself to the other within and through embodied intimacy and sexuality.

The growing body of literature on sexuality and intimacy during and after breast cancer mainly focuses on the negative side-effects of the treatment and its impact on individuals' sexual well-being (Mercadante 2012; Gilbert et al. 2010). Studies show that women's sexual desire and activity often decreases as a result of treatment-induced 
nausea, weight gain, fatigue, a decreased libido or vaginal dryness (Gilbert et al. 2010). This section, however, discusses how women diagnosed with breast cancer and their partners try to reconnect and familiarize themselves with each other while being intimate and having sex. These couples' specific bodily re-connecting strategies are a response to alterations in the women's appearance and her embodied feeling.

During treatment, women undergo drastic temporary or permanent changes in appearance such as baldness, breast(s) amputation, breast reconstruction or scarring. Martha and Bert's strategy of getting re-acquainted with her constantly changing balding, scarring - appearance was to gaze in the mirror together on a daily basis until both got used to it again and until, as he puts it, 'it was just normal [and] we were okay with it'. Apparently, affirmation about passing as a normal woman is important in this couple's process of re-connecting (see Goffman 1963; Ucok 2005). Nevertheless, as Luke implies, such affirmation does not necessarily lead to reconnecting and familiarization and may even be a source of tension:

My wife says: 'I have lost my femininity'. Next, she shows me [her reconstructed breasts] and [says]: 'what you think of that?'. And I always respond with 'it's just fine [to me]'. But Patricia keeps going on about it [asking what he thinks of her breasts]. And then I say to her like 'come on, am I married to your tits or am I married to you?' At this point she accepts it, and things will go alright for a while. Until I see her again in the bathroom in front of the mirror, and there we go again [deep sigh]. I can understand it. [...] Now she doesn't show them [her breasts] so much anymore; she does not want to. Locks the bathroom and stuff. (Luke)

Because in many relationships it is important what the partner thinks of her appearance, his feelings and preferences tend to be taken into account while deciding how to put forward her new looking body. This decision often involves his aesthetic preferences, but it may also involve preferences about her 'healthy' appearance. While talking about his sexual relationship with Eileen, Michael elaborates on his preferences:

So she was happy with the prostheses. Me too, right. Look, before the mirror with bright lights you still saw what was going on [that she has been very sick], but in the right bra you had no idea; that's what I liked very much. And [...] yes that [having sex] is not something you do under bright lights. So yes, very nice. (Michael)

The strategies mentioned by both Michael and Eileen and Patricia and Luke of covering up, hiding or disguising deviant, scarred bodies seem to underline Goffman's (1963) argument that we tend to normalize appearances outside the spectrum of what is generally considered acceptable, beautiful or healthy. Goffman, however, predominantly focuses on normalization practices in public contexts. In line with Ucok's findings about stigmatization of women's appearances in breast cancer, the above quotes show that 
normalization practices 'not only [pertain] to public life but also [have] a significant place in intimate contexts' $(2005,314)$. In the intimacy of her own house, for example, Patricia hides her deviant body by locking the bathroom. And in the bedroom, Eileen's absent breasts and the scars carved in her body seem to remind both partners of periods of sickness, something that impedes them from engaging with each other sexually. Wearing a bra with prostheses while putting on dimmed lights enables them to be intimate again. Yet in addition to the significance of intimate normalization practices, some of the experiences mentioned above also show that intimate relationships exactly allow space to be deviant from dominant normative structures, namely when baldness or scarring is eventually considered by both partners to be 'just normal' and 'okay' (Bert). In different ways, then, these intimate practices bring into view how both partners' efforts of re-connecting with her altered appearance is explicitly embedded in a sometimes restrictive, sometimes permitting - socio-cultural, normative context.

Apart from the woman's appearance, couples' re-acquaintance practices also apply to her changed body in a tactile and felt sense. Many women experience to some extent painfulness or numbness in the operated areas. In turn, some of their partners state that touching her breast(s) felt different than before: 'harder' (Stuart about touching his wife's painful breast) and 'like a stone' (James about touching Eva's numb, reconstructed breasts). These altered experiences in tactility and feeling often figure a sense of discomfort and unease for both partners and as such, couples require different dynamics of touching. Many of our interviewees report that he touches her painful breast(s) more lightly. Some couples say that he touches her less sensitive breast a bit harder so that she could feel it. Yet others tell that touching the affected areas was so unpleasant that he stopped touching this site all together.

The abovementioned felt/tactile experiences, as compared to the visual experiences conveyed, are interesting in the light of debates on the meaning of our senses in intersubjective bodily encounters. These debates often reflect prevailing convictions that the gaze is characterized by difference and the interval of distance and that touch as an embodied gesture sustains a reciprocal sense of receptivity and proximity. Foucault (1963) and Sartre (1943), for instance, attribute objectifying power to the gaze, which is made possible by the spacing between observer and observant. Moreover, within many feminist analyses of visuality the dominant objectifying gaze often corresponds with the male gaze pinning down the female observant as a sexual spectacle to be controlled and conquered (Bartky 1990; Garland-Thomson 2006). In turn, the tactile, as Shildrick (2001) puts it, is often seen as 'a sensation that both frustrates detachment and compromises objectivity by reason of its reversible nature' (Shildrick 2001 393; see also Grosz 1994). Although it is acknowledged that touching each other may indeed be harmful - in the case of physical violence - many feminist and care-ethics studies prioritize touch over the gaze in social encounters, because touch is generally understood as featuring more proximity, even immediacy, more openness and more affective engagement than the objectifying gaze (Shildrick 2001; Routasalo et al. 1996). 
Although these 'commonsense' narratives of what gazing and touching may entail touch on some strong and even very urgent points, they fail to consider the full array of affective complexities involved in visually or tactilely encountering the embodied other. Akin to Merleau-Ponty's description of vision in terms of touch and touch in terms of vision (Slatman 2005), the data in this study suggests that vision may be modeled after the meaning predominantly attributed to touch and vice versa. On the one hand, couples' reconnecting strategies reveal that vision does not only refer to distancing differences. Practices like looking in the mirror together or including the other's visual preferences in how to present her show that the gaze - similar to touch - fondles and molds how we feel about the (looks of the) other. Through this practice, couples attempt to - sometimes successfully - reconnect and familiarize with each other. It is, as Merleau-Ponty describes, through such a vision as a kind of palpation that we experience 'proximity through distance' (Merleau-Ponty 1964 in Slatman 2005, 315). On the other hand, although touching another person involves a self and other to be in close contact with each other, the couples in this study suggest that touching one's partner does not necessarily involve a sense of closeness and connectedness and may even signify more objectifying distance than the gaze. While many couples touch each other as an aspect of getting familiarized with each other again, the pain and insensitivity while actually being touched may lead to refraining from touching each other at the affected site all together. Furthermore, our data shows that touching the other may quite literally - feel as objectifying the other: as touching a lifeless object ('a stone'). So while we are inclined to consider touch as a sense of closeness, being in such close contact may also feature - twisting Merleau-Ponty's words - a sense of distance through proximity.

This kind of rethinking of the gaze/touch opposition, however, still does not do justice to the diversity and complexity of the interviewed couples' bodily encounters in their re-acquaintance practices. While the above-described cases show that vision may integrate a sense of touch and vice versa, these senses still appear as separately operating in re-connection practices. Some partners' reconnecting strategies, however, are based upon an amalgam of the gaze and touch. In contrast to scarring and absent breasts, treatment-induced felt and tactile changes are often not immediately noticeable, at least not for the other. Because of this disguised change, approaching each other's body differently calls for multi-sensory re-connecting strategies. Michael and Eileen's strategy is a good example of this:

Yes, and then you don't do that [touching her numb chest] anymore. I have tried it for a long time. We really sat down for it. And then I did this [make a touching gesture] very carefully, and kept looking at her, at her face, how she responded, right. If she responded at all [to his touch] [...] I thought it would be alright eventually, if only I would develop that fingerspitzen sense - sometimes found among 
blind people - where it [the touching] can be felt and [where it] cannot be felt. But, well, it wasn't meant to be. (Michael)

Michael's touching strategy can be interpreted as a way to initially dissect where she does (not) feel his touch through looking at her and, eventually, through this practice, develop a touching sense of how to caress her in a pleasant way. Or, as Merleau-Ponty beautifully writes, Michael wishes his 'fingertips to have eyes' $(1973,19)$. Although Michael's attempts are not successful, it does show how different senses may operate together in re-familiarization strategies. In this case, the gaze in combination with touch may potentially assume more receptiveness and reciprocity than the touch or the gaze alone. As such, at the intersection of these senses one may well find a very intimate, bodily mode of connectedness.

\section{Being like you: synchronizing life and body}

After being faced with the reality of a breast cancer diagnosis, many of the interviewed couples adjust and synchronize their daily, embodied activities. As of the day of the diagnosis, partners are caught up in a shared rhythm of treatments, hospitals visits and (providing/receiving) daily medical care. These experiences of synchronization are not necessarily harmonious, as Michael's account suggests:

It is all about Eileen and the cancer now; it dictates the course of our days, and in particular how Eileen feels on any given day. [...] She decides on the pace [of our activities] and what I do and stuff. Every now and then she gets irritated when things don't go her way. [...] It doesn't escalate right away, no big fights, but you try to make clear to each other that this is just part of the situation, that everybody tries to do their best, and that much work goes into making the best out of it. (Michael)

In addition, Bert's account shows that in synchronizing their daily lives couples are also dependent on others. When telling about their visits to the plastic surgeon before Martha's breast reconstruction, Bert refers to a sense of feeling excluded when the surgeon examined her breast behind a curtain: 'yes, it is a bit odd, because it feels like that in the whole process you are not really there all the time. I understand it, of course, but still it is an issue [...] I have to deal with the breast cancer as well.' That a patient's partner is not present at some parts of the examination and treatment may pose an obstacle for couples when it comes to synchronizing their lives during the stage of treatment. Such full participation in the illness experience may be to value for the partner as he in Bert's words - '[has to] deal with the breast cancer as well'.

The effort of partners to synchronize their lives does not stop upon the completion of treatment as is suggested in the case of Chris and Elsbeth. After their last hospital visit, Elsbeth and Chris celebrate this milestone by getting tattoos. Elsbeth chooses a 
colorful tattoo that symbolizes the end of a 'dark' period and welcomes a 'brighter' one: a flower surrounded by leaves and butterflies on the scars of her chest. In this case, getting a tattoo may be understood, according to Langellier, as capturing 'the palimpsest of breast cancer written on [a] body: the layered marking of breast cancer, the mastectomy scar, and tattoos, each inscription overwritten, imperfectly erased and still visible on the parchment/skin' $(2001,145)$. Langellier argues that the act of getting a tattooed marking to cover a tattooing scar may transform the meaning of such a marked body: while a mastectomy or radiotherapy may inflict markings on Elsbeth's body, by getting a layered tattoo she may reclaim embodied agency. Although Chris does not have an actual scar, he feels the need to get a similar, slightly more 'masculine' tattoo: a leaf on his arm. 'It felt good', he says, 'it was so intense, you shared well, yes, a lot. And now we share this as well.' As these words underscore, marking a body may be both a shared and a gendered matter. While Chris and Elsbeth's tattoos show that feminine bodies apparently need different markings than masculine ones, their tattoos still mean to represent that he is part of and partakes in her illness experience and its aftermath of reclaiming agency over a branded body. Chris and Elsbeth now share a similar, yet explicitly different palimpsested body.

Finally, some couples take their bodily sharing to such levels that one can no longer distinguish where one body ends and the other begins. This is well demonstrated by the account of Roland and Ines, with which this article started. Like many women who suffered from breast cancer, Ines has to live with the lasting physical consequences of treatment. She and Roland elaborate how they deal with this permanent bodily change:

Roland: Before the breast cancer we would easily take a walk for 2, 3 hours. We don't do that anymore, you know. Now we walk shorter distances, like an elderly couple, that's what I mean.

Ines: The first hill makes me already feel like pff...

Roland: Right, the first one is a pain already, while before we just walked and walked, even on steep hills. This is an example of that we've gotten older because of the breast cancer. Actually, we are older in a sense, in that we do stuff that you are only supposed to do when you are older. Not at our age, no.

Interviewer: And do both of you have that?

Roland: Mwah, my wife has it, yes.

Ines: You too!

Roland: Well yes, you simply adjust yourself; it comes naturally, you know. You never have cancer alone, always together. Our body, yes; or, well, I do not really mean 'our' body, but she and I... we have gone through a lot. 
Whereas Ines is the only one who - strictly speaking - is physically affected by the treatment, Roland appears to have adjusted to Ines to the extent that it also redefined what he can and cannot do. This brings about a new kind of understanding of what capabilities in intersubjective encounters may entail (Zeiler 2014). As Weiss argues (2009), the physical boundary between one person and another has always served as a means to distinguish one's capabilities from those of another. This view resonates with Merleau-Ponty's earlier discussed individualistic reasoning on embodied capabilities: his idea of 'I can' (1945). Although among partners, as we have argued, one person's (in)capabilities may be handled in relation to each other - resulting in locating that person's 'I can(not)' in couples' collaborative 'we can' - such capabilities may still be understood as the originary property of one person's body only. But the comments by Ines and Roland suggest that capabilities themselves are thoroughly intersubjective, or rather: intercorporeal. Ines and Roland do not just handle their (in)capability to walk in relation to one another; their (in)capability apparently even arises in a specific bodily self-other encounter. By walking together, their capabilities seem to be expressed and constituted in concert; they cannot do long hikes in the hills anymore. In speaking of 'our body', Roland seems to refer to this intercorporeal (in)capability, to this 'we cannot walk'. Importantly, while Roland seems to partake in Ines' capabilities up to a point that one is inclined to speak of intercorporeal capabilities, his somewhat resistant and hesitant way of speaking about a shared body reveals that as a couple they do not melt into each other on a bodily level. If the boundary between his and her body in terms of capabilities may be blurring, he keeps insisting on this boundary: 'my wife has it'; 'not really our body'; 'she and I'. Sharing an embodied life up to this extreme, then, is a matter of both inhabiting 'our body' and being a self apart from the other - an effort at balancing a separation line that seems to vanish with every attuned step.

\subsection{DISCUSSION: WE SHARE BREAST CANCER}

By taking Nancy's ontology of coexistence as a theoretical framework and by drawing on the stories of the participating couples, in this article we explored what is at stake in actually sharing a life in the context of breast cancer. For Nancy (2000), sharing is a matter of embodied exposure to others who are similarly exposed, an exposure in which the borders between a self and other are neither clearly drawn nor completely effaced. For the couples we interviewed, this means that being a 'we' involves complex affective, bodily encounters in which the many fault lines that both separate them into individual selves and join them together as a unity are continuously navigated, shaped and negotiated.

By way of distinguishing four ways of sharing, we outlined a spectrum of different modes of the fault lines of intimate partners' sameness and difference. We have seen that sharing could mean having different kinds of experiences of breast cancer - even the 
sustainment thereof - at the heart of a couples' protective connection, and that being a self apart - but not too apart - from the other is part and parcel of a co-constitutive relationship of care. Moreover, we have shown that obscure bodily encounters may take place in attempts to reconnect with each other: closely touching each other with indifferent distances, or objectifying gazes that facilitate intimacy. Note that this description of reconnecting practices provided a rethinking of the meaning of intersubjective sensuous encounters, one that avoids privileging one particular sense - such as the gaze or touch - over the other. Finally, we have seen that sharing may involve synchronization of life and body without merger, albeit sometimes only very provisionally.

As our argument established, such sharing takes on different ratios, that is, different proportions of sameness to difference between a self and other. Sometimes the two partners are more dissimilar than that they identify with one another; they are more alone than together, more distant than proximate. Some couples have such major differences with regard to coping with breast cancer that what may properly be understood as sharing a life is stretched beyond its limit. Conversely, sometimes couples are more mutually constitutive than that they are unique selves; more connected than disconnected; more communal than individual. Even more so, some couples are similar in their embodied capabilities to such an extent that one can only tentatively distinguish one (in)capable body from another.

Sharing an embodied life and maintaining the balance of being the same yet different proves to be a constant effort for the partners in our study. With every specific encounter - with every caring choreography, every look, touch and walk - couples have to define and negotiate how and where to draw the boundary between their sameness and difference. While these negotiations may be done in harmony or may remain implicit and involve subcutaneous struggles, some of these debates, as we have seen, are explicitly played out and even involve conflicts fought out in the interview. Here we see how Nancy's (2000) asserted ontological structure of our existence as 'being-with' impacts everyday life: our social condition compels us to act. Being a 'we' may be understood as something we have to do: as a verb instead of a pronoun - as a constant embodied navigating endeavour characterized by harmony, conflict or anything in between.

While this paper expands on the concept of 'we-disease' (Kayser et al. 2007), and, as such, focuses on intimate relationships between partners in the context of breast cancer, the interviewed partners show that sharing a life and body is not something one does in an intimate vacuum. Being, or rather 'doing a we' is embedded within a larger socio-cultural, normative context. For these couples, her non-conforming physical appearance, for instance, calls attention to her body and how she relates to prevailing norms about healthy appearance or feminine shapes. As a consequence, these couples' strategies of reconnecting to each other involve dealing with these norms in the intimacy of their private home. Moreover, the ways these couples share their embodied lives is also influenced by and co-dependent on concrete third parties: children, friends, 
fellow breast cancer survivors and, not in the least, surgeons, nurses and other professional caretakers. As such, the 'we' in 'we-disease' may be understood as not only referring to both partners, but also to close and distant others. In approaching breast cancer as such a thoroughly shared disease, Roland's words continue to echo: 'You never have cancer alone, always together'. 


\section{REFERENCES}

Badr, H. and Carmack Taylor, C.L. (2006). Social Constraints and Spousal Communication in Lung Cancer. Psycho-Oncology, 15(8), 673-683.

Bartky, S.L. (1990). Femininity and domination: Studies in the phenomenology of oppression. New York: Routledge.

Ben-Zur, H., Gilbar, O., and Lev, S. (2001). Coping with Breast Cancer: Patient, Spouse, and Dyad Models. Psychosomatic Medicine, 63(1), 32-39.

Blackman, L. (2010). Bodily Integrity. Body \& Society, 16(3), 1-9.

Dautenhahn, K. (1997). I could be you: The phenomenological dimension of social understanding. Cybernetics \& Systems, 28(5), 417-453.

Devisch, I. (2013). Jean-Luc Nancy and the Question of Community. London, New Delhi, New York and Sydney: Bloomsburry.

Foucault, M. (1963). Naissance de la clinique. Paris: PUF.

Garland-Thomson, R. (2015). A Habitable World: Harriet McBryde Johnson's "Case for My Life". Hypatia 30(1), 300-306.

Garland-Thomson, R. (2006). Ways of staring. Journal of visual culture, 5(2), 173-192.

Germino, B.B., Fife, B.L., and Funk, S.G. (1995). Cancer and the Partner Relationship: What Is Its Meaning? Seminars in Oncology Nursing, 11(1), 43-50.

Gilbert, E., Ussher, J.M., and Perz, J. (2010). Renegotiating sexuality and intimacy post-cancer: The experiences of carers in a couple relationship with a person with cancer. Archives of Sexual Behavior 39(4), 9981009.

Given, B.A., Given, C.W., and Kozachik, S. (2001). Family Support in Advanced Cancer. Cancer Journal for Clinicians, 51(4), 213-224.

Goffman, E. (1963). Stigma: Notes On the Management of Spoiled Identity. New York: Simon and Schuster Inc.

Grosz, E. (1994). Volatile Bodies: Toward a Corporeal Feminism. Bloomington and Indiana: Indiana University Press.

Hagedoorn, M., Sanderman, R., Bolks, H. N., Tuinstra, J., and Coyne, J. C. (2008). Distress in Couples Coping with Cancer: A Meta-Analysis and Critical Review of Role and Gender Effects. Psychological Bulletin 134(1), 1-30.

Hodges, L. J., Humphris, G. M., and Macfarlane, G. (2005). A Meta-Analytic Investigation of the Relationship between the Psychological Distress of Cancer Patients and Their Carers. Social Science and Medicine, $60(1), 1-12$.

Käll, L.F. (2009). A Being of Two Leaves - On the Founding Significance of the Lived Body. In: Bromseth, J., Käll, L.F. and Mattson, K. (eds.) Body Claims. Uppsala University Series in Gender Research: Crossroads of Knowledge.

Kayser, K., Watson, L. E., and Andrade, J. T. (2007). Cancer as a 'We-Disease': Examining the Process of Coping from a Relational Perspective. Families, Systems \& Health, 25(4), 404-418.

Langellier, K. M. (2001). You're marked. Breast cancer, tattoo and the narrative performance of identity. In: Brockmeier, J. and Carbaugh, D.A. (eds.) Narrative and identity: Studies in autobiography, self, and culture. Amsterdam and Philadelphia: John Benjamins Publishing.

Manne, S.L, Ostroff, J., Rini, C., Fox, K., Goldstein, L., and Grana, G. (2004). The interpersonal process model of intimacy: The role of self-disclosure, partner disclosure, and partner responsiveness in interactions between breast cancer patients and their partners. Journal of Family Psychology, 18(4), 589-599.

Mercadante, S., Vitrano, V., and Catania, V. (2012). Sexual issues in early and late stage cancer: A review. Supportive Care in Cancer, 18(6), 659-665.

Merleau-Ponty M. (1945). Phénomenologie de la perception. Paris: Gallimard.

Merleau-Ponty, M. (1973). The prose of the world. Chicago: Northwestern University Press.

Nancy, J-L. (1990). Corpus. Paris: Édition Métaillié.

Nancy, J-L. (2000). Being Singular Plural. Stanford: Stanford University Press. 
Perpich, D. (2005). Corpus Meum: Disintegrating Bodies and the Ideal of Integrity. Hypatia, 20(3), 75-91.

Ribbens McCarthy, J.R. and Prokhovnik, R. (2014). Embodied Relationality and Caring after Death. Body \& Society, 20(2), 18-43.

Routasalo, P. (1999). Physical touch in nursing studies: a literature review. Journal of Advanced Nursing, 30(4), 843-850.

Sartre, J-P. (1943). L'être et le néant: Essai d’ontologie phénoménologique. Paris: Éditions Gallimard.

Shildrick, M. (2008). Contesting Normative Embodiment: Some Reflections on the Psycho-social. Perspectives: International Postgraduate Journal of Philosophy, 1, 12-22.

Slatman, J. (2005). The Sense of Life: Husserl and Merleau-Ponty on Touching and Being Touched. Chiasmi International, 7, 305-325.

Slatman, J. (2014). Our Strange Body: Philosophical Reflections on Identity and Medical Interventions. Amsterdam: Amsterdam University Press.

Slatman, J. and Widdershoven, G. (2010). Hand Transplants and Bodily Integrity. Body \& Society, 16(3), 69-92.

Sorial, S. (2004). Heidegger, Jean-Luc Nancy, and the question of Dasein's embodiment: An ethics of touch and spacing. Philosophy Today, 48(2), 216-230.

Ucok, O. (2005). The Meaning of Appearance in Surviving Breast Cancer. Human Studies, 28(3), 291-316.

Ussher, J. M., Wong, W. T., and Perz, J. (2011). A qualitative analysis of changes in relationship dynamics and roles between people with cancer and their primary informal carer, Health, 15(6), 650-667.

Weiss, G. (1999). Body Images: Embodiment as Intercorporeality. London: Routledge.

Weiss, G. (2009), Intertwined Identities: Challenges to Bodily Autonomy. Perspectives: International Postgraduate Journal of Philosophy 2(1), 22-37.

Young, I.M. (2005). On female body experience. "Throwing like a girl" and other essays. Oxford: Oxford University Press.

Zahavi, D. (2014). Self and Other: Exploring Subjectivity, Empathy, and Shame. Oxford: Oxford University Press.

Zahlis, E.H. and Shandis, M.E. (1991). Breast Cancer: Demands of the Illness of the Patients Partner. Journal of Psychosocial Oncology, 9(1), 75-93.

Zeiler, K. (2014). A philosophical defense of the idea that we can hold each other in personhood: intercorporeal personhood in dementia care. Medicine, Health Care and Philosophy, 17(1), 131-141. 


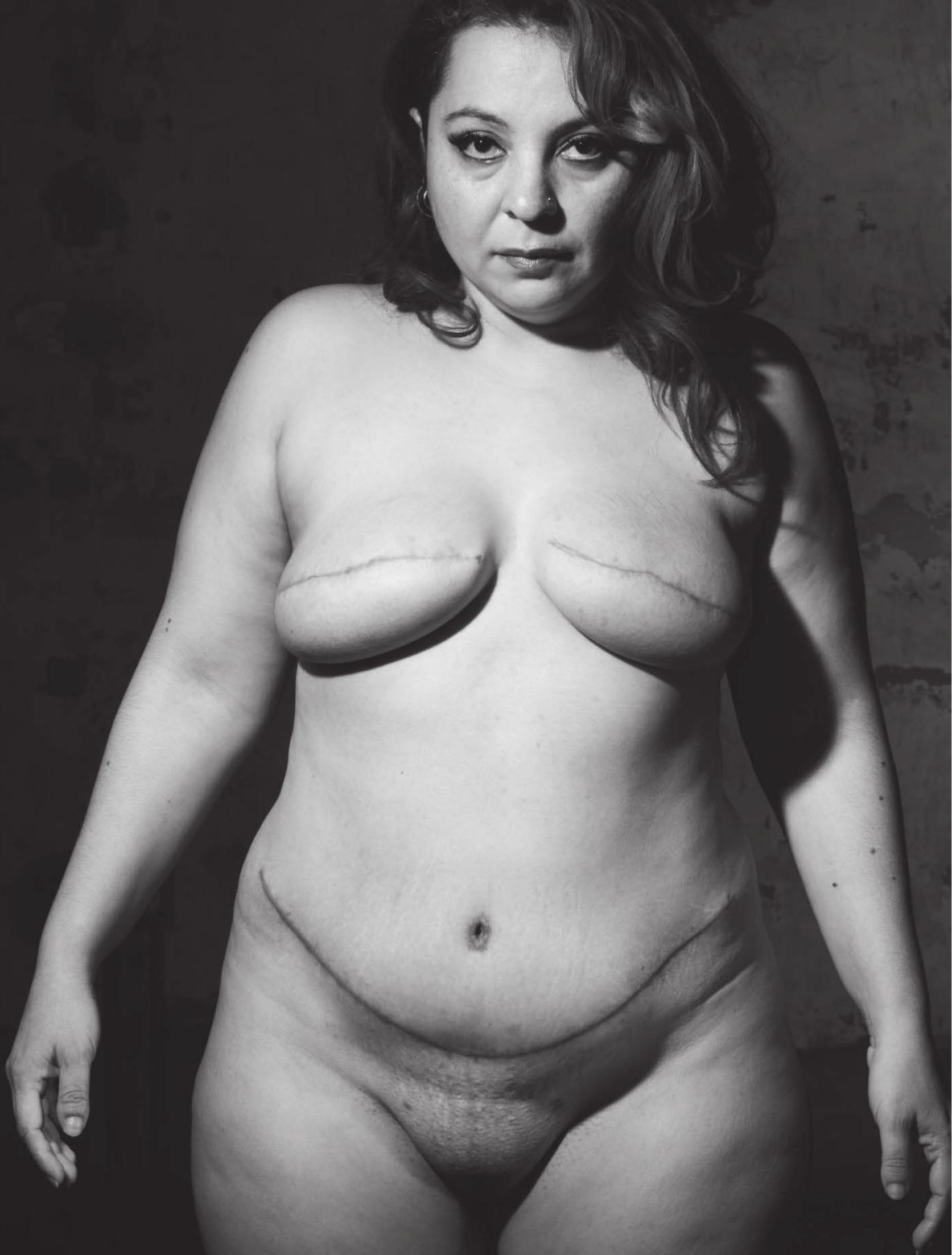




\section{CHAPTER}

\section{The surprise of a breast reconstruction A longitudinal phenomenological study to women's expectations about reconstructive surgery}

\section{Published as:}

De Boer, M.L., Hulst, R. van der, Slatman, J. (2015) The surprise of a breast reconstruction: A longitudinal phenomenological study to women's expectations about reconstructive surgery, Human Studies 38(3), 409-430. 



\subsection{INTRODUCTION}

Over the last decade, the demand for breast reconstructive surgery has increased thanks to, amongst other factors, the improved prognosis and survival rate of breast cancer and the possibility for screening BRCA 1/2-genes (Jagsi et al. 2014). Further, due to more available information about reconstruction, women are more likely to consider this post-mastectomy option (Losken et al. 2005). Those who opt for a reconstructive intervention undergo drastic and enduring bodily changes: not only do they get new breasts, they often also face a process of molding their new breast(s) through additional surgeries. Moreover, the procedure requires a long recovery and rehabilitation period and sometimes goes together with relapses or reconstruction failure. Being caught up in this life altering process, women pose various questions about their future breasts, their bodies, their lives and their relationships with others. How will I look? And how will it feel? Will I be in much pain? What will others think of the reconstruction? Is it - as the word presupposes - a reconstruction of my old breast? These kinds of questions go together with certain expectations. This article analyzes the expectations women have about their breast reconstruction.

Research on this topic is mostly conducted within the field of health sciences. These studies mainly discuss whether women's expectations can be said to be realistic or not (Denford et al. 2011; Holtzmann and Timm 2005; Snell et al. 2010; Spector et al. 2010). Realistic expectations are generally understood as "anticipating an event or outcome [that] is likely to occur" (Wiles et al. 2008: 565) and they are associated with the patient's satisfaction about the end result (Iversen et al. 1998). In the case of having unrealistic expectations, then, this literature often debates the issue how women-patients can be facilitated by medical professionals in formulating (more) realistic expectations (Denford et al. 2011; Snell et al. 2010; Spector et al. 2010).

Several scholars offer a critical voice to this kind of research by stating that people may have different views about what is realistic to expect (Davison et al.1991) and by arguing that medical professionals do not necessarily possess expert knowledge about what is realistic to expect, or at least that they are not the only experts (Hatt 1998). Moreover, various authors formulate the insight that expectations, their intensity and nature, may vary over time, in relation to other life events (Bury 1997; Wiles et al. 2008), and with regard to various aspects of embodiment such as appearance or sensitivity (Snell et al. 2010). Further, the rich tradition of sociology of expectations shows that expectations - its formulations and development - are socially mediated (Lindemann 2005; Luhmann 2014) and that expectations - rather than being explicitly articulated - may also be implicit and tacit (Garfinkel 1984).

In this article we expand on this critical stance toward the dichotomy between realistic and unrealistic expectations, while focusing on the preliminary question of what having expectations actually means. Our aim is to analyze and describe women's (possible) multiple bodily, ever-changing and contextualized expectations. To this purpose we 
present here the analysis and discussion of a qualitative and longitudinal empirical research which is explicitly framed within the philosophical phenomenological question of how we experience things and thus, of the meaning things have in our experience (Husserl 1960; Heidegger 1962). As shown in the next sections, by drawing specific attention to our contextualized, subjective, embodied and temporal experience, this framework offers a broader scope on the experience of expectations in comparison to the health science literature on this topic. As such, it contributes to unravelling the empirical complexities involved in expecting a breast reconstruction.

\subsection{PHENOMENOLOGY OF EXPECTATIONS}

Central in the phenomenological exploration of expectations is the concept of intentional time consciousness. Husserl (1960) claims that consciousness is intentional in the sense that it is conscious of something. In the directedness of consciousness, intentional objects are constituted. In his work on time, furthermore, he argues that consciousness has a triadic temporal structure. That is, our experience always contains a reference to past moments, a subjective now-standpoint, and an anticipation to moments of experience that are about to happen but are not yet actual (Husserl 1960). Strictly speaking then, expectations belong to the future part of the triadic temporal structure of our experience. According to Husserl, the experience of expecting something connotes being intentionally directed towards future objects, towards something that will happen (Gallagher 1979; Husserl 1960). A phenomenology of expectations is therefore always a phenomenology of a becoming, of a not-yet (Heidegger 1977).

As expectations concern a yet-to-come, Gallagher (1979) contends, they direct us to a certain future possible happening which has the form of believing or being convinced that this possibility will occur. Although expectations implicate possibilities, this does not mean that this phenomenon precludes any actual position. Steinbock (2006) argues that unlike other orientations towards the future - like hoping or wishing - the expectation's possibility is believed and anticipated as actually going to occur. Whereas hoping or wishing operates in the sphere of an open possibility - we can hope or wish anything, even if we do not believe that it will happen - expectations operate in the sphere of an actual possibility. Note that, as Steinbock writes, expectations and other orientations towards the future can be distinguished, they are also closely related. The object of our expectations may also be something we fear, want, wish or hope for, or our expectations may be motivated by our fears or desires.

Further, another kind of actuality is present in the so-called expected actual possibility. In expectations, we imagine future possibilities and we believe one of them will occur. Imagination, Ricoeur (1992) contends, is based on our own past experience or the represented experiences of others. That is, imagined possibilities are always slight and gradual modifications of actual (past) experiences of oneself or another. Expecta- 
tions are thus altered as-if appearances of (past) experiences and actualities. As such, the phenomenon of expectations does not only belong to the future part of Husserl's (1960) triadic temporal structure of our experience, but has to be understood as an entangled experience of the past, present and future. Having expectations now, Ricoeur (1992) asserts, involves positing a realm of future possibilities through imagination, something that is always already shaped by past experiences.

Taking the above-described characteristics of expectations into account, Dastur (2000) argues that this phenomenon has to be explored beyond its epistemology, beyond how time - the future, but also the present and past - is perceived and experienced within and through expectations. Rather, she asks, how do expectations appear within the context of their meaning? By believing that some possible happening will actually occur, Dastur points out, we attempt to fill in a yet-to-come and as such, we give meaning to and interpret what is by definition still unknown. We do so by positioning us on a delicate equilibrium between expectations' particular features: being moved by past, actual experiences; being convinced that something will actually occur; and being intentionally oriented towards future possibilities. Expectations as the attempted filling-in of a going-to-occur future through past-founded imaginations will never be completely fulfilled, she argues, since the mere idea of fulfillment of the expectation would destroy its basis, namely being intentionally oriented towards a future. In expecting, we remain in the mode of being open to the validation or invalidation of our convictions as it concerns an imagined and yet-to-come, unknown future. That is, however strong our belief of the happening of a certain future is, however convinced we are now that what will happen will be a modification of our past experience, it remains a conviction, an orientation towards a believed-to-come possibility rather than a yet-to-come determined (past-founded) actuality. In this sense, the event that is expected always comes - at least in part or to a certain degree - by surprise, as it is never completely how one expected it to be (Dastur 2000). Or, to quote Heraclitus, it is necessary to "expect the unexpected" (Heraclitus 1987 in Dastur 2000, 185). Paradoxically thus, through attempting to fill in the future, through having expectations, we have to be open to the indetermination of the future.

Ideally, this openness does not evaporate when the expected event has taken place. Linking up with the hermeneutical tradition, this article assumes that we constantly try to make sense of our future through fitting our expectations into our constantly changing life stories that express who we are, who we were, and who we will be (Ricoeur 1992). This means that while life unfolds, we attempt to formulate and reformulate, shape and reshape our former expectations and create new ones in light of our present and past experiences and always newly emerging future possibilities. 


\subsection{PHENOMENOLOGY AS A METHOD TO EXPLORE EXPECTATIONS ABOUT BREAST RECONSTRUCTION}

Turning to our empirical investigation of women's expectations, we account for this phenomenology of expectations by using the qualitative research method of Interpretative Phenomenological Analysis within a longitudinal research design. This method is especially suitable for uncovering what having expectations actually means within the process of having reconstructive surgery because it strives for openness: for describing and interpreting experiences and sense making processes in their own, detailed, embodied and continually evolving terms within the subject's context (Murray and Holmes 2014; Smith et al. 2009). For this particular study, we conducted 26 in-depth interviews with ten women at different stages of their reconstructive process in order to investigate how these women develop and redevelop their expectations and how they continually make sense of the reconstructive experience. The resulting data is then analyzed through an inductive way of coding: attributing open, descriptive codes after which more general storylines emerge.

In the data collection phase, the first author interviewed the same seven women several times over the course of 1 year: before the reconstructive intervention, 3 months afterwards, 6 months afterwards and 1 year afterwards (October 2012 - February 2014). These women were recruited upon their first visit to the plastic surgery facility of an academic hospital in the Netherlands. Out of this sample, one woman did not want to participate in the study anymore after her reconstruction. Another woman decided not to go through with the reconstruction after the first interview. The first author talked to her about this in a final second interview. Additionally, because (re-) developing expectations may well extend beyond 1 year after the reconstructive intervention, the first author interviewed three more women who had a breast reconstruction 5 years ago. These women were approached through their contact details in the archives of the same Dutch plastic surgery facility. In total, 26 interviews were conducted with ten women.

Among these women are those who have unilateral (one breast) or bilateral (both breasts) reconstructions and immediate (during the same operation as the mastectomy) or delayed reconstructions (any number of years after the mastectomy). Further, this study includes women who opted for reconstruction following curative mastectomy (after the diagnosis breast cancer) and following preventive mastectomy (after the diagnosis BRCA $1 / 2$ gene). The age of the women in this study ranged from 28 to 75 at the time of the first interview (see table 3 for an overview of the respondent's details). We obtained ethical clearance for this study from the hospital's ethical review board (File Number 13-4-086). Informed consent was obtained from all individual participants included in the study.

The interviews took place at the respondent's home, at the hospital or at another place of the respondent's choice. During the interviews, the women were initially en- 
couraged to tell freely about their reconstructive experiences in general. By building on these women's stories, the interviewer zoomed in on those issues that are related to expectations. If necessary, the interviewer raised the issue of expectations herself. This resulted in interviews with a length ranging from $50 \mathrm{~min}$ to $2 \mathrm{~h}$. All interviews were digitally recorded and transcribed verbatim. Upon transcription, all interviews were anonymized. Only the interviewer - also the first author - knows the identity of the respondents. In addition to the interviews, observation notes from the consultation room taken during the recruitment phase (one morning a week over a period of 4 months: October 2012 -January 2013) were also included in the study. Quotes from the observation notes and interviews are translated from Dutch by the first author of this article.

In the analysis phase, the first author attributed descriptive, open codes to exerts of the interviews and observation notes that are related to the shaping and reshaping of expectations. Examples of these codes are 'expectations before reconstruction: scarring', 'no expectations before reconstruction', 'expectations 3 months after: numbness breast', and ' 5 years after: unexpected feelings inside breast'. On the basis of these codes, more general themes and storylines involving expectations about a breast reconstruction were identified in consultation with the last author of the article.

\subsection{RESULTS}

Our analysis identified expectations prior to the intervention that refer to three different aspects of these women's embodiment, namely regarding their gazed body ('Expecting to look like a normal women'), their capable and practical body ('Expecting to have a practical and capable body'), and their felt body ('Expecting to feel a natural body'). As said, having expectations may also involve reconfiguring them, and these women do so in various ways. After reconstruction, they adjust the level of their initial expectations, they shift their focus from one (initial) expectation to another (new or old) one, and they (re-)write their initial expectations in retrospect ('Reconfiguring expectations'). Finally, some women face what apparently arrives as totally unexpected, namely their strange feeling breast or a failed reconstruction ('The unexpected').

Although we analytically distinguish between different kinds of bodily expectations before reconstruction and different kinds of reconfigurations and dealings afterwards, this does not mean that they are not interrelated in reality. As will be sketched out, these women's expectations, reconfigurations and other orientations towards their future intermingle and overlap in surprising and sometimes contradictory ways. Further, most women also have more than one kind of expectation or reconfiguration at one time and their expectations and dealings may also change over time. 


\section{Expecting to look like a normal woman}

Expectations of looking normal, feminine and sexy occur again and again in the interviews. These kind of expectations seem to be incorporated in the understanding of reconstruction that permeates the practice of plastic surgery. Within the consultation room, we observed, there is a lot of talk about, and practices on how the reconstructed body should and will look. As such, women are mainly prepared for their postoperative appearance. For instance, many women are shown before and after pictures of other women's reconstructed breast(s). These pictures represent the successful 'realistic' cases, where the reconstructed breast resembles a 'normal breast,' but not too natural looking in order to prevent women from having too high 'unrealistic' expectations. Furthermore, many women are shown how they will look after reconstruction through the surgeon molding their original breast(s) or external prostheses. Daphne, who will have an immediate bilateral reconstruction, is one of them. She negotiates her future appearance while the surgeon is shaping her breasts:

Daphne: Can they [the reconstructed breasts] come a bit more higher up?

Surgeon: Yes, yes, like this? And they will be a bit more firm [than her original breasts]

Daphne: Nice [...] Then I will look like I did before I got children! (Daphne, before reconstruction)

In reaction, the surgeon explains to Daphne that the reconstructed end-result will always be different than expected and will not be the same as her old breasts. Despite this warning, however, it seems that Daphne's expectations are shaped- through negotiation and seeing her breasts being molded-by her memories of how she looked before she breast-fed her children. It may be argued that Daphne's expectation and the accompanying negotiating/molding activity points to Ucok's (2005) assumption that within the practice of reconstruction women merely conform to certain standards of feminine appearance, such as having young and sexy breasts. Even more, it may be argued that Daphne's case underscores the argument of feminist scholar Lorde (1980) that opting for such a surgical procedure implies unrealistic re- constructive expectations, namely to return to looking as we did before. In having a reconstruction, she argues, we are facilitated and even encouraged to expect merely the visual recurrence of past actualities. Reconstruction is therefore not only a gazed, normalizing practice according to Lorde, but also a misguided one: it stands in the way of getting used to and accepting the unavoidable new masectomized and scarred body (Lorde 1980). However valid this critique is, these women's expectations are-as we will see-less straightforward than they may look at first glance and point to a more complex reality of the reconstructive experience. 
In the interview with Doris, one week before her reconstruction, we are coming back several times to her expectations regarding scarring. She says:

I think that the scarring will look bad and weird because they will cut you open from right to left, yes, and, of course, especially in the beginning with the wound and stuff. [...] But maybe after a while, I don't know, it will look better eh, when you put on a bra and t-shirt, nobody will see the scars and it will look normal again I guess. (Doris, before reconstruction)

Because of the scarring, Doris expects to only look normal again with clothes on. Also note the temporal dimension within this expectation of covert normality: Doris expects to look deviant "especially in the beginning" and only "after a while," she says, her reconstructed breast "will look normal," but still only with clothes on. This kind of expectation affects these women's expectations about dealing with their bodies in daily life, especially in situations in which nakedness is involved. For example, Pamela, who has a similar expectation as Doris, expects that after the reconstruction she will leave on a singlet while being intimate with her partner. For Doris and Pamela, their reconstruction is paradoxically presented as that which is expected to enable recovery from appearing deviant and that which signals deviance and, therefore, requires concealment.

For some women, however, it is very difficult to have expectations at all about how they will look after reconstruction, especially in relation to scarring. Before having an immediate unilateral reconstruction, Grace declares that:

I did look on the Internet and searched for photos [of reconstructed breasts] because [...] it might be good to see what you can expect. [...] But you know what it is? I am, I have a dark skin and on that [internet] page there were only white women. So I, I could not make a comparison with me. [...] I know for a fact that scar tissue heals differently with white women [than with dark skinned women]. [...] So it would have been nice to have some examples of negroid women, because now I cannot imagine how it will look like. (Grace, before reconstruction)

As the above quotes show, the issue of scarring and how this changes over time plays an important role in these women's expectations regarding their reconstructed appearance. Some expect to only look normal and feminine with their clothes on because of their - still deviant - scarred body. For Grace, imagining her scarred body seems to be impossible in itself because of the absence of appropriate (pictorially) represented experiences of similar (i.e., dark skinned) reconstructed bodies. As a result, it is difficult for her to have expectations at all about her scarred, reconstructed appearance.

\section{Expecting to have a practical and capable body}

Women also articulate various expectations about their practical and capable body, a body that allows them to go around (more) easily. For many women who already had a 
mastectomy and wear external prostheses, the hassles of such prostheses lead to a discussion of the possibility of reconstruction as an alternative. Mandy, for example, reports that cleaning them, putting them in and out every morning and constantly having to pull them down is "annoying". Once she has the reconstruction, she says, "everything will be just normal again". Beatrix also seeks reconstruction as a practical alternative to wearing external prostheses, particularly while interacting with her grandchildren. She explains:

I babysit my grandchildren a lot, and if you just wear external prostheses, at the moment when you lift a child and especially in the summer months, everything will hang forward. It will get loose, you're sweating, you hear it every time when they flap back like 'flush,' a really strange sound [...]. And you don't want to get your grandchildren a trauma because of that, it's weird enough that your grandmother does not have boobs. So that's why [she will have a reconstruction]. (Beatrix, before reconstruction)

Both Beatrix and Mandy expect that the reconstruction liberates them from constantly engaging with their prostheses: not having to clean them or not having to worry about strange sounds. Beatrix' words, moreover, show how such expectations may be socially mediated in complex ways. In line with Luhmann's (2014) argument that one's expectations may be based on one's expected expectations or preferences of others, Beatrix seems to expect that her grandchildren expect or anticipate her to have breasts, or at least to have a body that does not make strange sounds. In turn, Beatrix' expected expectations of her grandchildren seem to shape her view on what is significant to and expected from a breast reconstruction.

Additional to having a more practical body, some women also have expectations about their increased physical capability which in turn also has a liberating potential. Marly, for example, had a unilateral mastectomy 3 years ago and decided to have a reconstruction now that she feels that her mastectomy increasingly affects her capability. She is quite heavy breasted and with only one breast left, she walks crooked. Her hips, as a result, show signs of wear and walking hurts more and more. She expects that the weight of her new breast will help her to walk up straight again and to go around without having pain.

Other women do not have expectations about their capability in relation to the breasted end-result, but more in relation to the surgery itself. Commonly, these women find it rather difficult to formulate these kinds of expectations because of the unimaginability of pain that comes with having surgery and how it will affect them in daily routines. Like Pamela, who has a particular strategy in trying to overcome the difficulty in imagining what such an invasive operation will do to her:

I have nightmares about it [the operation] because it might hurt very much, but you can't imagine eh, you don't know what to expect and nobody can tell you 
how, where eh how it will hurt. And can I lift things? Can I even walk? [...] So I watch these shows [in which operations are broadcasted], but that does not help either really, or yeah, they don't show you if these women can wash the windows after the surgery [laughter]. But it will be okay, I'm sure. (Pamela, before reconstruction)

Pamela's strategy of watching the visual representation of the operation or even the pain of the patient does not sufficiently help her to imagine her felt pain after surgery and the capability of her body in recovery: extrapolating expectations about her future felt body and her resulting capability from visual representations of pain seems to be difficult. This difficulty may amount to the status of the involved senses. Phenomenologically speaking, subjectively felt experiences, like pain, are very intimate and are immediately accessible to the sensing subject (Husserl 1952; Lindemann 1997; MerleauPonty 1945; Ricoeur 1992). By contrast, visual experiences are characterized by distance and difference between what is observed and the observant-even when the observer and observant is the same subject -, and concern outer - instead of inner - states (Merleau-Ponty 1961). As such, imagining postsurgical pain and the resulting (in) capability may be difficult to extrapolate from a sensory mode that conveys external sensory perception (Lindemann 1997).

Curiously, after stating that Pamela is unable to formulate felt expectations, she adds that she is "sure" that it will be "okay". Perhaps this recovered-body expectation is based on the statistical information that most women will be "okay" after surgery, or perhaps it is motivated by her wanting or wishing to be able-bodied again. Either way, by repeating this expectation as a kind of mantra throughout the interview - especially after reporting having difficulties imagining and formulating expectations about her capable body - it seems that she tries to ward off her experienced difficulties and actively convinces herself that she may indeed expect a recovered body.

\section{Expecting to feel a natural breasted body}

In the interviews, women occasionally formulate explicit expectations about their felt body. These women expect different things with regard to sensitivity depending on what kind of reconstruction they will have. In general, there are two kinds of breast reconstructions: those that use artificial implants, and those that use the woman's own body tissue. In most of the implant reconstructions, a saline or silicone implant is placed beneath the skin. A breast reconstruction with one's own body tissue, a so called (free) flap-procedure, involves the removal of skin, muscle and fat from another part of the body, such as the abdomen, back or hip, and its transfer to the chest wall (Serletti et al. 2011). Other than with an implant reconstruction, a flap-reconstruction gets bigger or smaller when the body gains or loses weight. 
Mandy, who will undergo flap-reconstruction, elaborates on her expectations about how the reconstructed breast will feel:

Well I don't know what I expect, but maybe that, that it is warmer, like my breasts always were, in comparison to a reconstruction with something artificial. It's hard to explain, but it is your own flesh after all, so I think, well I hope that... And blood runs through it, so yes, a more natural feeling. (Mandy, before reconstruction)

Marly, who will have an implant reconstruction, decided to have this kind of reconstruction also because of the sensory feeling aspect, but in a different way than Mandy does. She says:

I think... yes, that an implant reconstruction is less invasive because well, they only cut you open on your chest, not other area's [of the body]. And that is important because then, only the breast region is affected and other parts [of the body] remain intact, also feeling wise. You know, no cutting and stuff here [points to her belly]. (Marly, before reconstruction)

Marly's expectation about her implant reconstruction refers to the felt, "intact" body in general: to how her reconstruction will not affect or compromise sensitivity in other areas than the breast. Mandy's expectation about her flap-reconstruction refers mainly to the "own", "natural feeling" in the breast: own flesh, own blood and warm just like her "breasts always were".

Mandy and Marly are two of the few women that formulate expectations about their felt body. These kinds of expectations are less present in the interviews in comparison to expectations about appearance, practicability and capability. Moreover, felt body expectations are also less well-articulated than these latter kind of expectations. In the cases that these women talk about their felt expectations they seem to be unsure, hesitant, and falter. They pause a lot, use expressions like 'maybe,' 'I guess' or 'I don't know,' and some express contradictory statements. A possible explanation is that these women's difficulties stem from the fact that they did not give this kind of expectation much thought before the interview. Although some eventually do turn out to have felt expectations about their breasted bodies - remaining "intact" (Marly) and natural as they "always were" (Mandy) - these felt expectations seem to be tacit until the interviewer explicitly asks about them. Consequently, they still have to work out their story. However, even when these women already have extensively reflected on their future felt bodies, it remains difficult for most of them to formulate felt expectations. Beatrix, who is scheduled for a flap-reconstruction, is a good example of this. After the interviewer brings up the issue of feeling in the beginning of the interview she says she never thought about it. But now that she does, it still seems difficult to formulate these kinds of expectations. Towards the end of the interview she says: 
But I cannot imagine and that's just not possible, eh, what it is, if you transfer tissue from one place to another. And you take tissue from somewhere and that, then put it elsewhere, and eh, that is just really difficult when...regarding how it will feel, if it will have feeling at all. (Beatrix, before reconstruction)

Just 3 days after the interview, Beatrix called the interviewer to inform her that she decided to not have the reconstruction after all. She explains her reasons in a second interview:

No, no, I still cannot imagine. But it is the insecurity you know, you don't know what will come. If it will come back [the feeling of her breast] and how [it will come back]. And I am not up for that. It is good as it is. (Beatrix, before reconstruction)

Curiously, even after Beatrix thinks about her future felt body, it is not her expectations about it that makes her decide not to go through with the reconstruction, rather it is her lack of (being able to have) expectations. It is the extreme insecurity about her reconstructed felt future, unimaginibility even, that makes her not want to pursue this future.

The difficulties that women experience while formulating felt expectations may not only, as we have seen, point to attempting to build this kind of expectation on another sensory mode, but may also point to an inherent problem in imagining felt bodily experiences. Ricoeur (1992) argues that having expectations about your future body requires imagining yourself into several 'others': projecting yourself into an 'other', future body through the re-presented experiences of a past 'other' self or of another person. In this sense, imagination involves the minimal distance of self-duplication: it contains an imagining (present) self-subject and an imagined (future, past, or alter-ego) self-object. This movement through otherness is a problem in imagining and expecting our future felt body. How our body feels for us is a very singular, momentarily experience. It corresponds to what Husserl has called the experience of one's own body as 'Leib', i.e., an experience of one's body that does not constitute observational content, and thus not an intentional object. Instead of providing physical qualities, the Leib experience constitutes a zero point for all action and perception (Husserl 1952). In line with Husserl, Ricoeur contends that this sensory experience "has no object, [...] it is the most intimate sense" (1992: 321; see also Lindemann 1997). If we feel pain or numbness, we feel it without distance, in this moment. It is difficult, then, to remember our own sensory feelings, let alone, to grasp how the body of another person feels like. As such, it is difficult for women to imagine and expect how their own 'other' future body will feel through re-presenting their own felt experiences or those of others. 


\section{Reconfiguring expectations}

After their reconstruction, women reconfigure their initial expectations and create new ones in multiple, complex and sometimes contradictory ways. Some women expect more or they may expect less, compared to their former expectation. Others shift their expectation focus to different kinds of expectations, and yet others retrospectively (re)formulate their initial expectations. Within these reconfigurations, these women's former (gazed, capable, practical, or felt) expectations become closely entangled and intersected. Further, while new possible futures emerge, new and different kinds of expectations present themselves. Some women even (re-)configure their expectations up to a point that their newly created and their initial expectations cannot be distinguished anymore.

Expecting more, expecting less - The most common reconfiguration is to adjust the degree of the expectation: these women expect more or less with regard to their initial expectation. For instance, Pamela - who had difficulties with imagining her capable body in recovery - tells the interviewer 3 months after the reconstruction that walking up straight is a problem. Because of tissue taken from her abdomen and her skin being stitched together again, her belly is very tight. As a result, she walks a bit stooped. This affects her expectation about to what extent and within what period she will have a capable body again. She says:

And they [the surgeons] told me today that the recovery will at least take 3 more months. And I think oh God, 3 months, because I have to train myself with walking up straight again so the skin will get loose again. [...] So I have to lower my expectations a bit, no heavy lifting for now, that I, eh, but I am willing to give a great deal for it. (Pamela, 3 months after reconstruction)

Pamela's words show that she expects now that her body will be - at least temporarily less able than she expected it would be before the reconstruction. Conversely, other women reconfigure their expectation so they expect more from their future. At first, Grace could not imagine how her scarred body would look like. Every time the interviewer speaks to her after reconstruction, she sets her expectations regarding her gazed body higher and higher. 3 months after reconstruction she says:

I got B cup silicones, and don't get me wrong, they look beautiful. But because I've always got C cups, it is just not what it's used to be. It just looks funny, you know. So the doctor will call soon to make an appointment to adjust them, a bit bigger yes. (Grace, 3 months after reconstruction)

In the interview 9 months later, she says she is very pleased with the enlargement of her breast. Nonetheless, she now realizes that more medical procedures have to be done - a nipple reconstruction and the removal of scar tissue - in order to get, she says, the body "I eventually expect to have, [that] looks the most beautiful as possible". Pam- 
ela's and Grace's quotes show that their adjusted expectations often assume various embodied activities and alterations on their part by and through which they work towards their expected future. For Pamela, this means doing exercises in order to stretch her skin, but it also means actively being passive - no heavy lifting - in order to allow her body to heal. In Grace's case, she up-scales her expectations, while choosing to have additional reconstructive procedures.

Shifting expectations - Some women reconfigure their expectations by partly shifting their expectation focus in the process of having a breast reconstruction. When the interviewer speaks to Marly 1 year after the reconstruction, her expectation to be able to walk up straight again is not actualized: the reconstructed breast was not heavy enough. Sporadically, she talks about this unfulfilled expectation: while searching for alternative options to make her breasts evenly heavy (i.e., through additional surgeries or wearing external prostheses), she seems to hold on to her expectation of eventually being able to walk up straight again. Meanwhile, her expectations regarding her gazed body come more to the foreground: while speaking about her future, she focuses more on her looks instead of her walking capabilities.

Other women have an expectation focus shift not because their former expectations were not met, but rather because new events take place: new people are met, and new interests unfold themselves. Amelia, who had an unilateral breast reconstruction 5 years ago, recounts her focus shift:

Yeah, it did not seem important at first but after a while you start to see the world again and become active with eh, men. And you just expect to be, well, feel natural you know, then. [...] And I also dance the tango and then you stand really close to each other. And then it becomes important. Because you do not want a man to notice the difference [between the reconstructed and the original breast] right away, I was anxious about that. [...] So I asked some good male friends to touch it and to tell me how they feel, whether they notice it [the difference between the breasts]. A kind of dry eh dry humping. (Amelia, 5 years after reconstruction)

Amelia formulates expectations about her tactile body when she starts being interested in having sexual partners again. Similar to Beatrix' socially mediated expectations, it seems that (projected) expectations of, in this case, male others about Amelia's body, makes Amelia shift her expectation focus (see Luhmann 2014). Note that this adjustment, just as with Grace and Pamela, comes with embodied activities. Amelia adopts a "dry humping" strategy to validate whether her tactile expectations are realized. Further, after one man says that her reconstructed breast feels harder than the other, she tweaks her reconstruction by putting soft tissues in her bra.

Expecting in retrospect - Not only are women's expectations about their yet-to-come future reconfigured after reconstruction, interestingly, some women also retrospectively (re-)configure their former expectations - or lack thereof - about their already- 
happened future. Sally states that before the reconstruction she - like many other women - had difficulties with formulating expectations about her felt body. Now, 5 years after her unilateral reconstruction, she says she "know[s] what [she] should have expected," and even more how to explain it to others who will still have the reconstruction. She states:

I showed them this [she puts her finger against the finger of the interviewer]. Now stroke with your other hand both fingers at the same time [she orders the interviewer]. This is how it [the feeling in her reconstructed and original breast] feels for me. (Sally, 5 years after reconstruction)

Sally not only configures the expectation she should have had before the reconstruction, she also tries to help other women in formulating their expectations by explaining how it feels for her.

An even more curious case of rewriting expectations is Barbara's reconfiguration. 5 years after her reconstruction she explains the feeling in her reconstructed breasts:

[Now they are] like a hard ball, it's not natural at all. [...] I remember being at the doctor's office [before reconstruction] talking about it [having reconstructed breasts] and how it would feel. And of course I thought, expected eh, I hoped it would feel natural, but I think I always knew in the back of my head that it would be different. [...] In a sense I always expected it to be this way, but yeah, you do not want that so you push it away I guess. (Barbara, 5 years after reconstruction)

Barbara's words bear witness of the complex temporality involved in having expectations. Her words may be interpreted as a way of rewriting the past and her former expectations, while taking into consideration her present experiences. She may have expected her breasts to feel natural before, but now that they don't, she says she always believed and implicitly expected - at least retrospectively - that they wouldn't. For her, the initial expectation did not actualize (primarily) because of the outcome, but (also) because it was - at least retrospectively - an unrealistic expectation to begin with. Barbara shows that having expectations is not an unambiguous matter of believing that a certain possibility will occur, as Gallagher (1979) and Steinbock (2006) seem to assume. In some way, Barbara believed and she didn't believe that her breasts would feel natural.

Further, in response to Steinbock's (2006) argued clear-cut distinction between different orientations towards the future, note that within Barbara's complex temporal narrative, various orientations like 'hoping,' 'wanting' and 'expecting' have an interesting interplay up to a point that they cannot be clearly distinguished anymore. At the time of the interview, Barbara says she did not want the expectation that she always actually - yet implicitly - expected that her reconstructed breasts wouldn't feel natural -, so she opted before the reconstruction for another expectation - that her reconstructed breasts would feel natural-that she now refers to as a mere hope. 


\section{The unexpected}

In a sense, every expectation incorporates the unexpected. As the above recounted cases show, these women reconfigure their expectations precisely because of the component of the unexpected inherent within their reconstructive experience which bring them towards unanticipated futures. Within their reconfigurations, they show that they are able to give new and altered meaning to their (expected/unexpected) experiences and to unfolding new possibilities. For some women, however, the event of the reconstruction fractures this possibility of giving meaning to their experiences and leaves them scattered, that is, unable to integrate the event of reconstruction within their life narrative. These women seem to experience the reconstruction as totally and destructively unexpected. This appears to happen in the case of a strange feeling breast and in the case of a failed reconstruction.

The most recounted unexpected experience is that of the felt breast. Before reconstruction, as Beatrix' and Sally's cases show, women often have difficulties with what to expect regarding their felt body. After the surgery, many of these women's reconstructed breasts feel numb or completely different from their former breast(s), something that they did not explicitly consider as a possibility or were not able to imagine and therefore appears to come totally unexpected. Like Daphne, who starts to cry when she tells the interviewer about the feeling in her breast 3 months after her reconstruction:

You felt it when you touched it, eh [short silence] but not felt, you did not feel it, also when you had an itch, and then you scratched and then you did not feel when you scratched it, but the itch goes away. Very, very strange. [...] Yes, not normal. [...] Just awful really, really, really awful. You cannot prepare for it. How, yes, how? (Daphne, 3 months after reconstruction)

Rather than interpreting Mandy's numbing experience as simply unexpected, we may argue that this experience is a breach of a very implicit felt expectation. Mandy's words suggest that she implicitly expected her present body to feel "normal," that is, more or less the same as it did before the reconstruction. As her current experiences are not those she had before, this expectation of continuation surfaces retrospectively in Mandy's story of - what may be understood as - disappointment (see Garfinkel 1984). Note that while we argued that it is difficult to formulate felt expectations because of the issue of immediacy and the problem of imaging another felt future, Mandy's case seems to show that formulating such expectations does not require imagining other futures per se, but may also involve extrapolating the present to the future.

Moreover, some unlucky women are confronted with the apparently totally unexpected event of a failed reconstruction. Although many of these women consider the 
event of a failed reconstruction as a (statistical) possibility ${ }^{13}$ - and, in this sense, is foreseen -, when it actually happens, it still emerges unexpectedly. These women do not believe that their reconstruction will be unsuccessful. 3 months after the reconstruction, Mandy recounts the situation in which she heard that her reconstruction has failed:

So I said to the surgeon, yes but I smell corpses, I, I, yes, she [the surgeon] says that's because your breast is rotting away. And then I said, I was like, I can't cope with this. [Now] I cannot look at that body anymore, I just avoid it. So that is very eh yes very hard, it's very emotional. [long silence] But the smell, and yes, that sticks with you, yes, yes, that's so, so difficult. (Mandy, 3 months after reconstruction $)^{14}$

Women like Daphne and Mandy speak of their (felt/failed) reconstruction in the mode of 'it happened to me'. They seem to experience no control over the event and its accompanying experiences, and in a way, it is the event which gives the order here (Dastur 2000). And that order, which swamps them, leaves them paralyzed and in chaos: they are not able to give meaning to this event and integrate it in the story of who they were, are, and will be. Daphne's strange feeling breast, for example, took her by surprise in such a way that a direct encounter with her present reconstructive experience seems to be impossible. She has trouble finding words and she only seems to be able to speak about her present experience in the second voice (you) and in the past tense. Mandy also avoids a direct, voluntary (visual) encounter with her present failed reconstruction. Even more, her experience neither allows her to reconfigure her former expectations, nor allows her to be open to other possible futures. She states that "I cannot have any expectations anymore. I won't [long silence]. This takes up too much". Women like Mandy and Daphne experience their incapacity to experience the traumatizing reconstructive event and, as a result, cannot interpret and give meaning to their present, past, and future.

However, these women are not completely paralyzed in relation to their unexpected reconstructive experiences: they keep trying to give meaning to it, though obscure and preliminary. In the three times the interviewer speaks to Daphne after reconstruction, she continues to try to find words for her numbing experience, although in a faltering, sometimes contradictory manner. Furthermore, Mandy finds herself involuntarily confronted with her failed reconstruction through the smell of the rejected body tissue that will not get out of her nose. As such, she seems to have to continue to deal with and speak about the failed reconstruction, thereby attempting to give meaning to it.

\footnotetext{
${ }^{13}$ Percentages of unsuccessful reconstructions (i.e., removed tissue/implant due to complications) vary between different kinds of reconstructions (see IKNL 2012).

${ }^{14}$ Needless to say, this quote represents this woman's subjective experiences and not necessarily what her doctor actually said in the described situation.
} 


\subsection{DISCUSSION AND CONCLUSION}

Based on this analysis, we can draw three conclusions: (1) The multiplicity of women's expectations about breast reconstruction shows that the reconstructive experience adheres to all aspects of their bodily existence. (2) This range of expectations complicates the understanding of the breast reconstructive practice as a re-construction of a breasted past. (3) The development of these women's multiple expectations can be understood as an active and continuously evolving, difficult, and sometimes impossible dynamic of expecting the surprise that is a breast reconstruction. We suggest that medical professionals can facilitate this dynamic in various ways.

\section{Multiple bodily expectations}

Feminist and health science literature generally portray breast reconstruction as a normalizing, 'gazed' practice. Lorde states, for example, that the practice of breast reconstruction rehearses the idea "that [women] are only what [they] look or appear" (Lorde 1980: 57). Similarly, health science research centers on expectations about postsurgical appearance, such as symmetry of the breasts and visibility of scar tissue, and the importance of realistically creating and adjusting them by medical professionals (Denford et al. 2011; Holtzmann and Timm 2005; Spector et al. 2010). As such, this literature seems to assume that this is the only aspect of these women's existence we need to address in preparing women for their reconstructive experience. Indeed, in this study, the most prominent and well-articulated expectations by the participating women are about normality and appearance. Such expectations seem to draw on larger sociocultural, normative frameworks that women should look normal, feminine and sexy. Nevertheless, many interviewed women expect to still look scarred and deviant after reconstruction. Even more, in line with the very few health science studies that address other bodily expectations than only gazed ones (see Snell et al. 2010), our results show that women's expectations often implicate the whole range of their bodily existence. These women have expectations about the practicality, capability, and feeling of their reconstructed breast(s) and body. Therefore, reconstruction cannot be understood as merely a gazed practice. As such, appearance is not the only aspect of women's embodied existence we need to address within the process of reconstruction. Building on Snell et al. (2010) recommendation, preoperative consultation may be improved by providing women with information about what they may or may not expect regarding their capable, practical, and felt body, along with information regarding their gazed body.

\section{Re-constructing past and future}

The range of these women's expectations about reconstruction demonstrate that they do not simply expect a re-construction. Counter to Lorde's (1980) fear that the recon- 
structive practice merely signals an expectation to return to a breasted past - something that will never be realized according to her -, these women's stories also indicate expectations of other futures. As we have seen, some women imagine and expect - however difficult it may be - a future with scarred, insensitive breasts and a body in recovery, something they did not experience before. These kind of expectations adhere to Ricoeur's (1992) argued triadic temporal structure of expectations. Within our present expectations about a future that is believed to occur, he argues, we refer to our past by slightly and gradually modifying those experiences just had. Although this may be the case for many women, this study shows that some of them, nevertheless, try to relate to an experience that is radically different from at least their own past experiences.

Moreover, the women that do expect some kind of return to their past, anticipate a future that is far more complex than what Lorde seems to assume: simply having breasts again. These women's expectations of a normally looking, practical, capable, painless, sensitive, silent, warm, and soft breasted body - indeed, just like they had before - can be interpreted as an expectation of a body that does not require constant care, attention, and devotion. This kind of expectation involves a rather implicit bodily experience: an experience of their body that retreats in the background and does not obstruct daily life; an experience of their body that is "absent" rather than present (Leder 1990). Here, Ricoeur's (1992) triadic temporal structure of expecting something takes on a specific temporal appearance. These women's present expectations about their future reconstructed body contain references to an implicit past experience - the body being absent - that only becomes a remembered, explicit experience in the present, while this experience is no longer actual. It seems, then, that their past, implicit absent - bodily experience only becomes recognized as an experience in the first place in the present, when their body is explicitly present (i.e., not-absent) in all its hardness, numbness, painfulness, or noisiness. This means that these women's expectations based upon their past, absent bodily experience, can only be configured in the context of their present - in both meanings of the word - bodily experience.

\section{Actively expecting the surprise of a breast reconstruction}

In contrast to what its etymology may suggest, having expectations in the context of a breast reconstruction is not a matter of awaiting. Rather, it involves many activities. The health science literature on expecting a breast reconstruction often places the work involved on the side of the medical professionals: they are responsible for the creation and adjustment of realistic expectations and for living up to them through performing medical procedures. Meanwhile, women who are candidates for the procedure are assumed to be passive: they wait to see whether their externally imposed, preferably realistic expectations come to pass (Denford et al. 2011; Holtzmann and Timm 2005; Snell et al. 2010; Spector et al. 2010). 
The women in this study, however, pursue various activities in their reconstructive process - often in relation to other people such as partners, friends, family and not the least: medical professionals. First of all, women deploy several strategies to imagine possible futures and formulate their expectations. Second, by taking up an active role in letting their expectations come to pass, they try to achieve their expected future. Third, these women validate whether their expected future did, in fact, come to pass. Last, these women reconfigure their expectations in light of their past and present experiences and newly emerging futures. By pursuing these kinds of activities, the women in this study confirm what Hatt (1998) already argued: medical professionals are not the only ones who have expert knowledge about what to expect. Women also inform themselves about this issue. As such, they share in the responsibility for creating and adjusting their expectations and living up to them through taking up a whole array of expectational activities.

We suggest that this joint work of both medical professionals and women patients may be facilitated by medical professionals in various ways. This means, first of all, that in healthcare settings medical professionals may operate as providers of information: not only informing women about what they may expect in relation to various bodily experiences, but also introducing them to a range of expectational - imagining, formulating, achieving, validating and reconfiguring - activities. Second, in order to do justice to the expectational work both medical professionals and women put in, we argue that a so-called informational approach should be complemented with an interpretive/hermeneutic approach (Emanuel and Emanuel 1992). This interpretive approach explicates expectations and its related facts and values, and explores how they are constructed. As shown, women's expectations and their factual and moral grounds are very personal and dynamic: they differ per individual and bodily experience and over contexts and time periods. Moreover, expectations (or lack thereof) turn out to be often ambiguous, conflicting, very implicit or inchoate. As such, medical professionals can only give adequate information and prioritize and select certain (medical) procedures when women's expectations are drawn out. In their turn, the women can only negotiate and navigate this information and these expectational activities when their expectations and related motives are articulated and elucidated. Thereby, the medical professional may work throughout the reconstructive process with the reconstruction candidate to explicate and explore her ever-changing expectations. This joint interpretative effort may take the form of medical professionals asking women open-ended questions like "what is important in a breast reconstruction for you?", "why?", "what do you expect regarding your capability just after reconstruction?", "and after a year?", "can you imagine how your reconstructed breast will feel?". The resulting dialogue may not only allow medical professionals to tailor-make their consultation and medical approach, but may also help these women to tease out and understand their (lack of) expectations and how to use this insight in the reconstructive process. 
Despite the best efforts of both women and medical professionals, however, our results suggest that women will always be confronted with unexpected experiences and outcomes. That is, the eventual reconstructive experience never completely correlates with the initial expectation. Sometimes even, imagining and expecting a future reconstructed body appears to be very difficult to begin with. Having reconstructed breasts we may say with Dastur (2000) - always arrives, in some way and to a certain extent, by surprise. In reference to health science literature on expecting a breast reconstruction (Snell et al. 2010; Holtzmann and Timm 2005; Denford et al. 2011; Spector et al. 2010), it seems that these women attempt to formulate and reconfigure - by definition - unrealistic expectations and achieve and validate their - eventually always - unexpected future. Within this spectrum of unexpectedness, most women appear to be able to deal with the component of surprise by re-narrating their life stories. Some women's renarrating ability, however, is stretched beyond its limits. Then, contrary to a fairly limited conceptualization of expectational work put forward by the existing expectation literature (see Denford et al. 2011; Spector et al. 2010), having expectations and jointly adjusting and (re-)working on them cannot be understood as primarily geared towards realizing one's reconstruction expectations. Rather, having expectations inherently means to try to be open to being transformed by the surprising event that is a breast reconstruction (Dastur 2000).

Again, achieving this openness may be part of a joint effort of women-patients and medical professionals. Medical professionals may inform these women of the unexpectedness ahead by saying that reality will always be different than expected. Additionally, medical professionals may directly facilitate these women's narrative sense making practices. By employing an interpretive approach throughout the process of reconstruction, medical professionals allow these women to (re-)tell their stories in their own terms, thereby helping them to (re-)fit their past experiences and newly emerging possibilities into their present life narrative. In this way, the dynamic of having expectations becomes a truly cooperative enterprise that involves both (re-)working on a believed-to-actually-occur reconstructed future and making sense of the unavoidable surprise that is a breast reconstruction. 


\section{REFERENCES}

Bury, M. (1997). Health and illness in a changing society. London: Routledge.

Dastur, F. (2000). Phenomenology of the event: Waiting and surprise. Hypatia, 15(4), 178-189.

Davison, C., Davey-Smith, G., and Frankel, S. (1991). Lay epidemiology and the prevention paradox: The implications of coronary candidacy for health education. Sociology of Health \& IIIness, 13(1), 1-19.

Denford, S., Harcourt, D., Rubin, L., and Pusic, A. (2011). Understand normality: A qualitative analysis of breast cancer patients' concepts of normality after mastectomy and reconstructive surgery. Psycho-Oncology, 20(5), 553-558.

Emanuel, E. J., and Emanuel, L. L. (1992). Four models of the physician-patient relationship. The Journal of American Medical Association, 267(16), 2221-2226.

Gallagher, S. (1979). Suggestions towards a revision of Husserl's phenomenology of time-consciousness. Man and World, 12(4), 445-464.

Garfinkel, H. (1984). Studies in ethnomethodology. Cambridge: Polity Press.

Hatt, G. (1998). Uncertainty in medical decision-making. In: A. Petersen and C. Waddell (eds.), Health matters; a sociology of illness prevention and care, 223-239. Buckingham: Open University Press.

Heidegger, M. (1962). Being and time. Oxford: Basil Blackwell.

Heidegger, M. (1977). Vier Seminare. Frankfurt am Main: Klostermann.

Heraclitus (1987). Fragments: a text and translation with a commentary by T. M. Robinson. Toronto: University of Toronto Press.

Holtzmann, J. S., and Timm, H. (2005). The experiences of and the nursing care for breast cancer patients undergoing immediate breast reconstruction. European Journal of Cancer Care, 14(4), 310-318.

Husserl, E. (1952). Ideas pertaining to a pure phenomenology and to a phenomenological philosophy, Second book. (R. Rojcewicz and A. Schuwer, eds., trans. 1989). Dordrecht, Boston and London: Kluwer Academic Publishers.

Husserl, E. (1960). Cartesian meditations: an introduction to phenomenology. The Hague: Martinus Nijhoff.

Integraal Kanker Centrum Nederland (IKNL) (2012). Mammacarcinoom, landelijke richtlijn [Translation title: Mammacarcinoom, national guideline]. www.nvpc.nl Accessed 10 Oct 2014.

Iversen, M. D., Daltroy, L. H., Fossel, A. H. and Katz, J. N. (1998). The prognostic importance of patient preoperative expectations of surgery for lumbar spinal stenosis. Patient Education and Counseling, 34(2), 169-178.

Jagsi, R., Jiang, J., Momoh, A. O., Alderman, A., Giordano, S. H., Buchholz, T. A. and Smith, B.D. (2014). Trends and variation in use of breast reconstruction in patients with breast cancer undergoing mastectomy in the United States. Journal of Clinical Oncology, 32(9), 919-926.

Leder, D. (1990). The absent body. Chicago: University of Chicago Press.

Lindemann, G. (1997). The body of gender difference. In: K. Davis (ed.), Embodied practices: Feminist perspectives on the body, 73-92. London: Sage Publications Ltd.

Lindemann, G. (2005). The analysis of the borders of the social world: A challenge for sociological theory. Journal for the Theory of Social Behaviour, 35(1), 69-98.

Lorde, A. (1980). The cancer journals. London: Sheba Feminist Publishers.

Losken, A., Burke, R., Elliott, L. F., and Carlson, G. W. (2005). Infonomics and breast reconstruction: Are patients using the internet? Annals of Plastic Surgery, 54(3), 247-250.

Luhmann, N. (2014). A sociological theory of law. New York: Routledge.

Merleau-Ponty, M. (1945). Phenomenology of perception (C. Smith, trans. 1962). London and New York: Routledge.

Merleau-Ponty, M. (1961). Eye and mind. In: Johnson, G. A., and Smith, M. B. (eds.) (1993). The Merleau-Ponty aesthetics reader: Philosophy and painting. Evanston: Northwestern University Press, 121-149.

Murray, S. J. and Holmes, D. (2014). Interpretative phenomenological analysis (IPA) and the ethics of body and place: Critical methodological reflections. Human Studies, 37(1), 15-30.

Ricoeur, P. (1992). Oneself as another. Trans. Kathleen Blamey. Chicago: University of Chicago Press. 


\section{CHAPTER 5}

Serletti, J. M., Fosnot, J., Nelson, J. A., Disa, J. J., and Bucky, L. P. (2011). Breast reconstruction after breast cancer. Plastic and Reconstructive Surgery, 127(6), 124-135.

Smith, J. A., Flowers, P., and Larkin, M. (2009). Interpretative phenomenological analysis. Theory, method and research. London: Sage.

Snell, L., McCarthy, C., Klassen, A., Cano, S., Rubin, L., Hurley, K. and Pusic, A. (2010). Clarifying the expectations of patients undergoing implant breast reconstruction: a qualitative study. Plastic and Reconstructive Surgery, 126(6), 1825-1830.

Spector, D., Mayer, D. K., Knafl, K., and Pusic, A. (2010). Not what I expected: Informational needs of women undergoing breast surgery. Plastic Surgery Nursing, 30(2), 70-74.

Steinbock, A.J. (2006). Time, otherness, and possibility in the experience of hope. In P. Vandevelde (Ed.), Issues in Interpretation Theory (pp. 271-289). Milwaukee: Marquette University Press.

Ucok, O. (2005). The meaning of appearance in surviving breast cancer. Human Studies, 28, 291-316.

Wiles, R., Cott, C., and Gibson, B. E. (2008). Hope, expectations and recovery from illness: A narrative synthesis of qualitative research. Journal of Advanced Nursing, 64(6), 564-573. 


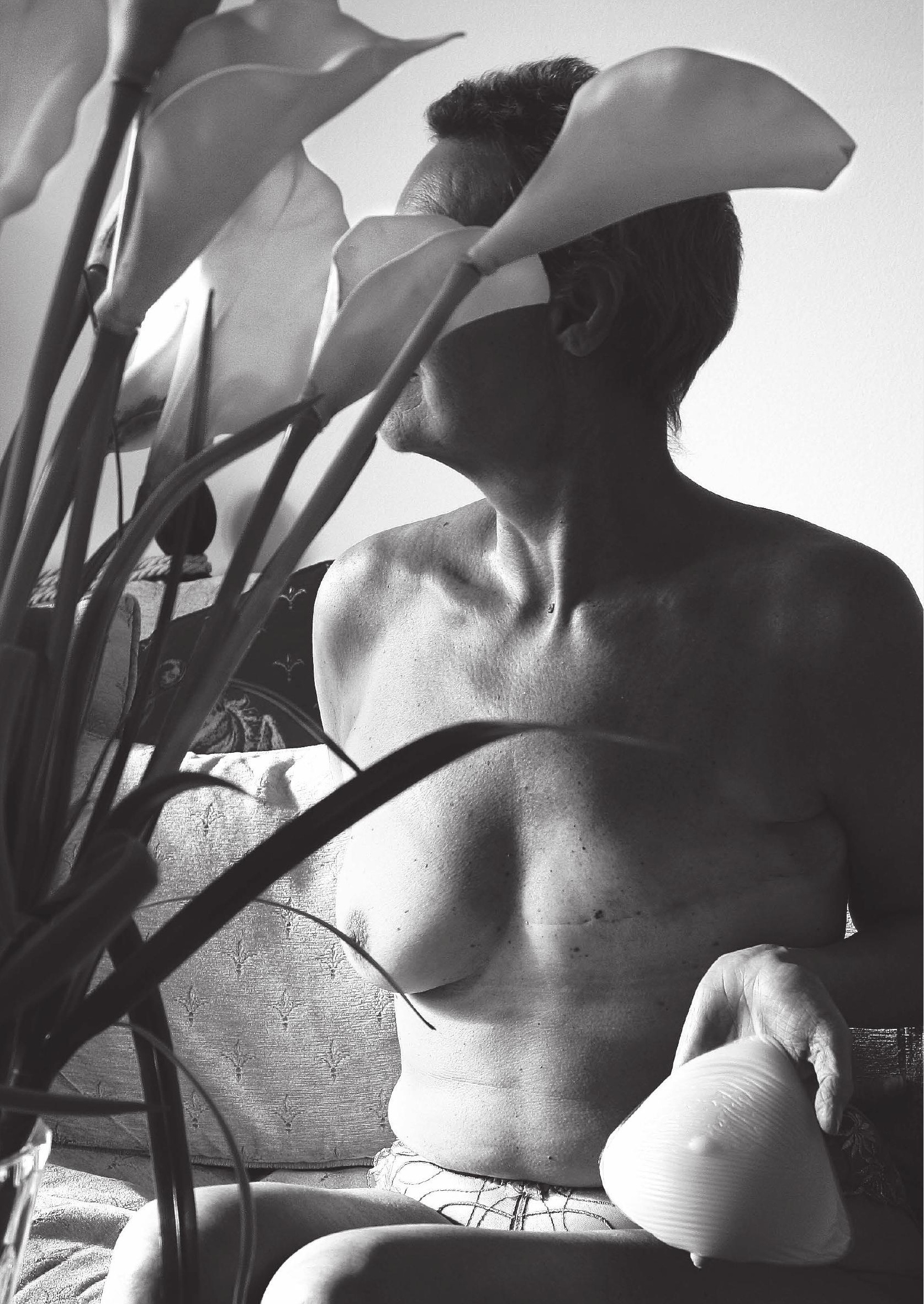


CHAPTER

\section{Discussion}

Extending the understanding of embodiment in breast cancer 

At the end of this study, I like to return to the story of Pamela, which I used at the beginning of my introductory chapter. Years after being medically cured from her breast cancer, this disease continues to be a central theme in Pamela's life: it severely influences the ways she experiences, deals with and makes sense of herself and her body. Since her mastectomy, she always wears breast prostheses and she does not even allow her husband to see her without them. For Pamela, wearing these artifacts is a paradoxical practice: it confronts her with the distressing fact that she lost her own, 'natural' breasts, but not wearing them would be even more painful in that it would leave her feeling naked and less feminine.

Pamela's illness narrative discloses the ambiguity of her experience of embodied life after breast cancer, and how this is co-determined by her relations to others and objects, notably, in this case, prosthetic artifacts and an intimate partner. Although her story is obviously very personal and unique, similar themes and concerns recur in the narratives of other women I have studied to learn more about their breast cancer experiences and the ways in which they make sense of them. My study shows that women's embodied illness experiences and sense-making processes are multifaceted, and arise and take shape in relation to the world and the different contexts in which they live. In this last chapter, I first present my main findings (sections 6.1 and 6.2). Subsequently, I reflect on the methodology I adopted and on how this approach has a bearing on the quality of the results and on respondents' lives (section 6.3). Finally, I sketch out this study's theoretical and practical value and discuss lessons that can be learnt from its findings (sections 6.4 and 6.5).

\subsection{MULTIPLE EMBODIED EXTENSIONS}

In starting from the general question as to how women experience and make sense of their lives and bodies in the context of breast cancer, I am inspired by a phenomenological perspective to embodiment. Phenomenologists emphasize that we live as embodied beings in a state of openness to the world we inhabit (De Beauvoir 1949; Heidegger 1962; Merleau-Ponty 1945; Nancy 2000). Given the fact that being embodied means that we are inescapably situated within a particular time and place, as well as in relation to certain objects, discourses, norms and other people, phenomenologists contend that the way we experience ourselves and our bodies takes shape within and through our engagements in that world. Recently, moreover, scholars working within and outside of the phenomenological tradition have argued that in illness, disfigurement and disability this existential condition of extended embodiment takes on specific shapes and characteristics (Svenaeus 2000; Shildrick 2012). For instance, being ill, disfigured or disabled implicates interactions with - and even incorporations of - unfamiliar medical devices (Dalibert 2015; Ihde 1990; Verbeek 2010); it entails running up against gendered norms governing the way we understand health, intactness and beauty (Slatman 2014; Young 
2005; Zeiler 2013), or it implicates increased dependency on our immediate social environment (Kayser et al. 2007). Illness experiences, then, can be seen as a particular example of the phenomenological idea of extended embodiment. It is this theoretical background against which the specific question guiding my study presented itself: how are women's embodied breast cancer experiences and sense-making processes shaped within and through the various contexts in which they live?

By collecting, describing and interpreting women's breast cancer stories, I identified four specific ways in which such extended embodiment presents itself: (1) in relation to employed medical technologies and prosthetic artifacts, (2) within and through women's narratives on their personal weblogs, (3) in relation to their intimate partners, and (4), within and through the temporal horizon of their past, present and future expectations of having a breast reconstruction. Surely, my discussion of these four manifestations does not comprise the extensive meaning of extended embodiment in breast cancer. My selection of these specific extensions was instead motivated by their prevalence in the empirical materials I collected, by the fact that each of these extensions refer to a larger thematic bodily extension - material, narrative, social and temporal extensions - and by the fact that these extensions are widely debated in the literature on disfiguring, disabling and illness experiences, which allowed me to reflect on and contribute to these discussions. This means that although this study is organized around separate discussions on particular extensions, taken together the various chapters provide insight into what it means to live as extended embodied beings not only as regards to breast cancer, but also in other situations of illness, disfigurement and disability.

\section{Material extensions}

Within philosophy of technology (Dalibert 2015; Ihde 1990; Verbeek 2010) and Science and Technology Studies (STS) (Akrich 1992; Latour 1994; Oudshoorn 2015), the concept of 'extended embodiment' is typically understood as 'materially and functionally extended'. This research explores how human beings, in their encounters with their environment and while being engaged in all kinds of projects and actions, extend their bodies by using various tools and devices. Chapter 2 addresses this established tradition of materially extended embodiment by analyzing how women's bodily experiences are shaped in relation to the various breast cancer technologies and artifacts they encounter, use and physically incorporate. Within this analysis, however, it was my aim to broaden the focus of the dominant approach toward the investigation of such material extendedness. In the literature, under the heading of the so-called 'material turn', it is argued that rather than analyzing human beings, a turn to exploring what things (can) do with and to us will offer a deeper understanding of how people exist - experience, perceive, act - in the world (Verbeek 2010). As such, and while extensive work has been done on the agency of artifacts and how these objects affect users' experiences (Ihde 1990; 2002; Verbeek 2006), the agency of users has largely been taken for granted 
(Dalibert 2015; van Dijck 2009; Oudshoorn 2015). By mobilizing the phenomenological concept of agency as people's embodied capacities to act in the world - their 'I can/not' - it became possible to foreground and investigate the significance of users' agency in human-technology relations (Ahmed 2006; Merleau-Ponty 1945; Young 2005).

Based on the analysis of my interviews with women, I have explored the modes and limits of their embodied agencies as they engaged - and still engage - with various breast cancer technologies and artifacts: a mammography machine, bras, breast prostheses, wigs and breast implants. In every encounter with such a material artifact, different kinds of capacities to act are at stake and different scopes of (possible) action are constituted, often in ambiguous ways. In interacting with a mammography machine, for instance, a woman's capacity to act is actually physically inhibited, temporarily, while this procedure also has an empowering effect because the resulting mammogram enables her to take (future) action toward preventing a possible disastrous future illness. Another example involves the external breast prosthesis, which requires constant pulling down, thereby inhibiting the wearer's ways of going around, especially in public. For her, getting an implant reconstruction is a valid alternative in that potentially it allows her to be less engaged with her appearance and thus to move around with more ease.

This analysis of the shaping of material agency draws attention to the significance of women's cultural environment. The ways in which they interact with technologies and artifacts is co-determined by built-in norms in the design and method of using such objects, norms that govern what it means to be and look healthy and normal. My study revealed, furthermore, that this cultural/material agency shaping is not characterized by a one-way conditioning of women's capacity to act by the artifact involved. Women also actively adjust their bodies in relation to these objects: in order to make the mammography experience more comfortable, for instance, a woman may massage her breasts beforehand. In addition, women also alter and personalize the artifacts themselves: for example, a woman colors her breast prosthesis so that it matches her skin color, which enables her to feel comfortable showing décolletage. By taking action and tinkering with (themselves in) their material context, the materials or artifacts co-determine the women using them, but the women also affirm their capacity to act and even influence and appropriate their scope of action.

As philosophy of technology and STS research mainly depart from the constitutive power of the material world in human existence, these studies merely descry a one-way conditioning of materialities influencing and co-determining human perceptions and actions (Ihde 1990; 2002; Verbeek 2006). In starting from a subjective perspective, while also acknowledging the constitutive power of the material context, I offer insight into a reciprocal dynamic of material agency-shaping. Women's embodied experiences and their possibilities to act in breast cancer are indeed constituted by objects, but they also appropriate their (positioning in their) material context, and thereby constitute their own extended experiences. There is a need, in my view, for one more turn after the 'material turn' (Verbeek 2006): we also should take into account the human side of 
the materialization of human agencies. By carefully considering this reciprocal dynamic of the materialization of people's agency, we can gain a deeper understanding of people's perceptions and experiences, and, accordingly, learn more about who they are.

\section{Narrative extensions}

In addition to their material environment, human beings also extend to their narrative context. Hermeneutical scholars contend that in creating and telling stories, people not only represent their experiences, but also re-interpret and make sense of them (Ricoeur 1991). Human beings are, in this sense, inherently narrative: as story-telling creatures, they define themselves within and through their stories. By taking this argument as a starting point in chapter 3, I explored women's extended embodiment to their breast cancer narratives. While my general aim was to investigate how women describe and give meaning to their breast cancerous lives and bodies in the narratives they create, I specifically focused on women's stories on their personal weblogs. This particular take is guided by feminists who, from the 1990s onward, suggested that the features of online narrations, and especially of weblogs, open up possibilities for emancipatory sense making processes of selves and bodies (Heilferty 2009; Page 2008; Poster 1995; Turkle 1995; Wilding 1998). Weblogging is a multi-media, self-designed, interactive genre that offers the possibility to continuous narrative adjustments. Because people give meaning to themselves in their narrations through readily incorporating or extruding larger cultural discourses, as argued by Internet feminists, the specific genre of weblogging facilitates the formation of critical narrative spaces that enable dialog with and resistance toward the - often - prescriptive aspects of mainstream discourses (Plant 2000; Sundén 2001). This critical space would allow for the creation of and adherence to new and alternative cultural discourses and thus for a wider range of self-definitions. Departing from this assertion, the chapter's specific aim is to understand how the genre of blogging influences and co-determines women's breast cancer experiences and sensemaking processes.

By sampling weblogs of women with breast cancer and by following these blogs for over a year, I collected thousands of pages of breast cancer narrations and captured changes and additions made in them by their authors. In these blogs, I identified four 'dramatis persona' or ways in which women define themselves as women who have (had) breast cancer: The Estranged Cancer Patient, The Transient, The Heroic Survivor, and The Disfigured Woman/Girl. For most women-bloggers, the progression of these self-narrations involves a particular temporal process of sense-making. As The Cancer Patient, these women narrate the embodied chaos that comes with having breast cancer. Through The Transient they make themselves ready to move on to The Heroic Survivor, in which they position themselves as actively fighting and conquering the disease. At the same time, they explicitly re-appropriate their feminine identity in The Woman/Girl. As I argued, this narrated quest echoes conventional and culturally preferred 
norms of appearance and gender (Young 2005), and of overcoming one's illness and the chaos and deviancy that comes with it (Frank 1995) - a finding that does not sit well with the abovementioned claims about the liberating potential of online narrative spaces. However, I also indicated that such norms may be distressing and harmful for women whose experiences cannot be organized within this narrative timeline. Therefore, some bloggers resist these dominant norms and/or adhere to alternative ones. For example, in re-appropriating themselves and their bodies toward healthiness and femininity, women narrate lingering senses of estrangement and disfigurement. Or in narrating their quest to survive, some women tell they (will) fail in doing so. It seems that blogs do not only reiterate dominant cultural norms, but also offer some potential for resistance and diversity. This ambiguous process of sense-making is co-determined by the specificity of weblogs as a medium. In general, women constantly add and re-write their narrations in progressing from one online persona to the next. More specifically, they include audio-visual material on their weblogs to define their (stereotypical) feminine identity, or they feel encouraged by online interactions with peers to utter their continuing chaotic illness stories.

In affirming that online narrating possibilities significantly shape the ways in which people experience and make sense of themselves and their bodies, this study tempers the emancipatory optimism of the Internet feminists of the 1990s (Poster 1995; Turkle 1995; Wilding 1998). Blogged narrations indeed enable women to resist and substitute prevailing cultural norms about breast cancer. These norms dictate a return to a healthy life with an unmarked, feminine body, in other words, an embodied life that passes as normal. Women's blogs, however, also tend to be interspersed with efforts to establish such an everyday embodied life. As such, online narrations are not to be understood as a utopia of free selves and free bodies, that is, of self-definitions separated from (offline) imperative cultural structures. Rather, by repelling, supplanting, affirming, or embracing mainstream norms, women's self-narrations are positioned in and shaped by these structures.

\section{Social extensions}

Increasingly, cancer is understood as a so-called 'we-disease' (Kayser et al. 2007), that is, a disease that affects both patients' and their partners' experiences (Ussher et al. 2011). Research on this aspect of illness experiences predominantly deals with the effects of cancer on the emotional well-being and behavior of the two partners (Hodges et al. 2005; Gilbert et al. 2010; Manne et al. 2004). In chapter 4, I took up this idea that cancer is an intersubjective experience. In doing so, however, I went beyond the psychological perspective in the literature by exploring how breast cancer may be understood as an embodied 'we-experience' by couples. By drawing on the philosophy of Nancy (2000), I approached such relationality and extendedness to one's partner as 'sharing' bodily experiences. 
Through analyzing duo-interviews with diagnosed women and their partners, I distinguished four ways of sharing an embodied life in breast cancer. First, in what I call 'being different together', partners have different kinds of breast cancerous experiences. These differences are due to partners' different bodies - only the woman, after all, physically undergoes the treatment - and to their different emotional and coping responses to bodily changes that come with having breast cancer. In the latter case, for example, the (male) partner is not able to talk about such changes, while the woman feels the need to discuss these changes with the other in order to cope with it. Although partners' experiences are different, they do not develop in isolation of each other. Partners relate to the other's divergent experiences: some couples (try to) understand and respect each other's dissimilarities, while others reluctantly try to find common ground. Second, in 'being there for you', I described how partners take care of each other in the process and aftermath of treatment. This kind of caretaking typically entails that ill women allow their partners to support them in their daily care and assist their partners as they do so. In this way, these women enable their partners to contribute to their recovery. Such reciprocal care routines are characterized by negotiations of when, how and where the caring takes place, negotiations in which partners carefully navigate between either being too independent from or too dependent on each other. Third, in 'being reconnected to you' I accounted for the fact that breast cancer is an illness that often drastically alters the body, and I discussed how partners relate to the woman's changed post-treatment body. While not all of the couples in my pool succeed in doing so, all partners try to re-acquaint themselves with each other through embodied routines like looking at her new naked appearance or by re-familiarizing themselves with what feels nice to the sensual touch. Such practices are positioned and conditioned by a shared cultural environment: what appears to be un/acceptable and un/comfortable is co-determined by prescriptive norms of appropriate femininity and sexuality. Finally, in 'being like you', I concentrated on how couples try to synchronize their lives and bodies throughout the breast cancer trajectory. These harmonizing efforts may entail sharing the daily rhythm of treatments, hospitals visits and daily care; getting a similar tattoo as a shared rite of passage toward overcoming breast cancer; or even sharing the physical inability to walk long distances in the aftermath of breast cancer treatment. In each of these different approaches to sharing the fate of breast cancer, partners may critically reflect on their communal lives and bodies, and even (try to) resist to sharing such an embodied life. This is why such efforts will always involve some element of negotiation in which the limits of sharing are delineated.

My analysis of these relational encounters in breast cancer has revealed that the concept of 'we-disease' (Kayser et al. 2007) extends to the dimension of embodied illness experiences. Partners tend to 'share' such experiences. In various ways and to varying degrees, the breast cancer experiences of couples in my sample were thoroughly influenced by their bodily modes of acting and interacting with each other. As my interviews established, the partners (verbally) relate to their different illness experiences, they take 
care of each other during treatment and in its aftermath, they reacquaint themselves with her changed body again, or they synchronize their daily, embodied lives. In these encounters, sharing is revealed to be a constitutive dimension of what it means for couples to live with/through breast cancer, and not as an optional extra that partners may or may not engage in. Although sharing, in this sense, is an existential condition, it does not come naturally. For all the couples in my sample, sharing involved complex affective and/or bodily encounters, whereby the fault lines that both separate partners into individual selves and join them together as a mutually reliant unity are continuously and actively debated and negotiated. Sharing the experience of breast cancer, in other words, requires a communal balancing effort of being and staying independent against the backdrop of situated - in this case, social and embodied - dependencies.

\section{Temporal extensions}

In the above-discussed chapters, I predominantly focused on manifestations of material, narrative and social embodied extendedness in breast cancer. However, these chapters also highlighted - albeit by implication - women's extendedness to their lived temporality. This pertains to several aspects: interactions with objects revolve around women's future im/possibilities to act; blogged narratives and self-definitions evolve over time; and the ways in which couples share their experiences with each other is constantly negotiated and therefore subject to change. In chapter 5, I explicitly attended to the significance of women's lived temporal dimensions for their embodied breast cancer experiences. More specifically, I explored how such experiences and sense-making processes take shape within and through women's expectations about their breast reconstruction. As this kind of surgical intervention is generally considered to be a major lifeand body changing event, the importance of exploring subjective expectations about reconstructive options is widely acknowledged in the literature (Denford et al. 2011; Snell et al. 2010; Spector et al. 2010). Most research on this topic discusses whether expectations anticipate an outcome that is likely to occur (Wiles et al. 2008). As it is assumed that these so-called 'realistic' - as opposed to 'unrealistic' - expectations prevent disappointment and being disillusioned in the treatment's aftermath and thus contribute to a person's well-being, they are explicitly preferred (Iversen et al. 1998). Accordingly, many studies offer suggestions for encouraging this kind of expectations in women (Denford et al. 2011; Snell et al. 2010; Spector et al. 2010). Rather than merely investigating whether women's expectations are realistic or not, I explored in this chapter what having expectations about reconstructive surgery - or a lack thereof - actually means in the first place. Departing from the existential notion that we, as human beings, not only live in the present, but also within and through our past (i.e., our memories) and our future (i.e., our wishes, hopes and expectations), I framed such expectations as ways in which we try to fill in and anticipate our future and thereby give meaning to our inherently temporal lives and bodies (Dastur 2000; Husserl 1960; Steinbock 2006). 
By documenting and analyzing the development of breast reconstruction stories of several women over time, I argued that women's expectations before their breast reconstruction predominantly concern three distinct aspects of their embodiment: their gazed, capable and felt body. Most of these women's expectations revolve around an anticipated return to normal embodiment prior to their breast removal. They thus expect their reconstruction to reconstitute their appearance as a feminine and sexy woman; to rehabilitate their able body; and/or to restore the breast's sensitivity and natural 'feel'. At the same time, some women also express expectations or, rather, worries, about their continuing deviant appearance, or about enduring unnatural sensations, while others prove to have difficulties formulating their expectations all together as they cannot imagine their future reconstructed body. Furthermore, as my argument demonstrated, women try to reconfigure their expectations in multiple ways after reconstruction, while life unfolds itself and new im/possible futures emerge. Some women come to expect more, or expect less from the procedure over time. Others shift their focus to entirely different kinds of expectations. And others retrospectively re-formulate their initial expectations. By formulating and reformulating their expectations, I argue, these women in fact continuously strive to align their lived past and living present with (imagined) futures they foresee. These shifting future expectations thus form part of these women's current life stories, stories through which they try to make sense of their ill/healthy and un/marked past, present and future body (Ricoeur 1992). Finally, in some cases - i.e. a strangely felt reconstructed breast, or a failed reconstruction - women are overwhelmed by their reconstructive experiences to such a degree that they are unable to reconfigure their expectations. This seriously hampers their capacity to both give meaning to their present embodied state and make sense of their future.

The development of the expectations as articulated by the interviewees should be understood as part of an active and continuous (re)configuration of the stories through which people make sense of their past, present and future body. That is, in formulating and re-formulating expectations, women set themselves the difficult, and sometimes impossible task of filling in and anticipating that which by definition is still unreal, unknown and always - to a certain extent - a surprise: their future. Difficult as it may be, this kind of temporal extendedness is crucial for women undergoing a reconstructive trajectory. Without the ability to (re)formulate expectations, after all, women cannot make sense of their temporal lived selves and bodies. As such, I suggest that, instead of focusing on encouraging 'realistic' expectations of likely futures (Denford et al. 2011; Snell et al. 2010; Spector et al. 2010), we take one step back and help these women with (re)configuring their expectations. Specific recommendations as to how healthcare professionals can harness the productive dynamic of women's expectations are relevant here. Rather than (immediately) prescribing what these women's expectations should entail in terms of the likelihood of their outcomes, such professionals may help these women to voice their (expectations in their) breast cancer stories and thus assist them in making sense of their unfolding experiences in their narrations. 


\subsection{UNDERSTANDING EXTENDED EMBODIMENT IN BREAST CANCER}

In this thesis I have developed a perspective on four specific manifestations of how women's bodily experiences and sense-making processes in breast cancer are extended to the contexts in which they live. This has revealed three general structures of what extended embodiment in breast cancer means.

The first, most evident common denominator is that women's embodied experiences encompass specific appearances of multiple bodily aspects in each of these material, narrative, social and temporal contexts. For example, in publicly sharing their stories on their multi-media personal weblogs, women frequently prove to refer to the visual, gendered aspects of their body by posting stereotypical feminine pictures or symbols. In using technologies and wearing artifacts, furthermore, women's capacity to act is revealed to be at stake, which, in turn, may be in line with how these women assume others to see them with their devices and artifacts. A basic concern in relation to intimate partners, technologies and artifacts, and expectations surrounding a breast reconstruction pertains to various sensorial dimensions: not only visual and capable bodily aspects but also ones associated with touch, hearing and smelling. Some women, for instance, occasionally talked about sensory feelings and tactility in relation to being intimate with their partners, or in relation to imagining their future with a reconstructed breast. One woman hesitantly elaborated on the shameful experience of her breast prosthesis making noises in public, while another woman reluctantly provided details about the unpleasant scent of the necrobiosis of the reconstructed tissue on her chest. These findings underscore that every individual context comes with its own, more or less prominent bodily aspects. The various modes and manifestations of bodily aspects will differ from one lived situation to the next, and in each individual case they may also change over time.

Second, my study lays bare the mechanism through which these women's breast cancer experiences and sense-making processes are extended to their lived contexts. On the one hand, these women's experiences are constituted and shaped by the contexts in which they are engaged. The design of an artifact, the given possibilities of the medium of weblogging, the structure of women's intimate relationships, and their unfolded past, living present, and unfolding future all influence and condition women's breast cancer experiences and the interrelated sense-making processes. On the other hand, these women also actively position themselves in their lived contexts and even (re-)shape these contexts. They do so by molding their bodies in relation to the objects they interact with or by altering these materialities themselves, by re-writing their online stories and by positioning themselves in relation to larger normative structures in these narrations, by negotiating the ways in which they interact with their partners, or by reconfiguring their expectations in the light of their current and past experiences. Here, the co-constitutive mechanism between women and their lived contexts is revealed. Women are not only passively extended to their contexts, but they also co- 
determine how their contextualized breast cancer experiences arise and shape up. In other words: they are actively involved in the ways in which they are extended.

Finally, my study discloses that for many women, giving meaning to bodily experiences within and through their lived contexts involves endeavors to be normal. These women try to conform to or not deviate from a generalized notion of what is standard or common in everyday life, something they often (to some extent) embodied before their breast cancer. For example, they try to pass as normally breasted women by wearing a breast prosthesis, they narrate their lives online as a journey toward returning to a healthy life or as a way to reconstitute their femininity, or they formulate expectations about having a capable body again in the process of breast reconstruction. Apparently, giving meaning to a breast-cancerous body often involves an effort to (re)turn to a healthy life and an unblemished body within and through employed objects, interactions with others, creating narratives and imagining futures. Such attempts to (re)live a (former) normal condition cannot be seen apart from a larger prescriptive cultural context (Frank 1995). The operative idea of the norm in contemporary Western societies, as pointed out by Davis (1995), not only helps to empirically divide people with normal bodies from those with non-normal bodies, but also assists attempts at (justifying) normalizing the non-normal and thus to diminish deviations from the normal. Here, a normal and common life and body has come to be seen as the preferred option to pursue. ${ }^{15}$ The desire of women to overcome their illness, including the disfigurements and defects that come with it, may be understood as a cultural imperative. This lived hegemony of the normal, however, seems to be at odds with the actual situation in which these women find themselves. All the women I interviewed testified that their sense of illness, chaos and deviancy continue to linger to a various extent and at various times. Their contextualized sense-making efforts and their aspiration to be normal may thus be paradoxically understood as (re)living up to the ideal of the common standard. Their attempts to be normal (again) were marked by their efforts to give meaning to and to integrate their chaotic and deviant experiences as a part of a more normal life. For example, couples re-acquaint themselves with her altered body, or blogging women connect with communities of fellow survivors in which having a breast-cancerous, marked body represents the normal situation. Other women fail to succeed in finding some sense of being normal in their chaotic experiences, possibly because they have trouble to make sense of these experiences to begin with. They may be left, for instance, with the reality of wearing breast prostheses that constantly remind them about the painful fact of having lost their own breasts, or they may be unable to narrate their fear of

\footnotetext{
${ }^{15}$ Note that attempts to justify the normalization of the non-normal has a long (disreputable) history in, among others, statistical eugenics, in which 'normal' has come to be seen as good or virtuous. This ideal should not be confused with Aristotle's idea of the virtuous mean. The mean, for Aristotle, is a heuristic device to assist in moral and ethical choices, in the sense that one should choose between two extremes. In his thinking, finding this middle way is a fictional construct and extremely hard to attain. As such, people generally do not fall into that mean (Davis 1995).
} 
dying on their weblogs; or, in the process of a breast reconstruction, they may be confronted with overwhelming and paralyzing experiences. As such, these women's contextualized sense-making processes do not merely represent an aspired journey of a culturally prescribed (re)turn to a normal everyday life, but may also be understood as a bumpy ride in which women with more or less success struggle to accommodate, normalize and give meaning to their new, chaotic life and marked body.

\subsection{COLLECTING AND ANALYZING BREAST CANCER STORIES: A REFLECTION}

While there are many ways to research women's contextualized illness experiences, I have adopted a qualitative, longitudinal phenomenological-narrative approach. Bearing in mind the distinctive features of this approach, the above-presented findings and conclusions about women's breast cancer experiences should be considered in light of my particular methodological take.

By reviewing the characteristics and development of women's stories as expressed in interviews or as uttered on their personal weblogs, I gained insight into how women not only describe and represent their breast cancer experiences, but also continuously (re)interpret and make sense of them (Ricoeur 1981). Moreover, because some scholars have argued that some (illness) experiences are not or cannot be expressed in spoken or written words (Frank 2001; Ricoeur 1981; Van Manen 1990), I tried to keep an open mind as to the ways in which women narrate their breast cancer experiences. This allowed me to understand how such experiences are not only voiced or written down, but also non-verbally articulated through silences, supportive gestures and by referring to pictures and symbols (Finlay 2006; Poland and Pederson 1998). In reviewing the constitutive conditions of women's narrated experiences in their stories, I furthermore investigated how their illness experiences take shape in relation to their lived contexts (Ricoeur 1981). Finally, by incorporating discussions with larger theoretical frameworks and by involving self-reflections on my role as an researcher, I considered a wide range of possible, relevant interpretations of women's experiences. These interpretations, then, remain sensitive to the nuances and ambiguities of the expressed experiences, and of the interview- and blog-contexts in which they were articulated.

The above demonstrates that the approach developed in this study significantly contributes to the scope and quality of its results. However, is should also acknowledged that some aspects of the employed methodology may cut both ways: regarding (the quality of) the findings and conclusions, as well as regarding the potential impact on participants.

A first significant issue to consider here is my approach to sampling respondents and weblogs. In total, I draw on 38 interviews and 5 selected weblogs, which I distributed across four separate thematic studies on extended embodiment in breast cancer. In phenomenological research, an adequate sample size is not determined by the possible 
generalizability of the findings - which is often the case in quantitative research - but by data saturation (Sandelowski 1995). This implies that one should continue to develop the weblog- and interview studies and their analysis until new themes and issues do not present themselves any longer; this is considered to be the point of data saturation or redundancy. This 'fullness' or comprehensiveness of the findings should be considered in the light of both my own selection criteria and the possible bias in the pool of respondents and weblogs. In designing this study I was in part dependent on the interviewees who were able and willing to participate and on weblogs that popped up in a Google search of breast cancer blogs. In my case, data saturation also comprises the exclusion of potential participants and weblogs that I have omitted myself, based on criteria such as severe co-morbidity and not being fluent in English or Dutch in the interview studies. I also ignored weblogs that hardly covered any personal issues or that had fewer than twenty posts. As such, my findings can neither be understood as directly generalizable to all other women with breast cancer and their partners, nor as encompassing the complete range of possible breast cancer experiences. However, conclusions drawn from my analysis - grounded as it is in in-depth, comprehensive, detailed, contextualized, 'thick' descriptions of breast cancer experiences - should certainly be considered as having a bearing on examinations of other (kinds of) breast cancer stories, and even on other kinds of illness stories and stories of disfigurement and disability (Geertz 1973). In the last two sections of this chapter (sections 6.4 and 6.5), I will elaborate on this.

Another important aspect deserving reflection involves my operationalization of the concept 'narrative'. In adopting a rather broad understanding of breast cancer narratives, I not only semantically interpret words, but I also describe and analyze the meaning of silences and supportive gestures, and, in the case of the blogs, of posted pictures, used background colors and audio-visual materials. While involving these materials in the analysis provides a great variety of breast cancer experiences, it also requires me to consider and deal with the issue that non-verbal and non-written empirical material generally allows greater freedom of interpretation than words usually do (Poland and Pederson 1998; Yoram and Rafaeli 2011). Dealing with such a wide and, in my experience, rather diffuse range of possible relevant interpretations called for caution and a more conservative interpretative approach, that is, being careful not to read too much into particular data or even (initially) refraining from interpreting them all together, or to rely on cross-verifying or triangulating my interpretations with less ambiguous verbal and written - materials. An illustrative example can be found in my blog study. At some point, one of the bloggers started to put empty posts on her weblog. At first, I did not grasp the significance of these blank pages and assumed that she posted them by accident. Although I picked up on their semantic value after she repeated this kind of 'silence' multiple times, I still did not understand their precise meaning. Was it an act of resistance to her commentators who frequently use warrior terminology - something she abhors - or was it an inability to express herself? Eventually, this blogger retrospec- 
tively writes about her period of online silence, thereby allowing me to attribute a proper meaning to her blank pages. Silence, it turns out, was the only way for her to let her readers know that she was afraid to die.

A final issue to consider is the approach's (potential) impact on my respondents' lives. In the interview study, I offered my respondents an open, non-judgmental space for narrating their breast cancer experiences in their own terms, after which I asked followup questions. This approach has resulted in original and rich empirical material about breast cancer experiences: some of the respondents shared experiences that they have never shared with anyone, or elaborated on experiences they had never given much thought (or never thought they had). As is well-documented in the literature, however, this kind of approach may have profound repercussions for respondents' narratives and the ways in which they give meaning to their bodies and lives (England 1994; Engelsrud 2005). In my case, this becomes clear in that many interviews triggered strong emotional responses with the respondents, even up to a point that a woman dropped out of the study because the interviews were too much of a burden for her. In the study's set-up and design, then, I endorsed the importance of considering the potential harmful impact of my approach. Without claiming that all of such consequences can/should be foreseen and forestalled, I managed to recognize and anticipate some of them. During the recruitment phase, for example, I informed women and couples about the option to seek (free) emotional support with a social worker at the hospital where (most of) the interviews took place. After the interviews, in addition, I approached women by email or by phone in order to inquire about their possible follow-up questions, comments or suggestions. By taking precautions and by briefing and debriefing the women participating in this study, I aimed to act on - and maybe even obviate - possible harmful, emotional repercussions of the interview study. Such precautions also allowed participants to make suggestions for better acting on women's responses in the future.

\subsection{EXTENDING THEORETICAL UNDERSTANDINGS OF BREAST CANCER EXPERIENCES}

In investigating how women experience and make sense of their breast-cancerous bodies within and through the contexts in which they live, I have positioned myself in the midst of an extensive, multi-disciplinary field of embodiment research. In this section, I will briefly discuss this scholarly field and show how my study to extended embodiment both builds on and contributes to these studies.

Onco-psychological and cancer nursing studies predominantly focus on how women individually experience and deal with visual and/or functional outcomes of their breast cancer treatments (Baxter et al 2006; Gilbert et al. 2010). By way of using self-report body image scales (Leunissen et al. 2015), these studies show that women's visual appreciation and/or valuation of their capability decreases right after disfiguring medical 
interventions, such as radio- and chemotherapy, a mastectomy and lymph node removal (Carver et al. 1998; Sears et al. 2003). After adjuvant treatments, such as breast reconstruction, or through individual coping strategies, such as wearing breast prostheses or exercising, women's body image would generally increase (Hoving et al. 2009; Turner et al. 2004; Roberts et al. 2003).

Science and Technology Studies (STS) research and social scientific studies on embodiment complement this focus on individuality in body image studies by describing how women's experiences and dealings are formed within the contexts in which they live. This research shows, for instance, how norms pertaining to health and feminine embodiment influence women's experiences of their appearance (Crompvoets 2003; Lorde 1980), their capability (Young 2005), and their management of their bodies in public (Manderson 2011). Or, to give another example, such studies reveal how objects co-determine the ways in which women experience their breast cancer and act in the world (Kaufert 2000; Sandell 2008). Social scientific and STS approaches thus subscribe to a 'social model' in which the societal and material context, more than a person's individual bodily condition, is considered to produce experiences and dealings (Slatman et al. 2015; Oliver 1990).

In investigating women's breast cancer experiences and their constituting contexts, I have sought to hook up with both psychological/nursing and social scientific/STS lines of research, and I do so from a particular phenomenological perspective. Phenomenologists contend that besides from bodily experiences, sense-making is an important theme in illness. New and altered bodily experiences that often come with illness situations implicate possible disturbances of one's sense of self, life and body, thereby pointing to the necessity to develop new sense structures (Leder 1990; Svenaeus 2011; Zeiler 2010). Yet, in providing an analysis of sense-making by women with breast cancer and their various experiences in their lived contexts, I depart in a crucial way from the majority of phenomenological research. Similar to psychological studies, conventional phenomenological studies are predominantly committed to the first-person perspective, to what presents itself to a person, and to how this person makes sense of these experiences (Toombs 1993). The attention is generally on individuals disclosing, and making sense of their engagement in the world (De Beauvoir 1949; Merleau-Ponty 1945; Ricoeur 1992). At this point, I go one step further by following Slatman (2014) in assuming this first-person perspective is itself constituted and conditioned by the world it discloses. As such, my phenomenological study (re)engages with STS and the social sciences because it considers the actual engagement and contextual embedding of an individual in the world. Against the background of a phenomenological framework of extended embodiment and through a phenomenological-narrative inquiry into situated breast cancer stories, I combine a focus on women's lived bodily experiences and sensemaking processes with one on the various conditioning contexts in which these experiences and processes become manifest. 
Guided by this specific take, my study thus theoretically contributes to the field of embodiment research. In arguing for the importance of inquiring into constituting contexts in exploring first-person experiences and sense-making processes, my contribution is one to general theory development in phenomenology, that is, to a field of study that tends to focus on the individual in investigating structures of lived embodiment. Moreover, in accounting for various dimensions of embodiment usually addressed separately in the literature - i.e., lived experiences, sense-making structures and conditioning contexts - I provide a comprehensive understanding of what it means to live with and through breast cancer. Concretely, I reveal three structures of extended embodied experiences and sense-making in breast cancer, which, each in their own way, contribute to facets of embodiment research about breast cancer.

First of all, I disclose the multiple bodily aspects that play a role in breast cancer, and how experiencing and giving meaning to these aspects is co-constituted by the contexts in which they occur. Existing body image research about breast cancer typically attends to women's breast cancer experiences by using quantifiable tools to measure the valuation of their appearance and capability (Baxter et al. 2006; Gilbert et al. 2010; Manderson 2011). While such studies are very helpful in collecting big samples and providing generalizable outcomes, they can only handle univocal and pre-defined categorical information due to their external validity requirement. They therefore cannot account for the multifaceted and ambiguous ways in which one's body can be experienced and made sense of. Moreover, as such studies inquire into women's experiencing at a specific time and place, these experiences are decontextualized and separated from their temporal dimension and place within the world (Slatman 2011). In taking a phenomenological approach, I outline how women's experiencing and sense-making of their appearance and capability, but also of other bodily aspects, are to be understood as coconstituted within their relationships with objects, narrative structures, others and temporal dimensions. Similar to body image studies, I show that women's appearance and capability is a prominent and rather coherent experience in breast cancer. For example, interactions with medical devices and prosthetic objects have a significant in/capacitating dimension; visual possibilities on blogs allow for (re)creating a look online; the gazed/gazing body takes on a crucial place in interactions with others; and in imagining a future body, women often picture their new appearance and regained capability. Sensorial experiences associated with tactility, sensitivity, hearing and smell are less frequently and more obscurely uttered, predominantly in relation to (very) close (present and/or expected) encounters with medical technologies, prosthetic objects and other people. However, these occasional and hampering experiences, I argue, do not necessarily indicate a lack (of importance), as is perhaps too hastily presumed in some of the literature (Alfano 2006). Rather, such hesitation may point to struggles to narrate experiences and thus to make sense of them in lived contexts (Ricoeur 1981; 1991). Frank (2001) captures some aspects of this issue when he remarks that "suffering is the unspeakable" (355). Indeed, for some women, their inhibited sense-making is 
related to the traumatic impact of their experiences, for example, while being confronted with the unexpected, paralyzing experience triggered by the bad smell of necrobiosis. More generally, limited available discourses - i.e., a repertoire of narrations, terminology, images and symbols - about sensing, smelling or hearing experiences in various contexts leave women unable to narrate and make sense of their bodies. As such, I reveal that sporadic and hampering experiences - perhaps even more than dominant and coherent ones - point to their pressing relevance when considering women's lived meaning and contextualized sense-making processes.

Note that this conclusion is not only interesting in relation to research on bodily experiences in breast cancer, but also in the light of larger philosophical debates on the meaning of our senses in our experiences. In many philosophical analyses, the gaze and visuality play a rather dominant role over the other senses (Jay 1993). Such studies allege the superior capacity of vision to provide access to the world, or claim its pivotal complicity in (political and social) modalities of surveillance, discipline and control (see for example: Foucault 1979). By displaying the contextualized significance of both the gaze and a wider range of bodily aspects in women's breast cancer experiences, my study challenges a hierarchy of bodily senses which over-privileges vision (Braidotti 2011). Even more, when taking into account the issue of sense structures, bodily aspects like smell, tactility and feeling could be considered as having greater importance than visuality.

Second, in considering whether and how women experience and make sense of their body in breast cancer, I show that these women are both shaped by and shaping the contexts in which they live. Giving meaning to their experiencing is formed, afforded and made possible by those contexts. But women also alter (themselves in) contexts, and in doing so, they actively shape their illness experiences. In line with philosophical, ethical, and social theorists that lay bare the myth of autonomous bodily subjectivity (Butler 2006; Fineman 2005; Käll and Zeiler 2014; Turner 2006). I describe these women, and their experiencing and sense-making, as inherently open to their lived world. Such modes of thinking about this existential condition of extendedness predominantly emphasize particular aspects of embodied dependency: namely, the fragility and injurability of the impressionable material body (Butler 2006; Turner 2006), and our need for bodily care and carefulness in averting such potential harm (Fineman 2005). On the one hand, I agree with this kind of thinking in that our embodied extendedness indeed makes us vulnerable to harm: for example, when women's im/possibility to act is inhibited in being engaged with breast cancer technologies; or when women become too dependent on their partners. On the other hand, I demonstrate that embodied extendedness also involves aspects of independency and self-determination, and therefore of autonomy. In being grounded in conditioning contexts, women actively position themselves in their contexts and even adjust those contexts. Herein, their breast cancer experiences are still contextually constituted, but women also constitute themselves in these contexts. In this way, instead of assuming an antagonistic relationship between 
dependency and autonomy - or between fragility and self-determination - women's existence can be characterized as, what Käll and Zeiler (2014) call, a "bodily relational autonomy". Rather than understanding women's (material, narrative, social, and temporal) contextual dependencies as (merely) eradicating their embodied selfdetermination, this relational account of autonomy understands these dependencies as providing the existential condition for such self-constitution. These women's existence thus includes the ontological premise of dependency on conditioning contexts - and of vulnerability to possible harm that comes with it - while also broadening this premise with an understanding of human beings as able to influence and condition their own extendedness.

Finally, I reveal that women's sense-making of their breast cancer experiencing in their material, narrative, social and temporal contexts is always also shaped within and through a larger cultural context. Women often aspire and try to achieve a normal healthy and unblemished - body, which is an imperative cultural ideal in journeying through breast cancer (Frank 1995). Attaining this normal template of what the body should be is also a recurring theme in the literature on breast cancer experiences. While many studies acknowledge that women may continue to struggle with the chaotic, disfiguring, inhibiting bodily effects of breast cancer - or even do not recover from breast cancer at all - these works still commonly end with recommendations on how these women's physical betterment and return to a normal, daily life can be encouraged and facilitated (Carver et al. 1993; Girgis 2000; Sears et al. 2003). Here, I am not defying the importance of advices regarding adjuvant treatments, exercising, or dealing with prosthetics as they may help women - even against all odds - to improve their scope and modes of going around, or the ways in which they comfortable deal with their new appearance and felt body (Carver et al. 1993; Hoving et al. 2009; Roberts et al. 2003; Turner et al. 2004). What is at stake, though, is the problematic underlying assumption of these recommendations that women's bodies - and by implication, their experiences and sense making processes - are to a large extent manageable and moldable to this normal, or at the least that women are able to make sense of their experiences. In adhering to a double ontological premise of both constituting oneself and being constituted, I show that women are also dependent on what is given, afforded and made possible to them by their bodies in their lived contexts. Women, for example, who feel they have to wear distressing prosthetic artifacts, who have lasting bodily imperfections that cannot be hidden from one's partner, and who have overwhelming mortifying or unexpected feelings of chaos may run up against the boundaries of managing their own bodies, of journeying toward health and standard embodiment. Even more, such bodily situations sometimes leave women unable to make sense of their experiences to begin with. A context of having to achieve a normal bodily condition may thus be distressing and harmful for those who cannot live up to such norms. As I will discuss more elaborately in the next section, the implications of a cultural hegemony of being normal are profound for people who deviate from the normal and extend into the 
very heart of their existential production. Therefore, I will underscore the importance of making public and discussing non-normal embodied experiences, not only in academic literature but also in public life. As I explain, it is through such narrative visibility of the non-normal that sense-making of deviant experiences is facilitated.

Before discussing this emancipatory value, note that the above-presented insights into what it means to live with and through breast cancer also have explanatory power for understanding other bodily situations. Granted, my study explicitly attends to breast cancerous embodiment and its repercussions for women's breasted, feminine and gendered experiences and sense-making. However, I create an opening for understanding situations in which the body becomes a pivotal theme - for example, in disability, disfigurement, bodily altering illness and body change at large - by outlining the general structures of extended embodiment. This becomes clear when we think through the example of experiences of those who sit and move in wheelchairs. Conventional disability theory predominantly focusses on these people's experiences of diminished physical capability and/or an altered and deviant physical appearance (Depoy and Gilson 2014; Linton 1998; Thomson 1997). With my study, first of all, I draw attention to other significant bodily aspects in people's contextualized experiences and sense-making processes: for example, the constant annoying feeling of the chair pressing into one's buttocks, which subsequently may be inhibiting in going around comfortably. Second, the outlined structures of extended embodiment not only stress the importance of understanding how moving in a wheelchair transforms persons' experiences (see for example: Winance 2010; 2015), but also invites explorations of whether and how people transform their wheelchair, and therefore themselves. Finally, my study points to the significance of investigating how societal, cultural norms appear not only in wheelchair users' actions (see for example: Nussbaum 2001), but also in their experiencing and sensemaking. These people may be inhibited in navigating daily life, that is, in a world where doorposts, bookshelves or buildings are often standardly designed for the usual standing and (staircase-) walking person. Consequently, their interactions with others are characterized by frequently having to ask for help, something they may dislike as they feel they should handle things independently. Thus, already in this brief and preliminary discussion of wheelchair users' experiences, we see that the outlined structures of extended embodiment may contribute to extending the understanding of other bodily experiences beyond breast cancer situations.

\subsection{EMANCIPATORY UNDERSTANDINGS OF BREAST CANCEROUS BODIES}

As I have outlined above, dominant discourses within the scholarly literature tend to be rather restrictive in disclosing what it can and should mean to live through breast cancer, namely actively (re)turning to a normal, healthy, feminine and unblemished embodied life (Carver et al. 1998; Sears et al. 2003). Similar discourses also exists outside of 
academia (Sontag 1990). In Western countries - most explicitly in the US and Canada, but arguably in European countries as well (Klawiter 2008) - breast cancer representations have been transformed from a stigmatized disease best dealt with privately and in isolation, to a process in which women have elicited their own journey toward publicly reclaiming health and their return to a normal daily life (King 2004; Leopold 2000). The 1971 declaration of 'the war on cancer' by US president Nixon triggered militaristic discourses in which women are portrayed as 'fighting' and 'conquering' their cancer through their 'courage' and 'vitality', after which they are seen as 'survivors' and 'beacons of hope' for other women who are still caught up in the 'battlefield'. In more recent years, pink ribbons predominantly represent a dramatic departure from the stigma and secrecy that surrounded breast cancer. This 'pink culture' markets visible signs of survivorship, through handing out and selling feminine and childlike products like pink ribbons but also bracelets and cuddly teddy bears, and emphasizes women's physical and emotional power - even their grace and increased wisdom - in overcoming their illness (Kaiser 2008; King 2004). Within such discourses, the breast cancer survivor represents the powerful promise of modern biomedicine to beat breast cancer and to help return women to their normal lives through monitoring, molding and controlling the body (Ehrenreich 2001; Rose 2007).

In the abovementioned breast cancer discourses, the virtual absence of scarred, disfigured or incapable bodies and of the harshness of dying is striking indeed. Yet alternative constructions of embodied life during and after breast cancer co-exist with these dominant imageries. Already in 1993, the artist and model Matuschka appeared on the cover of New York Times Magazine baring her mastectomy scar. The accompanying caption reads: "You can't look away anymore". More recently, the Showtime hit TV series 'The Big C', which first aired in 2010, also provides an alternative glance into what it means to live through cancer. This show pictures the severe emotional and bodily effects of medical treatments, and of the chaos that comes with a terminal prognosis. ${ }^{16}$ Furthermore, breast cancer biographies like those by Lorde (1980) and Sedgwick (1993) also serve as a place for women to express and recognize pain, fear and disfigurement. Such first-hand accounts of breast cancer become more accessible in contemporary times with the rise of the Internet and online social media. Here, more women are more able to represent and read breast-cancerous experiences and dealings that involve feelings of chaos and deviance (De Boer and Slatman 2014; Orgad 2005).

As the term suggests, however, these alternatives to mainstream breast cancer discourses - alternatives which, arguably, become increasingly visible - still predominantly roam around in the margins of public life (Kaiser 2008). As we have seen in this study, the meaning of embodiment in such dominant discourses is at odds with women's ac-

\footnotetext{
${ }^{16}$ In my view, the show is also being criticized for varying legitimate reasons. Such critiques revolve around its investment into a white, middle-class and youthful protagonist (Bradshaw 2013), the fact that the main character initially keeps her diagnosis from her family, and the show's ending, which pictures the main character living happily-ever-after in some afterlife (Sleasman 2013).
} 
tual illness experiences. When taking into account this discrepancy, we can see that the - sometimes propagandist - distribution of scenarios of a powerful and vigorous (re)turn to normal embodied life, of enterprising individuals who actively shape their own illness experiences, and of notions of biomedical moldable bodies, might be a significant existential problem. Shildrick (2012) explains that in being "caught up by powerful framing discourses that disavow [non-normal] concerns [and experiences], the [patient's] capacity to find authorized socio-cultural correlatives for their [more dynamic illness] experiences is severely limited. [As such,] some feel they cannot voice their [...] experiences that go beyond [these] narratives" (246). We may add with Ricoeur (1986) that such a lack of appropriate cultural discourses - that is, of larger narratives that people can relate to in their stories about themselves - not only amounts to an inability to express oneself, but is, by implication, also an existential issue. Socio-cultural discourses are the make-up of people's life narrative, and as such, the basis for and precondition of sense-making structures of themselves, their lives and their bodies. With the prevalence of breast cancer discourses that predominantly adhere to women's opportunities to powerfully return to normal, then, women have limited guidance and means through which they can give meaning to their enduring chaotic lives and their permanently affected, disfigured and incapable bodies. It is this sense that, as Matuschka (1993) puts it, "if we keep quiet about what cancer does to women's bodies, [...] we are doing a disservice to womankind" (162).

One could escape the shackles of such restrictive discursive contexts, Shildrick (2012) claims, by investigating and making public the multiplicity and ambiguity of bodily experiences, by also addressing how they manifest themselves in the stories of those who live(d) through disability, disfigurement and illness. In highlighting and thematizing such complex experiences, the 'other' chaotic and deviant bodily alternative is given a more prominent place and, hopefully, due consideration. Such enlarged repertoire of what it means to be disabled, disfigured or ill will give people extended resources through which they can utter their lived bodily experiences and give meaning to them. In other words, in allowing (more) people to make (more) sense of their bodies, we have to take up the task to describe, analyze and distribute actual, complex embodied experiences, experiences that adhere to, but also go beyond dominant bodily narratives.

In this study, I responded to this call to mark and make (more) public an extended range of, in this case, possibilities of what it means to embody breast cancer. I revealed how women struggle with narrating, giving meaning and normalizing their multiple bodily experiences within their lived contexts, and how they are not only active constitutors of their experiences and sense-making efforts, but are also constituted by their contextualized bodies. Moreover, I also suggested how medical professionals could and should - tease out women's ambiguous - normal and non-normal, active and passive, meaningful and meaningless - breast cancer experiences, experiences which are often not given much consideration in biomedical practices. In doing so, I (aim to) make new and additional knowledge about living with breast cancer and open up these wom- 
en's lives and bodies to more public visibility and sensibility. All the while, I contributed to destabilizing the dominance of discourses in the literature, daily life and biomedicine that constitute the normalizing, restrictive, and potentially harmful existential markers of breast cancerous embodiment. It is this kind of expanded account of what it means to embody breast cancer that enables the emancipation of (current, but also former and future) breast cancer patients, namely to give them both a podium and expose them to a frame of reference within and through which they can express and give meaning to their breast cancer experiences.

With this un-working and re-working of knowledge production about what bodies and selves in breast cancer are, can and should be, I hope to inspire more elaborate storytelling about not only breast-cancerous bodies, but also about other disabled, disfigured and ill bodies. After all, Shildrick's (2012) call concerns all bodily situations within which restrictive discourses prevail. This can be illustrated by returning to the example about wheelchair users. A major part of nursing studies, care ethics and conventional disability theory (Allen et al. 2006; Dekkers 2001; Proot 2000), but also of disability activism in public life (Shakespeare 2013), deals with reclaiming autonomy. Herein, autonomy is generally understood as the ability of disabled people to act and move around independently in daily life, or at least to have some degree of selfdetermination and control over oneself and one's environment. As phenomenology shows that extensions to and dependencies on contexts are ubiquitous (Heidegger 1962; Merleau-Ponty 1945), rather than restricted to the disabled or ill, it is surprising that the nature of dependencies of the disabled are questioned and marked as a problem to be fixed. Scully (2013) argues that such an attempted (re)constitution of autonomy of disabled people points to socio-political structures "that determine when a dependency is taken for granted and therefore normative and when it is [...] exceptional and therefore non-normative" (204). In this sense, wheelchair users' dependencies are characterized and labeled as (more) deviant from what is most people share, from what is normal, and are therefore seen as problematic (Davis 1995). These kind of labelling structures may be embraced by people in wheelchairs as well: they may feel inclined to do things by themselves and uncomfortable in asking for help. Although I agree that people with disabilities, such as those sitting in a wheelchair, should be able to comfortably move around in daily life - something which regrettably is not possible in all situations, the dominant approach of nursing studies, care ethics and disability theory misses the complexity and extensiveness of what it means to live with a wheelchair (Gibson 2006; Gleeson 1999; Shildrick and Price 1996; Shildrick 2015). Even with - or rather because of - appropriate adjustments, these people remain (to a certain extent) dependent on their context: on the help of others and on their wheelchair. It is within these dependencies, moreover, that people with disabilities may navigate life quite independently: they may direct the care of others (Garland-Thomson 2015), and with a so-called 'smart wheelchair' they may not be (that) dependent on others (Simpson 2004). Such independent dependencies, furthermore, may not be problematic by defi- 
nition. On the contrary, sitting in a wheelchair could involve the intimate and joyful experience of talking to one's grandchildren at their own height. At this point, we grasp the conflicting and potentially harmful situation of people in wheelchairs who are intersubjectively and materially dependent in a world which demands their full independence. I argue that we have to look beyond the normalizing impetus of autonomy in academic and public discourses, and attend to actual contextualized experiences of people in wheelchairs. By disclosing such narrations, we extend the understanding of what it means to sit and move in a wheelchair, and by implication, also extend our notion of autonomy to a more ambiguous, relational and less normalizing one. It is through this extended discourse around the notion of autonomy that wheelchair users have a wider range of understanding themselves as both (comfortably) dependent and independent.

With the analyzed ambiguous breast cancer narrations in this study and through the potential, hoped-for effect of these analyses on ways of storytelling about other disabled, disfigured and ill bodies, this study has a wide-ranging emancipatory value. Such an expanded storytelling enables a more extended understanding of what it means to live with a deviating body. What is at stake here, however, is not just providing new and altered understandings of bodies through extending ways of storytelling, but the existential emancipation of people who live with disfiguring, disabling and ill bodies through that storytelling. 


\section{REFERENCES}

Ahmed, S. (2006). Queer phenomenology: Orientations, objects, others. Durham: Duke University Press.

Akrich, M. (1992). The de-scription of technological objects. In: Bijker, W.E. and Law. J., Shaping technology/building society. Cambridge: MIT Press, 205-224.

Alfano, C. M. and Rowland, J. H. (2006). Recovery issues in cancer survivorship: a new challenge for supportive care. The Cancer Journal, 12(5), 432-443.

Allen, S., Resnik, L. and Roy, J. (2006). Promoting independence for wheelchair users: the role of home accommodations. The Gerontologist, 46(1), 115-123.

Baxter, N. N., Goodwin, P. J., Mcleod, R. S., Dion, R., Devins, G., and Bombardier, C. (2006). Reliability and validity of the body image after breast cancer questionnaire. The breast journal, 12(3), 221-232.

Bradshaw, L. (2013). Showtime's 'female problem': Cancer, quality and motherhood. Journal of Consumer Culture, 13(2), 160-177.

Braidotti, R. (2001). Nomadic Theory: The Portable Rosi Braidotti. New York: Columbia University Press.

Butler, J. (2006). Precarious life: The powers of mourning and violence. London: Verso.

Carver, C.S., Pozo-Kaderman, C., Price, A.A., Noriega, V., Harris, S.D., Derhagopian, R.P., Robinson, D.S., Moffatt, F.L. (1998). Concern about aspects of body image and adjustment to early stage breast cancer. Psychosomatic medicine, 60(2), 168-174.

Carver, C.S.; Pozo, C., Harris, S.D., Noriega, V., Scheier, M.F., Robinson, D.S., Ketcham, A.S., Moffat, F.L., Clark, K.C. (1993). How coping mediates the effect of optimism on distress: a study of women with early stage breast cancer. Journal of Personality and social psychology, 65(2), 375-390.

Crompvoets, S. (2003). Reconstructing the self: Breast cancer and the post-surgical body. Health Sociology Review, 12(2), 137-145.

Dalibert, L. (2015). Living with Spinal Cord Stimulation: Doing Embodiment and Incorporation. Science, Technology and Human Values: 10.1177/0162243915617833.

Dastur, F. (2000). Phenomenology of the event: Waiting and surprise. Hypatia, 15(4), 178-189.

Davis, L. J. (1995). Enforcing normalcy: Disability, deafness, and the body. London: Verso.

De Beauvoir, S. D. (1949). Le deuxième sexe. Paris: Gallimard.

De Boer, M. and Slatman, J. (2014). Blogging and breast cancer: Narrating one's life, body and self on the Internet. Women's Studies International Forum, 44, 17-25.

Dekkers, W. J. (2001). Autonomy and dependence: chronic physical illness and decision-making capacity. Medicine, Health Care and Philosophy, 4(2), 185-192.

Denford, S., Harcourt, D., Rubin, L., and Pusic, A. (2011). Understand normality: A qualitative analysis of breast cancer patients concepts of normality after mastectomy and reconstructive surgery. Psycho-Oncology, 20(5), 553-558.

DePoy, E., \& Gilson, S. (2014). Branding and Designing Disability: Reconceptualising Disability Studies. London and New York: Routledge.

Ehrenreich, B. (2001). Welcome to cancerland. Harper's Magazine 303(1818), 43-53.

Gilbert, E., Ussher, J. M. and Perz, J. (2010). Sexuality after breast cancer: a review. Maturitas, 66(4), 397-407.

Engelsrud, G. (2005). The lived body as experience and perspective: Methodological challenges. Qualitative Research, 5(3), 267-284.

England, K. (1994). Getting personal: Reflexivity, positionality, and feminist research. The Professional Geographer, 46(1), 80-89.

Fineman, M. A. (2005) The autonomy myth: the theory of dependency. New York: the New Press.

Finlay, L. (2006). The body's disclosure in phenomenological research. Qualitative research in psychology, 3(1), 19-30.

Foucault, M. (1979). Discipline and Punish. Translated by Sheridan, A. New York: Vintage.

Frank, A. W. (1995). The wounded storyteller, body, illness and ethics. Chicago and London: University of Chicago Press.

Frank, A. W. (2001). Can we research suffering? Qualitative health research, 11(3), 353-362. 


\section{CHAPTER 6}

Garland-Thomson, R. (2015). A Habitable World: Harriet McBryde Johnson's "Case for My Life". Hypatia 30(1), 300-306.

Geertz, C. (1973). Thick Description: Toward an Interpretive Theory of Culture. In: The Interpretation of Cultures: Selected Essays, 3-30. New York: Basic Books.

Gibson, B. E. (2006). Disability, connectivity and transgressing the autonomous body. Journal of Medical Humanities, 27(3), 187-196.

Girgis, A., Boyes, A., Sanson-Fisher, R. W. and Burrows, S. (2000). Perceived needs of women diagnosed with breast cancer: rural versus urban location. Australian and New Zealand journal of public health, 24(2), 166-173.

Gleeson, B. (1999). Geographies of disability. London: Psychology Press.

Heidegger, M. (1962). Being and time. Oxford: Basil Blackwell.

Heilferty, C. M. (2009). Toward a theory of online communication in illness: Concept analysis of illness blogs. Journal of Advanced Nursing, 65(7), 1539-1547.

Hodges, L. J., Humphris, G. M., and Macfarlane, G. (2005). A Meta-Analytic Investigation of the Relationship between the Psychological Distress of Cancer Patients and Their Carers. Social Science and Medicine, 60(1), 1-12.

Hoving, J. L., M. L. A. Broekhuizen, and M. H. W. Frings-Dresen (2009). Return to work of breast cancer survivors: a systematic review of intervention studies. BMC cancer, 9(1), 1.

Husserl, E. (1960). Cartesian meditations: an introduction to phenomenology. The Hague: Martinus Nijhoff.

Ihde, D. (1990). Technology and the lifeworld: From garden to earth. Bloomington and Indianapolis: Indiana University Press.

Ihde, D. (2002). Bodies in technology. Vol. 5. Minneapolis and London: University of Minnesota Press.

Iversen, M. D., Daltroy, L. H., Fossel, A. H. and Katz, J. N. (1998). The prognostic importance of patient preoperative expectations of surgery for lumbar spinal stenosis. Patient Education and Counseling, 34(2), 169-178.

Jay, M. (1993). Downcast eyes: The denigration of vision in twentieth-century French thought. Berkely, Los Angeles and London: University of California Press.

Kaiser, K. (2008). The meaning of the survivor identity for women with breast cancer. Social Science \& Medicine, 67(1), 79-87.

Käll, L.F. and Zeiler, K. (2014). Bodily Relational Autonomy. Journal of consciousness studies, 21(9-10), 100-120.

Kaufert, P. (2000). Screening the Body: The Pap Smear and the Mammogram. In: Living and Working with the New Medical Technologies, edited by M. Lock, A. Young and A. Cambrosio, 165-183. Cambridge: Cambridge University Press

Kayser, K., Watson, L. E., and Andrade, J. T. (2007). Cancer as a 'We-Disease': Examining the Process of Coping from a Relational Perspective. Families, Systems \& Health, 25(4), 404-418.

King, S. (2004). Pink Ribbons Inc: breast cancer activism and the politics of philanthropy. International Journal of Qualitative Studies in Education, 17(4), 473-492.

Klawiter, M. (2008). The biopolitics of breast cancer: Changing cultures of disease and activism. Minneapolis: University of Minnesota Press.

Latour, B. (1994). On technical mediation: Philosophy, sociology, genealogy. Common Knowledge, 3, 29-64.

Leder, D. (1990). The absent body. Chicago: University of Chicago Press.

Leopold, E. (2000). A darker ribbon: Breast cancer, women, and their doctors in the twentieth century. Boston: Beacon Press.

Leunissen, T., de Boer, M., van der Hulst, R., and Slatman, J. (2015). Exploring novel dimensions of body experience after breast reconstruction. JPRAS Open, 7, 32-41.

Linton, S. (1998). Claiming disability: Knowledge and identity. New York: NYU Press.

Lorde, A. (1980). The cancer journals. London: Sheba Feminist Publishers.

Manderson, L. (2011). Surface tensions: Surgery, bodily boundaries, and the social self. Walnut Creek: Left Coast Press. 
Manne, S.L, Ostroff, J., Rini, C., Fox, K., Goldstein, L., and Grana, G. (2004). The interpersonal process model of intimacy: The role of self-disclosure, partner disclosure, and partner responsiveness in interactions between breast cancer patients and their partners. Journal of Family Psychology, 18(4), 589-599.

Matuschka, J. (1993). Why I did it. Glamour Magazine, November 1993, 162-163.

Merleau-Ponty, M. (1945) Phénomenologie de la perception. Paris: Gallimard.

Nancy, J.-L. (2000). Being Singular Plural. Stanford: Stanford University Press.

Nussbaum, M. (2001). Disabled Lives: Who Cares? The New York Review of Books, 48(1), 34-37.

Oliver, M. (1990). The politics of disablement: Critical texts in social work and the welfare state. London: MacMillan.

Orgad, S. (2005). The transformative potential of online communication, the case of breast cancer patient's Internet spaces. Feminist Media Studies, 5(2), 141-161.

Oudshoorn, N. (2015). Sustaining cyborgs: Sensing and tuning agencies of pacemakers and implantable cardioverter defibrillators. Social studies of science, 45(1), 56-76.

Page, R. (2008). Gender and genre revisited: Narratives of illness on personal blogs. Genre: A quarterly devotes to generic criticism, 41(3-4), 149-175.

Plant, S. (2000). On the matrix: Cyberfeminist simulations. In: Bell, D. and Kennedy, M. (eds.) The cybercultures reader. London: Routledge, 325-436.

Poland, B. and Pederson, A. (1998). Reading between the lines: Interpreting silences in qualitative research. Qualitative Inquiry, 4(2), 293-312.

Poster, M. (1995). The second media age. Cambridge: Polity.

Proot, I. M., Abu-Saad, H. H., de Esch-Janssen, W. P., Crebolder, H. F. and ter Meulen, R. H. (2000). Patient autonomy during rehabilitation: the experiences of stroke patients in nursing homes. International journal of nursing studies, 37(3), 267-276.

Ricoeur, P. (1981). Hermeneutics and the Human Sciences: Essays on Language, Action and Interpretation. Trans. John B. Thompson. Cambridge: Cambridge University Press.

Ricoeur, P. (1986). The Rule of Metaphor: Multi-Disciplinary Studies of the Creation of Meaning in Language. Trans. Robert Czerny with Kathleen McLaughlin and John Costello, S. J. London: Routledge and Kegan Paul

Ricoeur, P. (1991). Narrative identity. In: D. Wood (ed.), On Paul Ricoeur: Narrative and Interpretation. London and New York: Routledge.

Ricoeur, P. (1992). Oneself as another. Trans. Kathleen Blamey. Chicago: University of Chicago Press.

Roberts, S., Livingston, P., White, V., \& Gibbs, A. (2003). External breast prosthesis use: experiences and views of women with breast cancer, breast care nurses, and prosthesis fitters. Cancer nursing, 26(3), 179-186.

Rose, N. (2009). The politics of life itself: Biomedicine, power, and subjectivity in the twenty-first century. Princeton: Princeton University Press.

Sandell, K. (2008). Stories without significance in the discourse of breast reconstruction. Science, Technology \& Human Values, 33(3), 326-344.

Sandelowski, M. (1995). Sample size in qualitative research. Research in nursing \& health, 18(2), 179-183.

Scully, J. L. (2013). Disability and Vulnerability: On Bodies, Dependence, and Power. In: Vulnerability: New Essays in Ethics and Feminist Philosophy, Mackenzie, C., Rogers, W. and S. Dodds, 204-221. Oxford: Oxford University Press.

Sears, S. R., Stanton, A. L., and Danoff-Burg, S. (2003). The yellow brick road and the emerald city: benefit finding, positive reappraisal coping and posttraumatic growth in women with early-stage breast cancer. Health Psychology, 22(5), 487-497.

Sedgwick, E. (1993). White glasses. In: Tendencies. Durham, N.C.: Columbia University Press, 252-266.

Shakespeare, T. (2013). Disability rights and wrongs revisited. London and New York: Routledge.

Shildrick, M. (2012). Imagining the heart: Incorporations, intrusions and identity. Somatechnics, 2(2), $233-249$.

Shildrick, M., and Price, J. (1996). Breaking the Boundaries of the Broken Body. Body \& Society, 2(4), 93-113.

Simpson, R., LoPresti, E., Hayashi, S., Nourbakhsh, I. and Miller, D. (2004). The smart wheelchair component system. Journal of Rehabilitation Research and Development, 41(3B), 429-442.

Slatman, J. (2011). The Meaning of Body Experience Evaluation in Oncology. Health Care Analysis, 19(4), 295311. 
Slatman, J. (2014). Our Strange Body: Philosophical Reflections on Identity and Medical Interventions. Amsterdam: Amsterdam University Press.

Slatman, J., Halsema, A. and Meershoek, A. (2015). Responding to Scars After Breast Surgery. Qualitative health research: 1049732315591146.

Sleasman, M. (2013). The Big C Series Finale Review: And They Lived Happily Ever After. URL: http://www.tv.com/news/the-big-c-series-finale-review-and-they-lived-happily-ever-after136909625888/, accessed on 5-5-2016.

Snell, L., McCarthy, C., Klassen, A., Cano, S., Rubin, L., Hurley, K. and Pusic, A. (2010). Clarifying the expectations of patients undergoing implant breast reconstruction: a qualitative study. Plastic and Reconstructive Surgery, 126(6), 1825-1830.

Sontag, S. (1990). Illness as Metaphor and AIDS and its metaphors. New York: Anchor Books.

Spector, D., Mayer, D. K., Knafl, K., and Pusic, A. (2010). Not what I expected: Informational needs of women undergoing breast surgery. Plastic Surgery Nursing, 30(2), 70-74.

Steinbock, A. J. (2006). Time, otherness, and possibility in the experience of hope. In: Vandevelde, P. (ed.) Issues in Interpretation Theory, Milwaukee: Marquette University Press, 271-289.

Sundén, J. (2001). What happened to difference in cyberspace? The (re)turn of the she-cyborg. Feminist Media Studies, 1(2), 215-232.

Svenaeus, F. (2000). The body uncanny-Further steps towards a phenomenology of illness. Medicine, Health Care and Philosophy, 3(2), 125-137.

Svenaeus, F. (2011). Illness as unhomelike being-in-the-world: Heidegger and the phenomenology of medicine. Medicine, Health Care and Philosophy, 14(3), 333-343.

Thomson, R. G. (1997). Extraordinary bodies: Figuring physical disability in American culture and literature. New York: Columbia University Press.

Toombs, S.K. (1993). The Meaning of Illness: A Phenomenological Account of the Different Perspectives of Physician and Patient. Dordrecht, Boston and London: Kluwer Academic Publishers.

Turkle, S. (1995). Life on the screen, identity in the age of the internet. London: Phoenix.

Turner, B. S. (2006). Vulnerability and human rights. University Park: Pennsylvania Stata University Press.

Turner, J. Hayes, S., and H. Reul-Hirche (2004). Improving the physical status and quality of life of women treated for breast cancer: a pilot study of a structured exercise intervention. Journal of surgical oncology, 86(3), 141-146.

Ussher, J. M., Wong, W. T., and Perz, J. (2011). A qualitative analysis of changes in relationship dynamics and roles between people with cancer and their primary informal carer. Health, 15(6), 650-667.

Van Dijck, J. (2009). Users like you? Theorizing agency in user-generated content. Media, culture, and society, 31(1), 41-58.

Van Manen, M. (1990). Researching lived experience: Human science for an action sensitive pedagogy. Albany, NY: State University of New York Press.

Verbeek, P.-P. (2006). Materializing morality design ethics and technological mediation. Science, Technology \& Human Values, 31(3), 361-380.

Verbeek, P.-P. (2010). What things do: Philosophical reflections on technology, agency, and design. Pennsylvania: Penn State Press.

Wilding, F. (1998). Where is the feminism in cyber feminism? n. paradoxa, 2, 6-13.

Wiles, R., Cott, C., and Gibson, B. E. (2008). Hope, expectations and recovery from illness: A narrative synthesis of qualitative research. Journal of Advanced Nursing, 64(6), 564-573.

Winance, M. (2010). Care and disability. Practices of experimenting, tinkering with, and arranging people and technical aids. Care in practice. On tinkering in clinics, homes and farms, 93-117.

Winance, M., Marcellini, A., \& de Léséleuc, É. (2015). From Repair to Enhancement: The Use of Technical Aids in the Field of Disability. In: Inquiring into Human Enhancement, 119-137. Palgrave Macmillan UK.

Kalman, Y. M. and Rafaeli, S. (2010). Online pauses and silence: Chronemic expectancy violations in written computer-mediated communication. Communication Research, 38(1), 54-69.

Young, I. M. (2005). On female body experience: "Throwing like a girl" and other essays. Oxford: Oxford University Press. 
Zeiler, K. (2010) A Phenomenological analysis of bodily self-awareness in pain and pleasure. On bodily dysappearance and eu-appearance. Medicine, Health Care and Philosophy, 13(4), 333-342.

Zeiler, K. (2013) A Phenomenology of Excorporation, Bodily Alienation and Resistance. Rethinking Sexed and Racialized Embodiment. Hypatia. A Journal of Feminist Philosophy, 28(1), 69-84. 



\section{Appendix}

Table 1. Respondent's details chapter 2

\begin{tabular}{|c|c|c|c|}
\hline & Age & Data included in analysis & Medical background \\
\hline Mary & 60 & $\begin{array}{l}\text { Interview; observation at her } \\
\text { breast screening. }\end{array}$ & Regular breast screenings. No breast cancer diagnosis. \\
\hline Karin & \pm 55 & $\begin{array}{l}\text { Interview; her personal weblogs } \\
\text { about breast cancer experiences }\end{array}$ & $\begin{array}{l}\text { Breast cancer diagnosis. Chemotherapy and } \\
\text { radiotherapy. Unilateral mastectomy. }\end{array}$ \\
\hline Grace & 58 & Interview & $\begin{array}{l}\text { Breast cancer diagnosis. Unilateral lumpectomy. } \\
\text { Chemotherapy. Wears partial external breast } \\
\text { prosthesis. }{ }^{17}\end{array}$ \\
\hline Barbara & 65 & Interview & $\begin{array}{l}\text { Breast cancer diagnosis. Chemotherapy. Two times a } \\
\text { unilateral mastectomy. First wore external breast } \\
\text { prostheses. Later on, she had an implant breast } \\
\text { reconstruction. }{ }^{18}\end{array}$ \\
\hline
\end{tabular}

Table 2. Respondent's details chapter 4

\begin{tabular}{llll}
\hline Couples' name and age & $\begin{array}{l}\text { Relation details (time together, } \\
\text { Woman (age) }\end{array}$ & Man (age) & children) \\
\hline Emma (60) & William (64) & 36 years, 3 children & Bilateral mastectomy, reconstruction \\
& Stuart (69) & 35 years, 2 children & Unilateral lumpectomy \\
Martha (61) & Bert (68) & 30 years, she: 2 children & Unilateral mastectomy, reconstruction \\
Kim (29) & Wesley (34) & 11 years, 2 children & Bilateral mastectomy, reconstruction \\
Patricia (67) & Luke (65) & 40 years, 1 child & Bilateral mastectomy, reconstruction \\
Claudia (42) & Billy (53) & 10 years, no children & Unilateral mastectomy, reconstruction \\
& Michael (60) & 10 years, he: 2 children, she: 3 children & Unilateral mastectomy, external \\
& & & prosthesis \\
Eva (52) & James (55) & 25 years, 2 children & Bilateral mastectomy, reconstruction \\
Ines (72) & Roland (71) & 51 years, 4 children & Bilateral mastectomy \\
Elsbeth (52) & Chris (50) & 21 years, no children & Unilateral mastectomy \\
\hline
\end{tabular}

\footnotetext{
${ }^{17}$ Later on, Grace's breast cancer returned and she had a unilateral mastectomy, followed by an immediate breast implant reconstruction. Her experiences with this kind of surgery are discussed in chapter 5 of this study.

${ }^{18}$ Barbara's breast reconstruction experiences are discussed in more detail in chapter 5 of this study.
} 
Table 3. Respondent's details chapter 5

\begin{tabular}{|c|c|c|c|c|c|c|c|}
\hline \multirow[t]{2}{*}{ Respondents } & \multirow[t]{2}{*}{ Age } & \multicolumn{5}{|c|}{ Interview moments } & \multirow{2}{*}{ Reconstruction and mastectomy details } \\
\hline & & Before & $\begin{array}{l}3 \text { months } \\
\text { after }\end{array}$ & $\begin{array}{l}6 \text { months } \\
\text { after }\end{array}$ & $\begin{array}{l}\text { s } 1 \text { year } \\
\text { after }\end{array}$ & $\begin{array}{l}5 \text { years } \\
\text { after }\end{array}$ & \\
\hline Doris & 33 & $x$ & & & & & Flap, bilateral, immediate, curative \\
\hline Pamela & 68 & $x$ & $x$ & $x$ & $x$ & & Flap, bilateral, delayed, curative ${ }^{19}$ \\
\hline Grace & 58 & $x$ & $x$ & $x$ & $x$ & & Implant, unilateral, immediate, curative \\
\hline Mandy & 41 & $x$ & $x$ & $x$ & $x$ & & Flap, bilateral, delayed, curative \\
\hline Beatrix & 75 & $x$ & $x^{20}$ & & & & Flap, bilateral, delayed, curative \\
\hline Marly & 61 & $x$ & $x$ & $x$ & $x$ & & Implant, unilateral, delayed, curative \\
\hline Daphne & 29 & $x$ & $x$ & $x$ & $x$ & & Flap, bilateral, immediate, preventive \\
\hline Amelia & 45 & & & & & $x$ & Flap, unilateral, delayed, curative \\
\hline Sally & 55 & & & & & $x$ & Flap, unilateral, immediate, curative \\
\hline Barbara & 65 & & & & & $x$ & Implant, bilateral, delayed, curative \\
\hline
\end{tabular}

Table 4. Details selected blogs chapter 3

\begin{tabular}{|c|c|c|c|c|c|}
\hline & Lucretia & Karin & Ingeborg & Jeanette & Cancer Chick \\
\hline Illness stage & Upon diagnoses & $\begin{array}{l}>5 \text { years after } \\
\text { treatment }\end{array}$ & $\begin{array}{l}3 \mathrm{yr} . \text { after } \\
\text { treatment }\end{array}$ & During treatment & $\begin{array}{l}1.5 \text { yrs. after } \\
\text { treatment }\end{array}$ \\
\hline Age & \pm 60 & \pm 55 & \pm 40 & 45 & 33 \\
\hline Professionalism & Amateur & $\begin{array}{l}\text { A professional } \\
\text { writer before } \\
\text { starting the } \\
\text { weblog }\end{array}$ & Amateur & Amateur & $\begin{array}{l}\text { Started writing } \\
\text { professionally } \\
\text { after starting the } \\
\text { weblog }\end{array}$ \\
\hline Design & $\begin{array}{l}\text { Many pictures } \\
\text { and colors }\end{array}$ & $\begin{array}{l}\text { Black-and-white } \\
\text { blog, emphasis } \\
\text { on text, one } \\
\text { picture per post }\end{array}$ & $\begin{array}{l}\text { Some pictures } \\
\text { and many colors }\end{array}$ & $\begin{array}{l}\text { Many pictures } \\
\text { and colors }\end{array}$ & $\begin{array}{l}\text { Some pictures } \\
\text { and many colors }\end{array}$ \\
\hline Intimacy & $\begin{array}{l}\text { Very personal but } \\
\text { also a lot of } \\
\text { references to } \\
\text { medical facts }\end{array}$ & $\begin{array}{l}\text { Analyzing } \\
\text { personal } \\
\text { experiences in } \\
\text { light of broader } \\
\text { sociocultural } \\
\text { debates }\end{array}$ & Very personal & Very personal & Very personal \\
\hline Scope & $\begin{array}{l}\text { Only breast } \\
\text { cancer }\end{array}$ & $\begin{array}{l}\text { Covering also } \\
\text { many other } \\
\text { subjects }\end{array}$ & $\begin{array}{l}\text { Only breast } \\
\text { cancer }\end{array}$ & $\begin{array}{l}\text { Only breast } \\
\text { cancer }\end{array}$ & $\begin{array}{l}\text { Only breast } \\
\text { cancer }\end{array}$ \\
\hline
\end{tabular}

\footnotetext{
${ }^{19}$ Before having a breast reconstruction, Pamela wore external breast prostheses. Her experiences with wearing this artifact are discussed in chapter 1 and chapter 6 of this study.

${ }^{20}$ Beatrix decided not to have the reconstruction and therefor did not participate in the study after the second interview.
} 



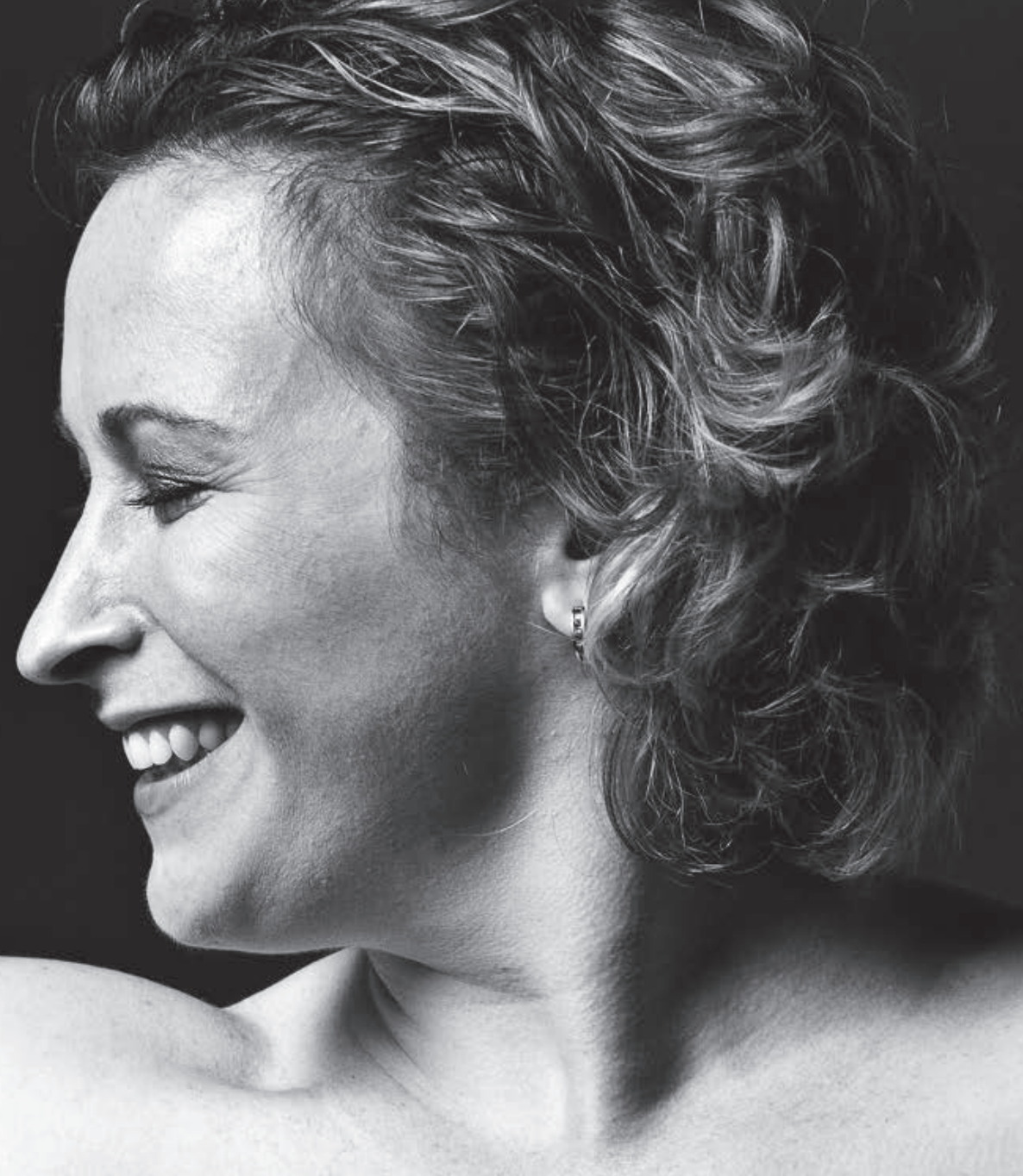




\section{Samenvatting}

\section{Uitgebreide lichamen}

Een empirisch-filosofische studie naar lichamelijke ervaringen van vrouwen met borstkanker 

Borstkanker is een ziekte die diep ingrijpt in de levens en lichamen van gediagnosticeerde vrouwen. Zij worden niet alleen geconfronteerd met hun eigen sterfelijkheid, maar ook met de fysieke (en emotionele) consequenties van de benodigde operaties en medische behandelingen. Littekenvorming en het verliezen van een of beide borsten door chirurgische ingrepen, of haarverlies, misselijkheid, pijn, vermoeidheid, stijfheid in de gewrichten, en gewichtstoename door chemo-, radio-, of hormoontherapie zijn slechts een aantal van deze fysieke gevolgen. In dit proefschrift onderzoek ik de lichamelijke ervaringen van vrouwen met borstkanker, en de manieren waarop zij aan hun veranderde leven en lichaam betekenis geven.

$\mathrm{Er}$ is al veel onderzoek gedaan naar lichamelijke ervaringen van borstkanker. Het overgrote deel van dit onderzoek is psychologisch van aard en richt zich op de (kwantitatieve) meting van individuele ervaringen van vrouwen. In dit soort onderzoek wordt vooral de subjectieve waardering van hun visuele voorkomen en van hun bewegingsvermogen na de operatie(s) beschreven. Vervolgens wordt er gekeken naar de manieren warop vrouwen omgaan met deze - veelal verminderde - lichamelijke waardering. Een ander deel van het onderzoek naar lichamelijke borstkankerervaringen is sociologisch van aard. Deze studies richten zich op de kwestie hoe ervaringen van vrouwen gevormd worden door de context waarin zij leven. Binnen deze literatuur worden contexten, zoals gedeelde normen en waarden of een sociale omgeving, - meer dan de individuele lichamelijke gesteldheid - beschouwd als hetgeen dat ervaringen produceert.

Om meer inzicht te krijgen in wat het betekent om met borstkanker te leven onderzoek ik beide bovengenoemde dimensies van lichamelijkheid: zowel subjectieve lichamelijke ervaringen als de vormende contexten waarin deze ervaringen plaatshebben. In mijn studie beschrijf en analyseer ik hoe lichamelijke ervaringen van vrouwen met borstkanker, en de manieren waarop zij hieraan betekenis geven, beïnvloed en gevormd worden door de verschillende contexten waarin zij leven.

Deze analyse vindt plaats tegen de achtergrond van een fenomenologisch verstaan van lichamelijkheid als open en uitgebreid naar de wereld. Fenomenologen betogen dat omdat we belichaamd zijn, we altijd in een bepaalde tijd en op een bepaalde plaats leven. Onze ervaringen van de wereld, van onszelf, en van ons lichaam worden gevormd door die concrete positionering in de wereld. Met andere woorden, onze lichamelijke ervaringen worden gedeeltelijk bepaald door elementen buiten ons fysieke lichaam. Belichaamd zijn betekent, opmerkelijk genoeg, dat we voorbij onze huid leven: we leven als uitgebreide lichamen.

Verscheidene filosofische tradities leren ons dat er meerdere manieren zijn waarop we onszelf uitbreiden als lichamelijke wezens. Zo laten existentialisten zien dat we leven in en door verschillende temporele dimensies. Wij veranderen, net als onze lichamen, naarmate de tijd verstrijkt. Maar ook onze huidige lichamelijke ervaringen kunnen niet los gedacht worden van ons verleden en onze toekomst, van wat we ons herinneren en van wat we verwachten. Techniekfilosofen laten daarnaast zien dat we ons lichamelijk uitbreiden naar onze materiële omgeving: ervaringen van onszelf en de wereld worden 
(mede) gevormd door objecten waarmee we in aanraking komen. Verder zijn er filosofen die laten zien dat we onszelf ervaren door de ander, door onze verhouding tot de ander en vice versa. Maar wellicht de meest fundamentele manier waarop we onszelf uitbreiden is door middel van verhalen. Binnen de hermeneutische filosofie wordt betoogd dat we continue bezig zijn om verhalen te vertellen over wie we zijn, wie we waren, en wie we worden. In deze verhalen refereren we aan verschillende elementen uit onze omgeving: we vertellen over de objecten die we tegenkomen, verwijzen naar de verhalen van anderen, en beroepen ons op culturele normen en waarden. Hierbij beschrijven we niet alleen onze ervaringen van onszelf in de wereld, maar interpreteren en geven we ook betekenis aan deze ervaringen, en daarmee aan onszelf.

In mijn onderzoek analyseer ik de invloed van temporele, materiële, sociale en verhalende contexten op de vorming van borstkankerervaringen. Hierbij gebruik ik de fenomenologie niet alleen als een theoretisch kader, maar ook als methodologische benaderingswijze in de kwalitatief empirische opzet van mijn onderzoek. Het verzamelen van borstkankerverhalen vindt plaats door het afnemen van individuele interviews met vrouwen, van interviews met vrouwen en hun partners, en door het selecteren van persoonlijke borstkanker weblogs. Door het interpreteren van deze verhalen komt naar voren hoe vrouwen (en hun partners) hun ervaringen beschrijven en hoe zij betekenis geven aan deze ervaringen.

Tijdens het analyseren van dit empirische materiaal, identificeerde ik vier specifieke manieren waarop lichamelijke uitgebreidheid zich manifesteert bij vrouwen met borstkanker. In dit proefschrift beschrijf ik hoe vrouwen met borstkanker hun lichaam ervaren (1) in relatie tot verschillende soorten protheses en medische technologieën, (2) in hun verhalen op hun persoonlijke weblogs, (3) in relatie tot hun partners, en (4) door hun verwachtingen van een borstreconstructie.

Allereerst sluit ik in mijn proefschrift aan bij een gevestigde onderzoekstraditie naar lichamelijke uitgebreidheid. Binnen de techniekfilosofie en de filosofische fenomenologie wordt lichamelijkheid doorgaans begrepen als uitgebreid door middel van (het gebruik van) verschillende materialen, objecten en gereedschappen. In hoofdstuk 2 onderzoek ik hoe de lichamelijke ervaringen van vrouwen die borstkanker hebben (gehad) beïnvloed worden door hun omgang met protheses en medische technologieën. Waar de bestaande literatuur zich vooral concentreert op de agency - letterlijk vertaald 'agentschap' - van materialen en objecten, namelijk wat zij doen met ons en onze ervaringen als gebruikers, staat in mijn onderzoek de lichamelijke agency van vrouwen als gebruikers centraal. Onder de term 'agency' versta ik het vermogen van een persoon om te kunnen handelen, waarnemen, en ervaren in de wereld, iets wat gevat kan worden in de uitspraak 'ik kan' of 'ik kan niet'.

In lijn met de literatuur binnen de techniekfilosofie laat ik zien dat lichamelijke ervaringen van vrouwen met borstkanker en hun vermogen om te handelen inderdaad worden gevormd door objecten, zoals door mammografie-apparaten, borstprotheses, pruiken, of borstimplantaten. Dit gebeurt vaak op meerduidige wijze. Een mammografie- 
apparaat perkt bijvoorbeeld de handelingsmogelijkheid van een vrouw tijdelijk in op het moment dat haar borst in het apparaat ligt. Tegelijkertijd wordt haar vermogen om te handelen - of haar 'ik kan' - vergroot door de diagnostische functie van het apparaat, namelijk doordat deze haar de mogelijkheid biedt om te anticiperen op een toekomstig ziekte scenario. Naast deze beschrijvingen van het vormende vermogen van objecten, laat ik zien dat vrouwen ook hun eigen uitgebreide lichamelijke ervaringen vormgeven. Dit doen zij door zichzelf op een bepaalde manier te positioneren ten opzichte van objecten, of door deze objecten aan te passen. Zo probeert een vrouw haar mammografie ervaring zo pijnloos mogelijk te laten verlopen door van tevoren haar borst te masseren. Een andere vrouw, die een enkelzijdige borstverwijderingsoperatie heeft ondergaan, verstelt haar beha zodat deze haar één-borstige lichaam beter past. De totstandkoming van de lichamelijke agency van vrouwen met borstkanker vindt dus plaats binnen een wederkerige dynamiek: de handelingen en ervaringen van deze vrouwen worden gevormd door hun materiële context, een context die zijzelf mede vormgeven.

In hoofdstuk 3 richt ik mij op de narratieve - of verhalende - lichamelijke uitgebreidheid van vrouwen met borstkanker, en specifiek op de manier waarop deze vrouwen hun borstkanker verhalen vertellen op hun persoonlijke weblogs. De keuze om mij te richten op deze specifieke narratieve context is geïnspireerd op feministische theorieën over de mogelijkheden van Internet. Deze theorieën betogen dat de kenmerken van online media een scala aan mogelijkheden biedt voor vrouwen om op emancipatoire wijze betekenis te geven aan zichzelf en hun lichaam. Mensen geven betekenis aan zichzelf door zich te verhouden tot bepaalde gedeelde opvattingen - dat wil zeggen, tot bepaalde culturele vertogen - in hun verhalen. Weblogs zouden dan als specifiek multimediaal, interactief, en dynamisch narratief genre mogelijkheden bieden tot kritiek en verzet tegen heersende - en vaak onderdrukkende - culturele vertogen over vrouwelijkheid en ziek-zijn. Dit verzet biedt dan een opening voor vrouwen om hun eigen lichamelijkheid en ziekte op een andere, alternatieve wijze te verstaan.

In mijn onderzoek laat ik zien dat de specificiteit van weblogs inderdaad de ervaringen en betekenisgevingstructuren van vrouwen met borstkanker in grote mate beïnvloed. Dit medium geeft vrouwen de mogelijkheid zich te verzetten tegen heersende normen die stellen dat na een periode van ziekte je dient terug te keren naar een normaal, gezond leven met een (schijnbaar) onaangetast lichaam. Door onder andere een levendige weblog gemeenschap van (ex)borstkankerpatiënten lijken vrouwen zich online vrij genoeg te voelen om zich te definiëren als een permanent gemarkeerde vrouw, of als kankerpatiënt lang nadat zij uitbehandeld zijn. Tegelijkertijd tempert mijn onderzoek het emancipatoire optimisme van de bovengenoemde Internet feministen. Weblogs van vrouwen zijn namelijk ook doorspekt met (narratieve) pogingen om (terug) te keren naar een dergelijk normaal - gezond, onaangetast, vrouwelijk - leven en lichaam. Op deze blogs proberen vrouwen bijvoorbeeld hun vrouwelijkheid te herstellen en te onderstrepen: zij versieren hun blogs met roze symbolen en in hun verhalen gebruiken zij feminiene stereotypen. Online verhalen, zoals we die vinden op weblogs, kunnen dus 
niet begrepen worden als utopieën van vrije en vrijgevochten vrouwen en hun lichamen, dat wil zeggen, van lichamelijke zelf-interpretaties die losstaan van (offline) culturele structuren. Deze verhalen en hun vertellers, die zowel heersende normen omarmen als zich ertegen verzetten, moeten eerder begrepen worden als plaatshebbend middenin deze normatieve structuren.

In hoofdstuk 4 focus ik mij op borstkanker als een sociale, intersubjectieve ervaring. Vooral binnen de psychologie en de zorgwetenschappen wordt kanker in toenemende mate begrepen als een ziekte die zowel de (vrouwelijke) patiënten als hun levenspartner betreffen en aantasten. Onderzoek naar deze zogenaamde gedeelde kankerervaringen beperkt zich doorgaans tot een verkenning van het emotionele en communicatieve welzijn - of het gebrek daaraan - van beide partners. In dit hoofdstuk benader ik deze gedeelde ervaringen op een andere manier, namelijk als lichamelijke ervaringen. Door middel van duo-interviews met partners en Nancy's filosofische werk over 'delen', analyseer ik de verhalen van partners waarvan de vrouw borstkanker heeft (gehad). Deze analyse laat zien dat lichamelijke borstkankerervaringen - op soms vergaande wijzen worden beïnvloed door de manier waarop partners met elkaar omgaan. Zo verhouden partners zich (verbaal of non-verbaal) tot hun verschillende ziekte ervaringen, zorgen zij voor elkaar tijdens de (na)behandeling, proberen zij weer vertrouwd te raken met haar veranderde lichaam door onder andere intimiteit en seksualiteit, en stemmen zij hun dagelijkse, belichaamde levens op elkaar af. Voor partners, zo blijkt uit deze verschillende ontmoetingen, is het delen van borstkankerervaringen wezenlijk voor het 'samenleven' met deze ziekte. Dit betekent echter niet dat een dergelijk delen als vanzelfsprekend en harmonieus tot stand komt. Voor alle koppels in mijn onderzoek geldt dat het delen van borstkankerervaringen samengaat met onderhandelingen, en soms met conflict. Partners onderhandelen hoe zij een onderling afhankelijke eenheid kunnen zijn, zonder dat zij hun individualiteit verliezen. Het delen van borstkankerervaringen behelst dus een gezamenlijke evenwichtsoefening tussen lichamelijke onafhankelijkheid en afhankelijkheid.

Hoewel de nadruk in de voorgaande hoofdstukken ligt op materiële, narratieve en sociale uitbreidingen van lichamelijkheid, stip ik in deze hoofdstukken ook aan dat lichamelijke uitgebreidheid plaatsheeft in de temporele dimensies waarin vrouwen met borstkanker leven. Hierbij kan gedacht worden aan interacties met borstkankertechnologieën die invloed hebben op de (on)voorziene handelingsmogelijkheden van gebruikers, of dat verhalen op blogs voortdurend worden aangepast, of dat partners constant onderhandelen over de manier waarop zij hun ervaringen delen, iets waardoor deze ervaringen continu onderhevig zijn aan verandering. In hoofdstuk 5 richt ik mij expliciet op het aspect van tijd en tijdelijkheid in borstkankerervaringen, namelijk door te onderzoeken hoe ervaringen van vrouwen die een borstreconstructie (hebben) ondergaan worden gevormd door hun verwachtingen over deze chirurgische ingreep. Het bestaande onderzoek naar dit onderwerp vertrekt veelal vanuit de vraag of de verwachtingen van deze vrouwen realistisch dan wel onrealistisch zijn, namelijk of verwachtingen ver- 
wijzen naar een (statistisch) waarschijnlijk of onwaarschijnlijk toekomst scenario. Dit is een belangrijke vraag aangezien onrealistische verwachtingen lijken samen te hangen met een laag welzijn van vrouwen na de reconstructieve chirurgische ingreep. Desalniettemin ga ik in mijn onderzoek voorbij aan deze tweeledige definitie van verwachtingen, en bevraag ik wat de betekenis is van verwachtingen in de manier waarop deze vrouwen hun lichaam ervaren. Daarbij maak ik gebruik van de existentiële filosofie van Dastur en analyseer ik meerdere interviews met dezelfde vrouwen tijdens het proces van het ondergaan van een borstreconstructie.

Ik laat in dit onderzoek zien dat voor vrouwen het hebben en ontwikkelen van verwachtingen een cruciaal deel is van het betekenis (kunnen) geven aan de tijdelijke structuur van hun levens, dat wil zeggen, aan hun eigen voorbije, huidige en toekomstige lichaam. Zij formuleren en herformuleren verwachtingen over hoe zij eruit zullen zien na de operatie, over hun vermogen om te kunnen handelen, en over hoe hun lichaam zal (aan)voelen. Deze betekenisgeving gaat doorgaans niet zonder slag of stoot: in het steeds weer opnieuw (her)formuleren van verwachtingen stellen vrouwen zichzelf voor de moeilijke taak om hun toekomst in te vullen en erop te (kunnen) anticiperen. Dit is moeilijk - en soms zelfs onmogelijk - omdat de toekomst per definitie onrealistisch is, namelijk vooralsnog onbekend en tot op zekere hoogte dus altijd een verassing. Aan de hand van deze conclusie stel ik dat we ons niet (alleen) moeten richten op het stimuleren van realistische verwachtingen over waarschijnlijke reconstructieve toekomsten, iets wat de literatuur vaak voorstelt. We zouden een stapje terug moeten doen en vrouwen ondersteunen om überhaupt verwachtingen te (kunnen) formuleren, iets wat op zichzelf al moeilijk genoeg is. Medische professionals kunnen hierbij een sleutelrol spelen, namelijk door vrouwen te helpen om hun borstkanker verhalen te vertellen. Daarmee helpen zij deze vrouwen om hun verwachtingen te (her)formuleren in deze verhalen, en dus om betekenis te geven aan hun tijdelijke borstkankerervaringen.

Op basis van mijn empirische studies naar uitgebreide lichamelijkheid kunnen er drie structuren ontwaard worden waarop vrouwen met borstkanker hun lichaam ervaren en er betekenis aan geven in en door de context waarin zij leven. Allereerst komt naar voren dat er een scala is aan sensorische aspecten die een rol spelen in de lichamelijke ervaring van borstkanker, namelijk hoe een lichaam eruitziet, het reukvermogen, en het vermogen tot handelen, voelen, en horen. De manier waarop deze aspecten ervaren worden en eraan betekenis gegeven wordt, wordt mede gevormd door de (materiële, narratieve, sociale, en temporele) contexten waarin ze naar voren komen. Daarnaast laat ik in dit onderzoek niet alleen zien hoe borstkankerervaringen van vrouwen gevormd worden in en door deze verschillende contexten, maar ook dat vrouwen deze contexten zelf vormgeven en daarmee dus hun eigen uitgebreide ervaringen vormen. Het bestaan van deze vrouwen kan daarmee getypeerd worden door zowel begrippen als afhankelijkheid en ontvankelijkheid, als door autonomie en zelfbepaling. Ten slotte komt naar voren dat de vorming van borstkankerervaringen niet alleen plaatsheeft in materiële, narratieve, sociale en temporele contexten, maar ook in een grotere culture- 
le context. In lijn met de hermeneutische traditie laten de verhalen van deze vrouwen zien dat ervaringen worden gevormd in verhouding tot culturele, en vaak normatieve vertogen. Meer concreet betekent dit dat in het vormen van en gevormd worden door hun geleefde contexten, deze vrouwen dikwijls streven naar een gezond, vrouwelijk en (schijnbaar) onaangetast leven en lichaam. Dit streven kan niet losgezien worden van het hedendaagse culturele ideaal om na een periode van ziekte weer terug te keren naar een bepaalde normaliteit, dat wil zeggen, naar een gezond en onaangetast bestaan die door de meeste mensen geleefd wordt. De gevolgen van een dergelijk gedeelde opvatting van 'normaal-moeten-zijn' zijn verstrekkend voor degenen die niet aan deze normaliteit kunnen (of willen) voldoen. Ondanks hun streven naar een normaal leven, blijkt dit het geval voor veel vrouwen die borstkanker hebben (gehad). Deze vrouwen kampen met de tijdelijke of permanente invaliderende en verminkende gevolgen van borstkanker(behandelingen). Voor deze vrouwen zijn er maar weinig publieke vertogen waartoe zij zich kunnen verhouden in het betekenisgeven aan hun 'niet-normale' ervaringen. Dit heeft als gevolg dat veel vrouwen moeite hebben met betekenis te geven aan hun borstkankerervaringen, - en daarmee aan zichzelf - en dat sommigen hieraan zelfs helemaal geen betekenis kunnen geven.

Naar aanleiding van deze laatste conclusie, benadruk ik in het afsluitende deel van mijn proefschrift het belang van het (meer) publiek maken van afwijkende of 'nietnormale' ervaringen, ervaringen van bijvoorbeeld ziekte of lichamelijke aantasting door ziekte. Mijns inziens moet dit niet alleen gebeuren in de academische literatuur, zoals door middel van dit proefschrift, maar ook in het dagelijkse leven en specifiek binnen de geneeskunde. Een hoge zichtbaarheid van zulke ziekte ervaringen draagt immers bij aan een grotere verscheidenheid van vertogen over lichamelijkheid. Deze verscheidenheid draagt dan op haar beurt weer bij aan de (vergrote) mogelijkheden om betekenis te geven aan lichamelijkheid, en vooral aan lichamen die niet doorsnee of standaard zijn. Het beschrijven en publiek maken van subjectieve ervaringen van zieke, invalide, verminkte en aangetaste lichamen is daarmee dus van existentieel belang voor mensen die leven met zulke lichamen. 




\section{Valorization}

\section{Extending discourses}
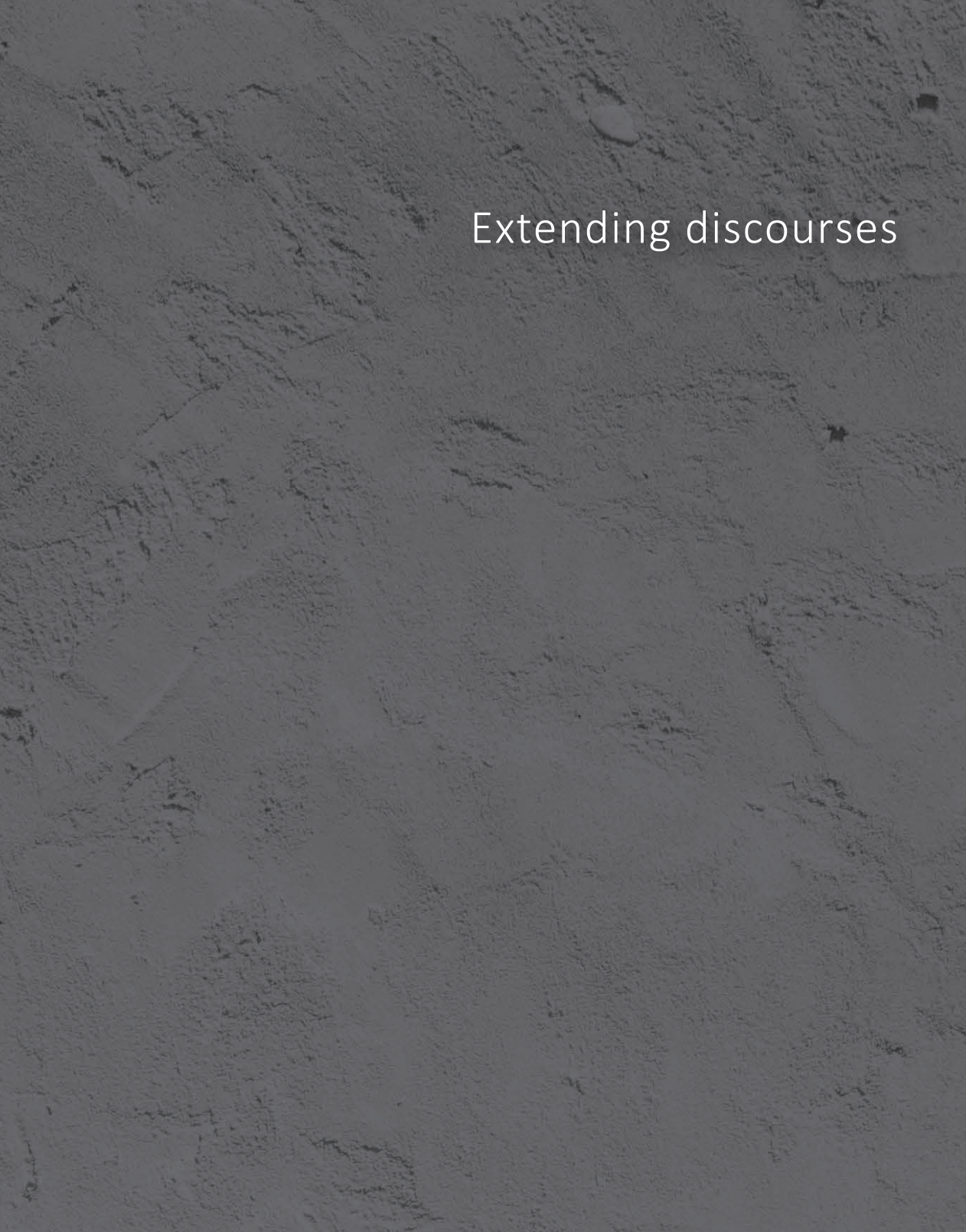

With a life time risk of 1 out of 8 , breast cancer is the most common type of cancer for women in Europe and Northern America. Being diagnosed with this disease not only confronts women with their own mortality, but also preludes an emotionally demanding and body altering trajectory of medical treatments and surgical interventions. Scarring, breast loss, lymphedema, balding, nausea, pain, fatigue, stiffness of the joints, increase in body weight, heart problems and loss of bodily functions are among the many physical consequences of breast cancer treatments. Understandably, living with and through this illness is a life changing process and severely affects the ways women experience and give meaning to their bodies. In this study, I describe and analyze how women's bodily experiencing in breast cancer, and sense making structures thereof, arise and take shape in relation to the different contexts in which these women live.

In my aim to unravel breast cancer experiences and sense making structures, I take an empirical-philosophical approach. Within philosophy, the question of how humans make sense of themselves is the domain of philosophical anthropology: a reflexive and theoretical discipline. In my study, however, I endorse the idea that philosophy, if it pretends to understand human existence, should not consist of reflection alone but should also include empirical research. This study therefore starts from the assumption that a person's experiences and sense making processes can be traced in their life story. By collecting and reading stories of (former) breast cancer patients, as well as the stories of others involved (partners, medical professionals), I tease out, articulate and interpret illness experiences.

This presentation of subjective breast cancer experiences is of great emancipatory value for women with breast cancer. While representations of living with breast cancer are no longer silenced and have acquired a steady place in public life, dominant existing discourses are restrictive in disclosing what it can and should mean to live through breast cancer (King 2004; Leopold 2000). Women who have (had) breast cancer are generally represented as unmarked, feminine and energetic survivors. As I show in this study, however, women's breast cancer experiences cover a wider range of selfdefinitions: they also present themselves as disfigured, disabled and ill. By attending to women's actually lived illness experiences, I escape the shackles of restrictive discursive frameworks and broaden public discourses about breast cancer. Such a broadening of discourses is of existential significance for those who live - and have lived or will live with breast cancer. After all, a wider range of public discourses increases the possibilities to relate to relevant discourses in defining and making sense of oneself, one's life, and one's body. Even more, an extended range of public discourses about breast cancer may also be beneficial to people with ill, disfigured and disabled bodies in general. The way this study attends to a wide range of actually lived bodily experiences may function as an exponent of how one can and should disclose bodies.

In this valorization chapter, I will first elaborate on the prevalent existing discourses about breast cancer and discuss the importance of reflecting on and broadening these dominant imaginaries. Thereafter, I describe my concrete reflection and broadening 
efforts. As we will see, these efforts revolve around breast cancer discourses in public life, in biomedical practices, and around larger discourses about deviant and ill bodies.

\section{EXISTING DISCOURSES AND EXISTENTIAL ISSUES}

Public discourses often disclose that living with breast cancer is an active journey in which women elicit their own journey of overcoming this illness and (re)turn to a normal embodied life, that is, to a healthy, feminine, and unblemished body (Carver et al. 1998; Sears et al. 2003). Such discourses enterprise individuals which actively shape their own illness experiences with the help of the monitoring, molding, and controlling activities of modern biomedicine (Ehrenreich 2001; Rose 2009). Granted, alternative constructions of an embodied life during and after breast cancer co-exist with these mainstream discourses. A magazine cover that displays a woman's permanently scarred, unbreasted chest, a TV show that features a woman's struggles with terminal cancer, and autobiographies which chronicle the severe pain that comes with having breast cancer are all part of these alternative breast cancer discourses. As the term suggest, however, in everyday life such alternative discourses are rather marginal and not (yet) very visible. Consequently, scarred, disfigured, incapable, or dying bodies, that is, bodies that cannot (fully) (re)turn to a normal - healthy, feminine, and unblemished - condition are virtually absent in the public realm. In my study I show, however, that these bodies are often the ones women actually live with in breast cancer.

With a prevalence of discourses that disavow actual breast cancer experiences, these women are presented with a possible existential problem. Ricoeur (1981) argues that without discourses that involve narratives that people can relate to in their stories about themselves, people may not only be unable to express themselves, but by implication, may also be inhibited in making sense of their lives and bodies. Then, mainstream discourses that adhere to women's opportunities to powerfully return to a normal life offer women limited guidance in giving meaning to their enduring illness experiences and their affected, disfigured and incapable bodies.

Over the last couple of years, more voices in disability and feminist studies call for making the multiplicity of actually lived illness experiences more public (Shildrick 2012; 2015; Scully 2013). These voices emphasize the existential importance of attending to narrations about bodies that fall out of the range of some generalized notion of what is normal or standard in public life. With my study about breast cancer, I not only tie in with this activist academic tradition, but I also contribute to diversifying representations about non-normal bodies in everyday life. 


\section{EXTENDING DISCOURSES AND EXISTENTIAL EMANCIPATION BEYOND ACADEMIA}

By describing how women give meaning to their multiple illness experiences I mark out an extended range of possibilities of what it means to embody breast cancer. In women's stories, their normal as well as their non-normal aspects of their bodies become subject matter. They describe their (re-)breasted, unmarked, feminine, capable, and healthy bodies, but also their un/one-breasted, scarred, disfigured, incapable, leaking, painful, dying ones. Such descriptions in this study's chapters offer women who have (had) breast cancer a podium and a frame of reference within and through which they can express and give meaning to their illness experiences. However, the scope of emancipatory guidance of these chapters alone is fairly limited. After all, these chapters are (or will be) published as articles in academic journals, and thus mainly reach an academic audience. Therefore, sharing women's narrations and the study's results with a larger public is part of my emancipatory effort of allowing more women - and people with non-normal bodies at large - to make more sense of themselves, their lives and their bodies.

Extending discourses in public life - One of my efforts to share the findings of my study with a large audience is to publish illustrative breast cancer narrations online, namely on a bi-lingual (i.e. Dutch and English) project website, and by means of the project's Twitter account (see textbox a). Moreover, on this website and Twitter account, I publish the study's results and findings. Both the website and the Twitter account are a spin-off of the five-year research project Bodily Integrity in Blemished Bodies of which this study is part. Three researchers involved in the project, including myself, contribute to this website and to the Twitter account. With online media, we reach a broad, international public of academics, medical professionals, (informed) layman, breast cancer patients, and their close ones. In this sense,

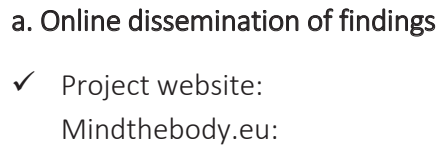
experiences as narrated in the study, and summary of the published chapters 'The surprise of a breast reconstruction' and 'Blogging and Breast Cancer'.

Twitter account

@mindthebodyeu:

Tweets: 209

Following: 191

Followers: 152

Likes: 34 online media serves as a public platform of sharing and disseminating knowledge about what it means to live with breast cancer, knowledge which - as I argue in more depth in paragraph 6.5 - has a significant existential weight. 
Extending discourses in biomedical practices - My study's approach and findings are particularly valuable and relevant in the context of medical practices around preventing and treating breast cancer. Women's bodily experiences differ per individual and over contexts and time periods, and are often ambiguous, conflicting, very implicit or inchoate. Just as in everyday life, such experiences are not given much consideration in biomedical practices (see paragraph 5.5 and 6.5). With my study, I distribute new knowledge about breast cancer experiences to medical professionals. Moreover, by encouraging these professionals to attend to and tease out the complex ways in which women experience their bodies in cancer care, I aim to make professionals sensitive to the importance of including these experiences in the development, evaluation and adjustment of breast cancer care interventions, promotions and treatments. After all, medical professionals can only give adequate information and prioritize and select certain (medical) procedures when women's experiences are drawn out. In teasing out women's stories, I argue, medical professionals also actively enable and assist women in their existential emancipation.

First, I make the approach and results of my study known to medical professionals by collaborating with them in the context of data collection, analysis, and through writing articles together. I also disseminate the study's findings by giving a presentation at the plastic surgery department of the hospital at which parts of the research was conducted, by discussing my findings with oncologists, social workers, and breast prosthesis designers at the same hospital, by co-supervising the master's theses of two medical students, and by publishing my findings and results in multidisciplinary journals which (also) target an audience of medical professionals (see textbox b). Second, besides from disseminating knowledge about breast cancer experiences to medical professionals, I

\section{b. Dissemination of findings to medical professionals}

$\checkmark$ Collaboration with medical professionals at the Plastic surgery department Medical Hospital Maastricht (MUMC+), from September 2011 onwards.

$\checkmark$ 'Women's experiences of breast reconstruction' - Presentation Plastic surgery department MUMC+, November 2012.

$\checkmark$ Several meetings with oncologists, social workers, and breast prosthesis designers at MUMC+, November 2012 - April 2013.

$\checkmark$ Co-supervision of master's theses of two students in education program of Medicine at Maastricht University.

$\checkmark$ Publications in academic, multidisciplinary journals which target medical professionals:

- Leunissen, T., Boer, M.L. de, Hulst, R. van der, Slatman, J. (accepted: October 2015) 'Exploring new dimensions in embodiment after implant based and autologous breast reconstruction', Journal of Plastic, Reconstructive \& Aesthetic Surgery 7, 31-40.

- Boer, M.L. de, Hulst, R. van der, Slatman, J. (2015) 'The surprise of a breast reconstruction: A longitudinal phenomenological study to women's expectations about reconstructive surgery', Human Studies 38 (3), 409-430. 
also aim to assist and enable professionals in actively teasing out women's individual multiplicit breast cancer experiences. This, however, is not a straightforward task and requires specific narrative and interpretative skills. In my publications, therefore, suggestions are made to acquire such skills. For example, in my study on women's expectations about their breast reconstruction, tools are given for initiating a patient-doctor dialogue through which women may come to understand their (lack of) expectations and how to use this insight in the reconstructive process (see paragraph 5.5). Asking women open-ended questions like 'what is important in a breast reconstruction for you?', 'why?', 'what do you expect regarding your capability just after reconstruction?', 'and after a year?', 'can you imagine how your reconstructed breast will feel?' are a crucial part of this dialogue.

Extending discourses beyond breast cancer - The presented breast cancer narrations in this study are not only used for applying discourses about breast cancer in an alternative way: they also invite us to broaden discourses about disabled, disfigured, and ill bodies at large. As I argue in paragraphs 6.4 and 6.5, the larger structures about what it means to live with breast cancer are exemplary for a wider array of bodily deviance. By keeping these structures in mind, this study offers insights into lived non-normal embodiment, and as such, contributes to discussions about diversifying representations about such bodies. Moreover, by making public how people who live with bodies that are deviant to a societally shared notion of what is normal, more people are able to make more sense of their lived experiences.

\section{c. Contributions to diversifying discourses about non-normal bodies}

$\checkmark$ Tweets on project's Twitter account: @mindthebody.eu

$\checkmark$ Tweets on personal Twitter account: @Marjoleinlotte

$\checkmark$ 'De grenzen van ons lichaam' [Title: The boundaries of our body] - Speaker Philosophy Festival Radboud Reflects, April 2016

$\checkmark$ Interview with Maarten Meester about nippleless FEMENactivists on Facebook. in: website Filosofie Magazine, May 2013, URL: http://www.filosofie.nl/nl/content/35693/tepel loze-activisten.html
In several ways, I contribute to diversifying discourses about nonnormal bodies (see textbox c). On the project's Twitter account and my personal Twitter account, I regularly post articles and statements about the stigmatization and marginalization of people living

with deviant bodies. Furthermore, as an invited speaker to a public philosophy festival I spoke about how people experience their bodies through interacting with materials and artifacts, such as prostheses and piercings. Herein, I extensively discussed one of my study's findings, namely the issue that how people experience their materialized bodies is heavily influenced by the cultural, normative context in which these interactions take place. After all, whether people experience their prosthetic or their pierced bodies as beautiful or capable is co-determined by cultural standards of what beauty and capabil- 
ity is. On request of Filosofie Magazine, moreover, I gave an interview about the meaning of women's nipples in the public realm. In 2013, a debate was going on about Facebook removing photos of women who showed their breasts as part of their protests against patriarchal structures in society. As a way of getting through the 'scan' of Facebook, these women blurred their nipples before sharing their topless selfies online. In the interview, I posed the question why women's nipples are apparently not allowed to be seen on Facebook. This question is particularly important in the context of Facebook's sexist removal policy: photos of men's nipples are not removed by Facebook. I argued that women's nipples represent the intolerable, or 'abject' body: the body that leaks and wastes fluids with breast feeding, or that involuntarily changes shapes with temperature variations and with sexual arousal. Similar to one of my conclusions within my breast cancer study (see paragraphs 2.4, 3.5, 4.5, 5.5), I argue that we disavow this kind of body because it is a sign of disorder and of the limits of self-control, and thus a violation of the wish and hope for a clean and proper body. The abjectness of the nippled female body is therefore a body that is considered deviant from the norm, from what we desire. In the interview, I focused on how such an understanding of abject nipples may be stigmatizing and harmful for women.

The described efforts to contribute to bodily sense making processes show that this study aims to be beneficial for women with breast cancer, but also for people with deviant bodies in general. This study contributes to this kind of sense making by describing and making public a wide( $r$ ) range of possible embodied experiences. Such descriptions involve bodies that people can relate to in their own sense making, namely bodies that are healthy, two-breasted, unmarked, and capable, but also those that are ill, one/unbreasted, scarred, and disabled. The potential and hoped-for effect of these descriptions, moreover, is that they will inspire more extended storytelling about bodies in public life, and thus to have a large emancipatory value for all those people who live with non-normal bodies. 


\section{REFERENCES}

Carver, C.S., Pozo-Kaderman, C., Price, A.A., Noriega, V., Harris, S.D., Derhagopian, R.P., Robinson, D.S., Moffatt, F.L. (1998). Concern about aspects of body image and adjustment to early stage breast cancer. Psychosomatic medicine, 60(2), 168-174.

Ehrenreich, B. (2001). Welcome to cancerland. Harper's Magazine 303(1818), 43-53.

King, S. (2004). Pink Ribbons Inc: breast cancer activism and the politics of philanthropy. International Journal of Qualitative Studies in Education, 17(4), 473-492.

Leopold, E. (2000). A darker ribbon: Breast cancer, women, and their doctors in the twentieth century. Boston: Beacon Press.

Rose, N. (2009). The politics of life itself: Biomedicine, power, and subjectivity in the twenty-first century. Princeton: Princeton University Press.

Ricoeur, P. (1981). Hermeneutics and the Human Sciences: Essays on Language, Action and Interpretation. Trans. John B. Thompson. Cambridge: Cambridge University Press.

Scully, J. L. (2013). Disability and Vulnerability: On Bodies, Dependence, and Power. In: Vulnerability: New Essays in Ethics and Feminist Philosophy, Mackenzie, C., Rogers, W. and S. Dodds, 204-221. Oxford: Oxford University Press.

Sears, S. R., Stanton, A. L., and Danoff-Burg, S. (2003). The yellow brick road and the emerald city: benefit finding, positive reappraisal coping and posttraumatic growth in women with early-stage breast cancer. Health Psychology, 22(5), 487-497.

Shildrick, M. (2012). Imagining the heart: Incorporations, intrusions and identity. Somatechnics, 2(2), $233-249$.

Shildrick, M. (2015). "Why Should Our Bodies End at the Skin?": Embodiment, Boundaries and Somatechnics. Hypatia, 30(1), 13-29. 



\section{Acknowledgements | Dankwoord}


After five years of working on my PhD thesis, it is finished! I look back on a journey of describing and analyzing many interesting - and sometimes painful - breast cancer stories, of writing and rewriting, of incorporating new ideas and - even more difficult deleting old ones. Although I spent many hours happily alone behind my computer, writing a PhD thesis is not something I did by myself. I did it together with others. Here, I would like to thank the many people who contributed to this study.

First and foremost, my sincere gratitude goes out to all the women and their partners who shared their illness stories with me. Thank you for your trust and openness. Without you, writing this thesis would not have been possible. Ethical and confidentiality considerations prevent me from thanking anyone in particular. Instead, I would like thank one woman who shared her breast cancer story with me but who was technically not part of this study: my mother-in-law Geertje. You were one of the reasons why I wanted to pursue this study in the first place. Your story about what it means to live with breast cancer for 15 years was an inspiration for me. It fills me with great sadness that you cannot be here anymore with us. This book is dedicated to you.

The last five years several medical professionals allowed me to sit and walk with them in their daily practice of seeing and treating patients. Their stories and my observations in their consultation rooms were pivotal to this study. To all these professionals: I am very grateful for your hospitality, your patience, and your openness. A special thanks goes to two people with whom I worked with the most: René van der Hulst and Stephania Tuinder. René, as the head of the Plastic Surgery Department at the MUMC+ you invited me to do research to breast reconstruction experiences. Your enthusiasm for this study and your medical view while writing articles together is greatly appreciated and highly valued. Stephania, I would like to thank you for welcoming me as an empirical researcher in your consultation room. I admire your dedication to your patients and your deep concern for their wellbeing.

Three more persons have been crucial in my PhD-trajectory: my main supervisor and co-promotor Jenny Slatman, and my promotors Klasien Horstman and Eddy Houwaart. I learnt a great deal from all of you and I will miss our project team meetings in which you were always able to reinvigorate my thinking when I got stuck between one too many theories.

Jenny, you have been particularly invaluable to my PhD: you offered me the opportunity to work with you in your NWO Vidi-project 'Bodily Integrity in Blemished Bodies'. Throughout the last five years, your door was always open to me and you supported and guided me with great commitment. Thank you for your always thought provoking questions and comments, for encouraging me to go the extra mile, for introducing me to the work of many different thinkers, for loaning me your books (and for your patience when I forgot to return them), for preventing me from overcomplicating my work, and for sharing your experiences about working in academia with me. Thank you for everything! 
Klasien, your sharp eye, your ability to build bridges between academic disciplines, your provocative statements through which you offered me new perspectives, and your reminders that I have to listen to what my empirical data 'has to say' have been indispensable. Thank you!

Eddy, your enthusiasm and critical comments, the historical and medical lens you provided, the ways you think along with me, and your kind words and encouragements were crucial within my PhD-trajectory. Thank you!

I would also like to thank the members of the assessment committee, Prof. dr. Guido de Wert, Prof. dr. Ignaas Devisch, Prof. dr. Jany Rademakers, Prof. dr. Fredrik Svenaeus, and dr. Aagje Swinnen, for their willingness to critically read and comment on my manuscript.

Also many thanks to Ton Brouwers, Nadine Blankvoort, and Adam Sundberg for your editorial work and your comments on my writing. I would like to thank Hellen Heutz for transcribing my interviews.

The Health, Ethics and Society Department at Maastricht University was a great place for me to pursue my PhD and allowed me to grow as a researcher, as a tutor, and as a person. Many thanks to my former colleagues, of whom some became friends over the years. I am going to miss all the interesting discussions, conversations and laughs we had in the hallways, during the 'body reading group' meetings, during colloquia, harvest days, department outings, and at Thembi. Lisette Bongers, Lucie Dalibert, Wybo Dondorp, Dorothee Horstkötter, Sanne van der Hout, Rob Houtepen, Mare Knibbe, Tesse Leunissen, Marisol Marini, Floor Moes, Daphne Pommé, Sara Rodrigues, Melisa SotoLafontaine, Greg Stapleton, Guido de Wert, Anna Wolters, and Birgit Wouters: I enjoyed working with you very much. Here, I would like to especially thank Inge Lecluijze and Gili Yaron. Inge, thank you for letting me rave and rage about PhD-related frustrations, for sharing your experiences as a PhD-student with me, and for the (sometimes endless) coffee breaks and walks that prevented me from becoming an academic hermit. Gili, my 'PhD-partner in crime' and my philosophical buddy, thank you for being such an attentive and critical reader of earlier drafts of my PhD-thesis. But most of all, thank you for your support and for the many talks about how life is as a PhD-student and, importantly, about other essential things in life besides a PhD.

During my stay in Sweden as a visiting PhD-student, different groups of scholars welcomed me in their midst. Thanks to the scholars of the Department of Thematic Studies at Linköping University and to the scholars of the Center for Practical Knowledge at Södertörn University. I enjoyed our lively discussions during seminars and reading groups, and our conversations during the many 'fikas' very much. I am particularly indebted to Kristin Zeiler and Fredrik Svenaeus, my main supervisors in Sweden. Kristin, thank you for your spot-on comments on my empirical material and critical readings of parts of my thesis. It is a great pleasure to work with you and write articles together, and I hope we will continue doing so in the future. Fredrik, I am grateful for welcoming me so generously at Södertörn University. My work has benefited very much from your 
insightful comments and suggestions. It is an honor that you are part of my assessment committee.

While living in Stockholm, I was lucky enough to have a wonderful host: Hannah Hallgren. Hannah, you offered me more than a place to stay while I was in Sweden: you gave me a home-away-from-home. I treasure our conversations around the kitchen table about feminism, and I greatly appreciate you looking out for me and introducing me to Stockholm life.

During my PhD-trajectory, I was part of the graduate school of Science, Technology and Modern Culture (WTMC). This school opened up a whole new field of study to me: Science and Technology Studies (STS). When I look back on my time at WTMC, I remember the beautiful location of the monastery in Ravenstein and sleeping in the former cells of the nuns, but above all, I remember all the inspiring teachers and scholars, and how much I enjoyed the interesting lectures, stimulating discussions, fun activities, and the dinners and drinks in the bar with all the other PhD-students. Thank you Willem Halffman, Bernike Pasveer, Govert Valkenburg, Sally Wyatt, and Teun Zuiderent-Jerak for making this all possible.

After I finished the WTMC graduate program, I became a PhD-representative at the WTMC board. Many thanks to all the members of the board, and especially to Paul Wouters as the chair and Colette Bos as my fellow PhD-representative, for making my time at the board an interesting and educational one.

To my dear friends: I am very thankful for all your loving care and support over the last five years. Anne, you are not only a wonderful friend, but I also appreciate your philosophical input and kind comments on bits of my thesis very much. Fieke, thank you for all the sweet post cards, and for being there for me with motivational words, or a day of relaxing at the sauna when I needed it. Herman and Anchen, my fellow 'maties': good coffee, good conversations, and good friends made our meet-ups in South-Africa, Paris, and Den Bosch a great way to unwind and relax. Baie dankie! Ilse, it was always nice (and sometimes necessary) to get away from my desk and enjoy a dinner with you in Utrecht or a walk on the beach. Thank you!

I would like to thank two dear friends in particular: Krista and Lisa. You both know what it is to be a PhD-student: the opportunities, but also the challenges. Your support and understanding means a lot to me. Krista, thanks for being so considerate, for your enthusiasm, for being able to lift my spirits, and for keeping me sane with the many nights with wine, good food, and a movie. Thank you for being such a great friend! Lisa, we have been friends for twenty years now. We share so many things. Thank you for your listening ear, for your genuine advise, and for just being there for me for such a long time. I treasure our friendship very much! Thank you both for being my paranymph.

Stephanie, my big little sister, I also want to thank you. We are very different, but in so many ways also alike. I admire your caring nature, your generosity, and your pa- 
tience. Thank you for being a kind person, a wonderful aunt to my daughter, and above all, a great sister!

To my parents, Margot and Cees: I am very happy to have you. Mama en papa, jullie zijn er altijd voor mij: met motiverende woorden, discussies aan de eettafel, advies, geduldige belangstelling, en het vermogen om dingen te relativeren. Ook al ben ik allang uitgevlogen, bij jullie voelt het nog steeds als 'thuis-thuis'. Dank voor alles!

For you, Harm, a mere 'thank you' does not cut it. You have done so much for me over the last couple of years. I am grateful to you for typing out my many and sometimes illegible notes, for the meticulous work of putting together my reference lists, and for tidying up my lay-out. But most of all, I am thankful for your trust and patience, for your sweet and uplifting words, for encouraging me to take a break, for your ability to keep me grounded, and for your sympathetic ear when I - as you call it - "weer eens college sta te geven". Lieve Harm, je bent een geweldige partner. Zonder jou had dit boek hier nu niet gelegen.

Lieve Freya, je bent pas een paar weken oud als ik dit schrijf, maar ik kan mij een leven zonder jou niet meer voorstellen. Toen je in mijn buik zat, motiveerde je mij om mijn proefschrift snel af te schrijven. En nu je er bent, laat je mij zien dat er zoveel meer is dan alleen maar een proefschrift schrijven. Met jou is het leven oneindig veel rijker en voller geworden!

Marjolein de Boer

's Hertogenbosch, summer 2016 



\section{About the author}

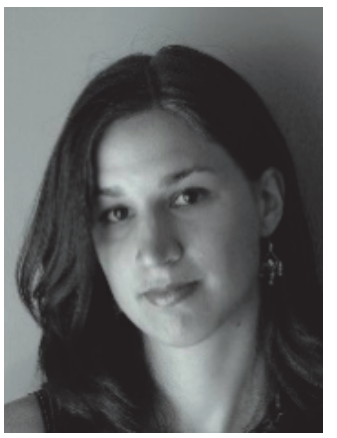

Marjolein de Boer was born on August $7^{\text {th }} 1986$ in Warnsveld, the Netherlands. After completing her secondary education at Stedelijk Daltoncollege in Zutphen in 2004, she studied sociology (BSc in 2008) and philosophy (BA in 2009 and research MA in 2011, both with distinction) at the Radboud University Nijmegen, the Netherlands. During her BA education in philosophy, she spent a semester at Stellenbosch University in South-Africa. As part of her master's thesis, which focused on the narrative possibility of political forgiveness in the works of Paul Ricoeur, she spent a semester at DePaul University, Chicago, USA.

Marjolein researched women's illness experiences during her studies, within her internship at the Dutch Ministry of Foreign Affairs, and as a research assistant. As a PhDstudent at the research school CAPHRI, department of Health, Ethics and Society of Maastricht University, the Netherlands, she continued working on this topic. Her PhDproject, which is part of a larger NWO-Vidi project about experiencing bodily disfigurements, deals with women's bodily experiences in breast cancer from an empiricalphilosophical perspective. As part of her field work, Marjolein conducted many interviews with women who have (had) breast cancer, as well as duo-interviews with these women and their partners. She also studied women's personal breast cancer weblogs. In 2013, she was awarded a Jo Kolk Study grant and an Association for Scientific Research Limburg (SWOL) grant which enabled her to become a visiting scholar for four months at the Department of Thematic Studies at Linköping University and at the Department of Practical Knowledge at Södertörn University (both in Sweden). Marjolein presented her PhD-research at various international conferences. Her work is published in international peer reviewed journals.

While working on her dissertation, Marjolein finished the two-year training program of the Netherlands Graduate Research School of Science, Technology and Modern Culture (WTMC). From 2014 to 2016, she represented the PhD-students within the general board of this graduate school. During her PhD-trajectory, she also worked as a tutor and as a coordinator in the bachelor's program of Health Sciences, and as a thesis cosupervisor in the master's program of Medicine.

In November 2015, Marjolein's research proposal was awarded a Marie Curie (FP7) / Scientia Fellow co-fund grant. With this grant, she will become a postdoctoral fellow at the Institute for Health and Society at the University of Oslo, Norway. Here, she will study women's bodily experiences in the process of In Vitro Fertilization (IVF) treatment.

Marjolein currently lives in 's Hertogenbosch with her husband Harm and their newborn Freya. 



\section{List of publications (selection)}

\section{INTERNATIONAL JOURNALS}

Leunissen, T., Boer, M.L. de, Hulst, R. van der, Slatman, J. (2016) 'Exploring new dimensions in embodiment after implant based and autologous breast reconstruction', Journal of Plastic, Reconstructive \& Aesthetic Surgery 7, 32-41.

Boer, M.L. de, Hulst, R. van der, Slatman, J. (2015) 'The surprise of a breast reconstruction: A longitudinal phenomenological study to women's expectations about reconstructive surgery', Human Studies 38 (3), 409-430.

Boer, M.L. de, Slatman, J. (2014) 'Blogging and Breast Cancer, Narrating One's Life, Body and Self on the Internet', Women's Studies International Forum 44, 17-25.

\section{NATIONAL JOURNAL}

Boer, M.L. de (2011) 'De hemel dat zijn de anderen, de ethische betekenis van de seksuele liefde bij Simone de Beauvoir', in: Ethische Perspectieven 21 (1), p. 37-54. [Title: Heaven are the others, the ethical meaning of sexual love in the works of Simone de Beauvoir]

\section{BOOK CHAPTER}

Boer, M.L. de (2010) 'Anarchisme: religieuze redelijkheid. Een essay over het mystieke anarchisme van Michael Bakoenin', in: Terpstra, Marin en Inigo Bocken (red.) Religie en rede: een dialoog, Speldenprikjes tegen wederzijdse vooroordelen, Eburon, Delft, p. 6786. [Title: Anarchism: religious reason. An essay about the mystic anarchism of Michael Bakunin]

\section{INTERVIEW}

Interview with Marjolein de Boer about nippleless FEMEN-activists on Facebook, in: website Filosofie Magazine, May 2013 URL:

http://www.filosofie.nl/nl/content/35693/tepelloze-activisten.html. 
